\title{
Conformationally Restricted, $\alpha-\alpha$ Directly Linked BisBODIPYs as Highly Fluorescent Near-Infrared Absorbing Dyes
}

\author{
Qinghua Wu, Guowei Jia, Bing Tang, Xing Guo, Hao Wu, Changjiang Yu, Erhong Hao*
} and Lijuan Jiao*

Laboratory of Functional Molecular Solids, Ministry of Education; School of Chemistry and Materials Science, Anhui Normal University, Wuhu, 241002, China

*To whom correspondence should be addressed.

E-mail: haoehong@ahnu.edu.cn, jiao421@ahnu.edu.cn

\section{Contents}

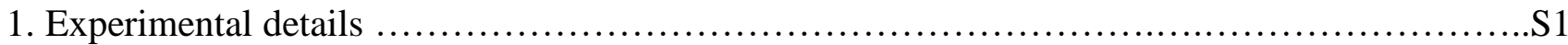

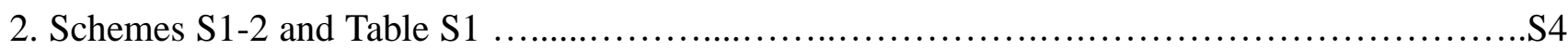

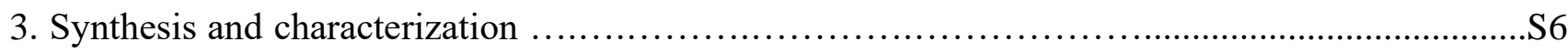

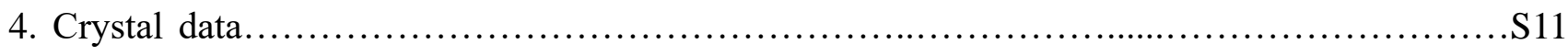

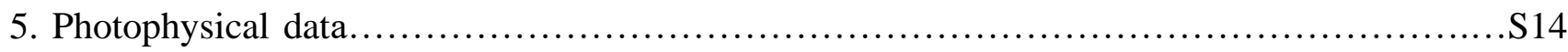

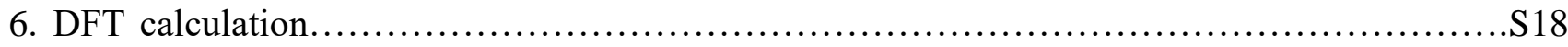

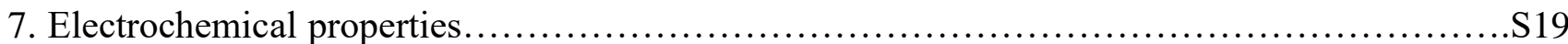

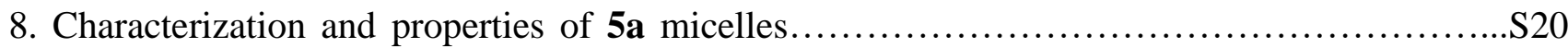

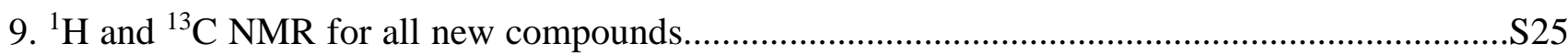

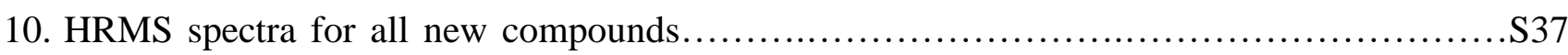

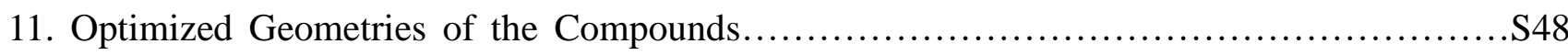




\section{Experimental details}

General information. Reagents and solvents were used as received from commercial suppliers (Energy Chemicals, Shanghai, China) unless noted otherwise. All reactions were performed in oven-dried or flame-dried glassware unless stated otherwise and were monitored by TLC using 0.25 $\mathrm{mm}$ silica gel plates with UV indicator (60F-254). ${ }^{1} \mathrm{H}$ and ${ }^{13} \mathrm{C}$ spectra were recorded on a 300 or 500 $\mathrm{MHz}$ NMR spectrometer at room temperature. Chemical shifts $(\delta)$ are given in ppm relative to $\mathrm{CDCl}_{3}\left(7.26 \mathrm{ppm}\right.$ for ${ }^{1} \mathrm{H}$ and $77 \mathrm{ppm}$ for ${ }^{13} \mathrm{C}$ ) or to internal TMS. High-resolution mass spectra (HRMS) were recorded on a matrix-assisted laser desorption/ionization time-of-flight (MALDI-TOF) mass spectrometer (Agilent 6540 UHD accurate-mass Q-TOF mass spectrometer system) in positive mode or on a ESI-TOF mass spectrometer (Agilent 6200 series Time-of-Flight LC/MS system) in positive mode.

Absorption and emission measurements. UV-visible absorption and fluorescence emission spectra were recorded on commercial spectrophotometers (Shimadzu UV-2450 and Edinburgh FLS1000 spectrometers). All measurements were made at $25{ }^{\circ} \mathrm{C}$, using $5 \times 10 \mathrm{~mm}$ cuvettes. Relative fluorescence quantum efficiencies of BODIPY derivatives were obtained by comparing the areas under the corrected emission spectrum of the test sample in various solvents with Rhodamine $\mathrm{B}(\Phi=$ 0.49 in ethanol $)^{1}$ and Indocyanine Green $(\Phi=0.12 \text { in dimethyl sulfoxide })^{2}$. Non-degassed, spectroscopic grade solvents and a $10 \mathrm{~mm}$ quartz cuvette were used. Dilute solutions $(0.01<\mathrm{A}<0.05)$ were used to minimize the reabsorption effects. Quantum yields were determined using the following equation ${ }^{3}$ :

$$
\Phi_{\mathrm{X}}=\Phi_{\mathrm{S}}\left(\mathrm{I}_{\mathrm{X}} / \mathrm{I}_{\mathrm{S}}\right)\left(\mathrm{A}_{\mathrm{S}} / \mathrm{A}_{\mathrm{X}}\right)\left(n_{\mathrm{X}} / n_{\mathrm{S}}\right)^{2}
$$

Where $\Phi_{\mathrm{S}}$ stands for the reported quantum yield of the standard, I stands for the integrated emission spectra, A stands for the absorbance at the excitation wavelength and $n$ stands for the refractive index of the solvent being used. $\mathrm{X}$ subscript stands for the test sample, and $\mathrm{S}$ subscript stands for the standard.

X-ray structure analysis. Crystals of compounds 5a and 5f suitable for X-ray analysis were obtained via the slow diffusion of petroleum ether into their dichloromethane solutions. The vial containing this solution was placed, loosely capped, to promote the crystallization. A suitable crystal 
was chosen and mounted on a glass fiber using grease. Data were collected using a diffractometer equipped with a graphite crystal monochromator situated in the incident beam for data collection at room temperature. Cell parameters were retrieved using SMART ${ }^{4}$ software and refined using SAINT on all observed reflections. The determination of unit cell parameters and data collections were performed with Mo $K \alpha$ radiation $(\lambda)$ at $0.71073 \AA$. Data reduction was performed using the SAINT software, ${ }^{5}$ which corrects for Lp and decay. The structure was solved by the direct method using the SHELXS- $97^{4}$ program and refined by least squares method on $F^{2}$, SHELXL-2018/3, ${ }^{6}$ incorporated in SHELXTL V5.10. ${ }^{7}$ CCDC-1939980 (5a) and CCDC-1939981 (5f) contain the supplementary crystallographic data for this paper. These data can be obtained free of charge from The Cambridge Crystallographic Data Centre via www.ccdc.cam.ac.uk/data_request/cif.

Electrochemical measurements. Cyclic voltammograms of $1 \mathrm{mM} \mathbf{4 a}$ and $\mathbf{5 a}$ were measured in dichloromethane solution, containing $0.1 \mathrm{M} \mathrm{TBAPF}_{6}$ as the supporting electrolyte, glassy carbon electrode as a working electrode, $\mathrm{Pt}$ wire as a counter electrode, and saturated calomel electrode (SCE) as reference electrode at $50 \mathrm{mV} \mathrm{s}^{-1}$ of scanning rate at room temperature.

Self-assembly of 5 a micelles. A chloroform solution of $5 \mathbf{a}(253 \mu \mathrm{L}, 198 \mu \mathrm{M})$ and a chloroform solution of Cremophor-EL ( $484 \mu \mathrm{L}, 6.2 \mathrm{mg} \mathrm{mL}^{-1}$ ) were added to a flask contained $1 \mathrm{~mL}$ chloroform. The obtained mixture was then dried under vacuum in a rotary evaporator to remove the chloroform completely. After that, DI water $(5 \mathrm{~mL})$ was added, and the flask was placed under sonication for several minutes to give the aqueous dispersion of $\mathbf{5 a}$ micelles.

Cell culture. HeLa cells (human cervical cancer cells) were cultured in culture media (RPMI-1640, supplemented with $10 \% \mathrm{FBS}$ and $1 \%$ penicillin/streptomycin solution) at $37{ }^{\circ} \mathrm{C}$ in an atmosphere of $5 \% \mathrm{CO}_{2}$ and $95 \%$ humidified atmosphere for $24 \mathrm{~h}$.

Cell incubation and colocalization imaging. A total of $30000 \mathrm{HeLa}$ cells were seeded into a glass bottom dish and were cultured in culture media (RPMI-1640, supplemented with 10\% FBS and 1\% penicillin and streptomycin) at $37{ }^{\circ} \mathrm{C}$ in an atmosphere of $5 \% \mathrm{CO}_{2}$ and $95 \%$ humidified atmosphere for $24 \mathrm{~h}$. HeLa cells were first stained with 5 a micelles $(1 \mu \mathrm{M})$ and Rhodamin $123(5 \mu \mathrm{M})$ at $37{ }^{\circ} \mathrm{C}$ in an atmosphere of $5 \% \mathrm{CO}_{2}$ for $1 \mathrm{~h}$. After washing the plates two times with PBS, the cells were fixed by $4 \%$ formaldehyde for $20 \mathrm{~min}$. The organelle tracer 4,6-diamidino-2-phenylindole (DAPI, 0.08 $\mu \mathrm{g} / \mathrm{mL}$ ) was added subsequently and was incubated for $30 \mathrm{~min}$ to stain the nucleus. Finally, the plates 
were washed again with PBS and the morphologies of the HeLa cells were observed using a confocal fluorescence microscope (Leica Microsystems SP8 MP, excitation at 405, 488 and $635 \mathrm{~nm}$ for DAPI, Rhodamin 123 and 5a micelles, respectively).

Cellular uptake. A total of $30000 \mathrm{HeLa}$ cells were seeded into a glass bottom dish and were cultivated in RPMI-1640 with $10 \%$ FBS and $1 \%$ penicillin and streptomycin at $37{ }^{\circ} \mathrm{C}, 5 \% \mathrm{CO}_{2}$ and 95\% humidity for 24 h. 5a micelles ( $5 \mu \mathrm{M}, 1640$ complete medium) were cultivated with HeLa cells for 10, 20, 30, 60, 120 and $240 \mathrm{~min}$, respectively. The above cells were washed twice with PBS. Then these cells were used to measure the fluorescence intensity using a confocal fluorescence microscope.

Cytotoxicity determined by the CCK-8 method. The HeLa cells (5000) per well were seeded on 96-well plates and incubated in 1640 complete medium for $24 \mathrm{~h}$ at $37{ }^{\circ} \mathrm{C}$. Then, a gradient concentration of $\mathbf{5 a}$ micelles from 0.05 to $30 \mu \mathrm{M}$ in a fresh medium were added into the 96-well plate, and the cells with the probe were incubated at $37{ }^{\circ} \mathrm{C}$. Each experiment was performed for at least three times. After $24 \mathrm{~h}$, the working solutions were then removed, and the cells were washed with PBS buffer for two times. A total of $10 \mu \mathrm{L}$ of CCK- 8 (Cell Counting Kit-8, BIOMIKY) was added into each well, and the cells were further incubated at $37{ }^{\circ} \mathrm{C}$ for $1.5 \mathrm{~h}$. Then the plate was shaken for $5 \mathrm{~min}$, and the absorbance at $450 \mathrm{~nm}$ was measured with a microplate reader (Multiskan Sky).

Ex vivo imaging in cat skeletal muscle tissues. The domestic cat skeletal muscle tissues were bought from Fenghua teaching company limited. The tissues were stained with $\mathbf{5 a}$ micelles $(5 \mu \mathrm{M})$ at room temperature in culture medium (RPMI-1640, supplemented with 10\% FBS and 1\% penicillin and streptomycin) in $5 \% \mathrm{CO}_{2} /$ air at $37{ }^{\circ} \mathrm{C}$ in a humidified incubator for $5 \mathrm{~min}$. The tissues were then directly used for imaging under excitation wavelengths of $638 \mathrm{~nm}$.

Imaging studies of zebrafish. To ascertain whether probe 5a micelles can produce a marked effect in imaging in vivo, we used a 12-day-old zebrafish (AB stain). The 12-day-old zebrafish was incubated with $5 \mathbf{a}$ micelles $(5 \mu \mathrm{M}$, water) for $4 \mathrm{~h}$, then the water was used to clean and remove the residual micelles, and finally confocal fluorescence microscopy was used to observe (Leica Microsystems SP8 MP, excitation at $638 \mathrm{~nm}$ ). 


\section{Schemes S1-2 and Table S1}

Benzaldehyde dimethyl acetal 2a was purchased. Other acetals 2b-d (Scheme S1) were synthesized by following the literature procedure. ${ }^{8,9}$

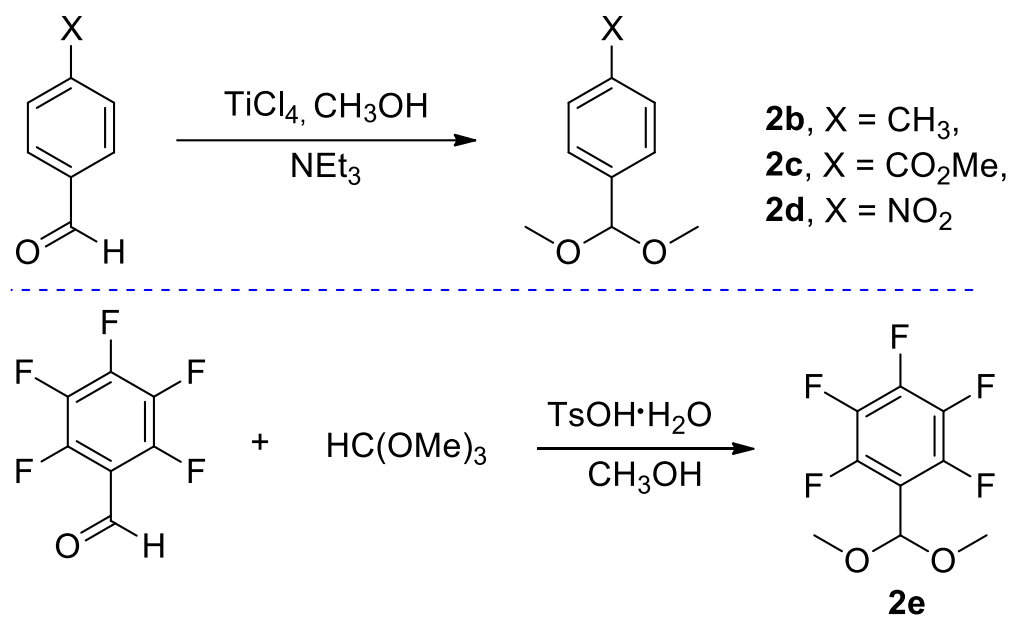

Scheme S1. Synthesis of acetals 2 b-e.

$\beta$, $\beta^{\prime}$-Linked DiformylDipyrromethanes 3 were synthesized by following the literature procedure. ${ }^{10}$

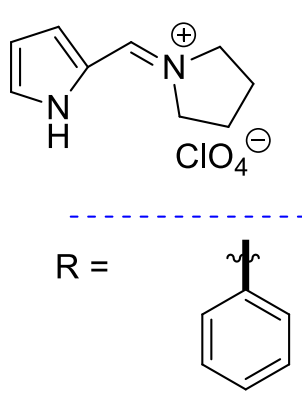

3a<smiles>[R]C(OC)OC</smiles>

2

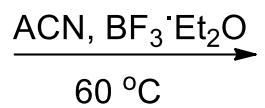
$60^{\circ} \mathrm{C}$<smiles>Cc1ccc(C(F)(F)F)cc1</smiles>

3b<smiles>COC(=O)c1ccc(C(C)(C)C)cc1</smiles>

$3 c$<smiles>[R]C(c1c[nH]c(C=O)c1)c1c[nH]c(C=O)c1</smiles>

3<smiles>CC(C)(C)c1c(F)c(F)c(F)c(F)c1F</smiles>

$3 e$

Scheme S2. Synthesis of $\beta, \beta^{\prime}$-linked diformyldipyrromethanes 3. 
Table S1. Optimization of the reaction conditions ${ }^{a}$.
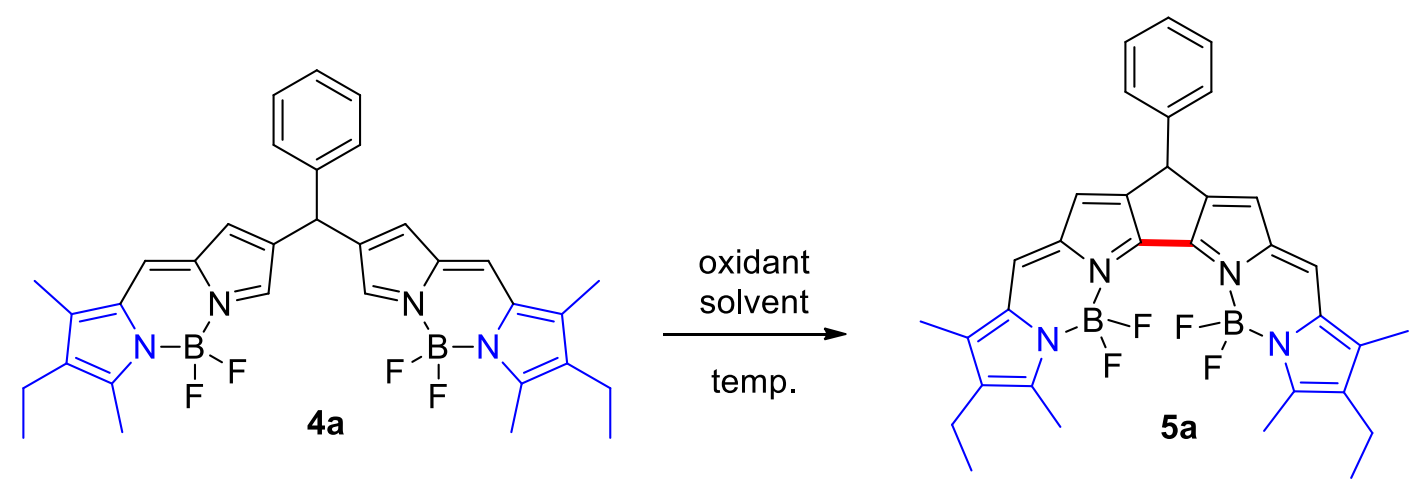

\begin{tabular}{ccccc}
\hline Entry & oxidant & equiv & $\begin{array}{c}\text { temp. } \\
\left({ }^{\circ} \mathrm{C}\right)\end{array}$ & $\begin{array}{c}\text { yields of } \\
\mathbf{5}(\%)^{b}\end{array}$ \\
\hline 1 & $\mathrm{FeCl}_{3}$ & 1.1 & $\mathrm{rt}$ & $<5$ \\
2 & $\mathrm{FeCl}_{3}$ & 1.1 & 0 & $<5$ \\
3 & $\mathrm{FeCl}_{3}$ & 1.1 & -10 & 10 \\
4 & $\mathrm{MoCl}_{5}$ & 1.1 & -30 & 10 \\
5 & $\mathrm{MoCl}_{5}$ & 1.1 & -10 & 23 \\
6 & $\mathrm{MoCl}_{5}$ & 1.1 & 0 & 29 \\
7 & $\mathrm{MoCl}_{5}$ & 1.1 & 10 & 26 \\
8 & $\mathrm{MoCl}_{5}$ & 2 & 0 & 30 \\
9 & $\mathrm{MoCl}_{5}$ & 4 & 0 & 39 \\
10 & $\mathrm{MoCl}_{5}$ & 6 & 0 & 49 \\
$\mathbf{1 1}$ & $\mathrm{MoCl}_{5}$ & $\mathbf{7 . 5}$ & $\mathbf{0}$ & $\mathbf{6 3}$ \\
12 & $\mathrm{MoCl}_{5}$ & 9 & 0 & 59
\end{tabular}

${ }^{a}$ Reaction conditions: $4(0.1 \mathrm{mmol})$, dry dichloromethane $(20 \mathrm{~mL}) .{ }^{b}$ Yield of the isolated product. 


\section{Synthesis and characterization}

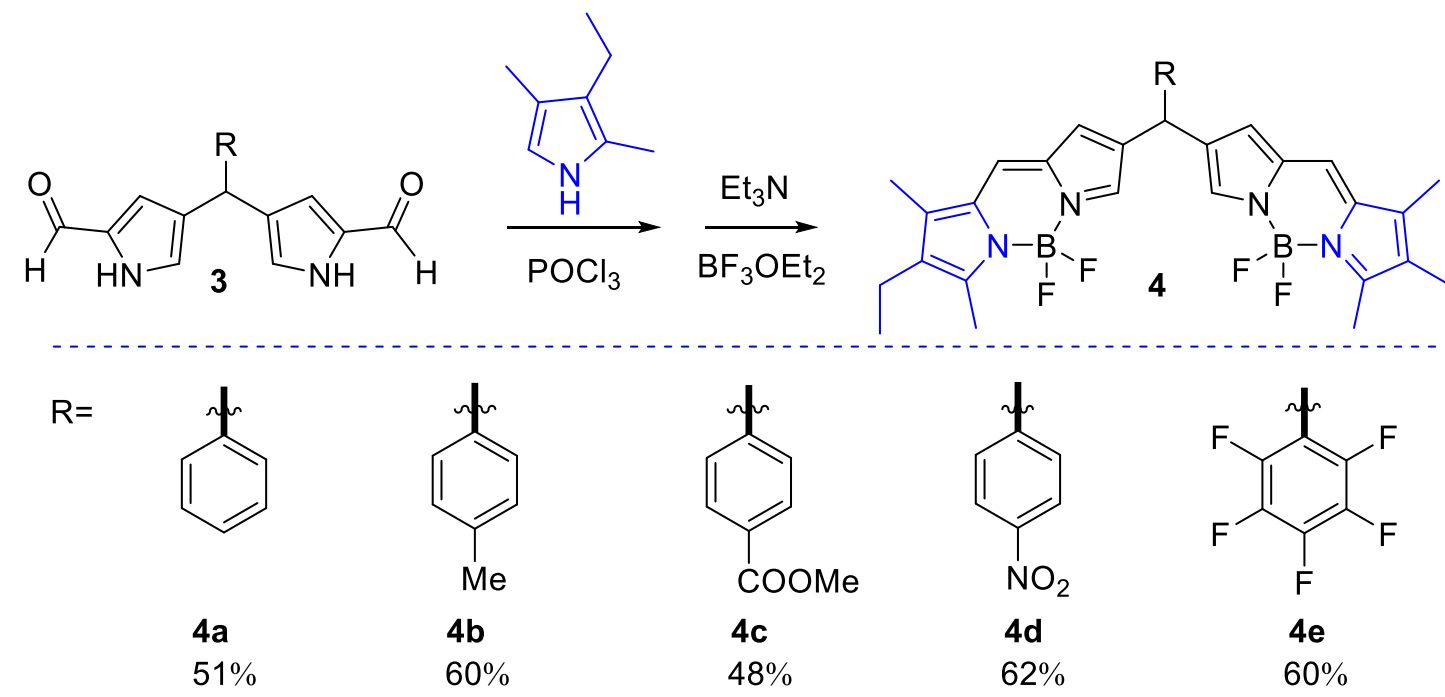

Syntheses of bisBODIPY 4a: To a solution of freshly prepared 3a $(278 \mathrm{mg}, 1 \mathrm{mmol})$ in distilled dichloromethane $(20 \mathrm{~mL})$ was first added 3-ethyl-2,4-dimethylpyrrole $(0.33 \mathrm{~mL}, 2.5 \mathrm{mmol})$, and then $\mathrm{POCl}_{3}(0.01 \mathrm{~mL}, 0.1 \mathrm{mmol})$. The reaction mixture was stirred at room temperature for $15 \mathrm{~min}$. After $\mathrm{Et}_{3} \mathrm{~N}(2.7 \mathrm{~mL}, 20 \mathrm{mmol})$ was added into the reaction mixture, the mixture was stirred for $30 \mathrm{~min}$, $\mathrm{BF}_{3} \cdot \mathrm{OEt}_{2}(3.8 \mathrm{~mL}, 30 \mathrm{mmol})$ was then added under ice-cold condition. After stirred at room temperature for $2 \mathrm{~h}$, the reaction mixture was diluted with dichloromethane (100 mL), washed twice with water $\left(150 \mathrm{~mL}\right.$ each), dried over anhydrous $\mathrm{Na}_{2} \mathrm{SO}_{4}$, and evaporated under vacuum. The crude product was purified by chromatography (silica gel, hexane/ $\mathrm{CH}_{2} \mathrm{Cl}_{2}=1.5 / 1$, v/v) to afford $\mathbf{4 a}$ in $51 \%$ (300 mg) yield. ${ }^{1} \mathrm{H}$ NMR (300 MHz, $\left.\mathrm{CDCl}_{3}\right) \delta 7.35$ (s, 2H), 7.30 - 7.26 (m, 5H), 7.02 (s, 2H), 6.63 (s, 2H), $5.21(\mathrm{~s}, 1 \mathrm{H}), 2.54(\mathrm{~s}, 6 \mathrm{H}), 2.40(\mathrm{q}, J=6.0 \mathrm{~Hz}, 4 \mathrm{H}), 2.36(\mathrm{~s}, 6 \mathrm{H}), 1.13(\mathrm{t}, J=6.0 \mathrm{~Hz}, 6 \mathrm{H}) ;{ }^{13} \mathrm{C}$ NMR (75 MHz, $\left.\mathrm{CDCl}_{3}\right) \delta 162.9,143.8,140.7,137.6,136.1,134.5,132.4,128.5,126.6,124.4,123.3$, 42.1, 17.3, 14.2, 13.3, 9.5. HRMS (MALDI-TOF) m/z: $[\mathrm{M}+\mathrm{Na}]^{+}$Calcd for $\mathrm{C}_{33} \mathrm{H}_{34} \mathrm{~B}_{2} \mathrm{~F}_{4} \mathrm{~N}_{4} \mathrm{Na}$ 607.2798, Found 607.2796.

4b was obtained in $60 \%$ (359 mg) yield from $3 \mathbf{b}(292 \mathrm{mg}, 1 \mathrm{mmol})$ using the same procedure described above for the synthesis of $\mathbf{4 a}$ and purified by chromatography (silica gel, hexane/ $\mathrm{CH}_{2} \mathrm{Cl}_{2}=$ 1.5/1, v/v). ${ }^{1} \mathrm{H} \mathrm{NMR}\left(500 \mathrm{MHz}, \mathrm{CDCl}_{3}\right) \delta 7.34(\mathrm{~s}, 2 \mathrm{H}), 7.13(\mathrm{q}, J=8.0 \mathrm{~Hz}, 4 \mathrm{H}), 7.01(\mathrm{~s}, 2 \mathrm{H}), 6.63$ (s, 2H), $5.17(\mathrm{~s}, 1 \mathrm{H}), 2.54(\mathrm{~s}, 6 \mathrm{H}), 2.40(\mathrm{q}, J=7.5 \mathrm{~Hz}, 4 \mathrm{H}), 2.33(\mathrm{~s}, 3 \mathrm{H}), 2.16(\mathrm{~s}, 6 \mathrm{H}), 1.07$ (t, $J=7.5 \mathrm{~Hz}$, 
$6 \mathrm{H}) ;{ }^{13} \mathrm{C} \mathrm{NMR}\left(126 \mathrm{MHz}, \mathrm{CDCl}_{3}\right) \delta 162.7,140.8,140.7,137.7,136.1,136.0,134.8,134.4,132.4$, 129.2, 128.3, 124.4, 123.3, 41.7, 21.1, 17.2, 14.2, 13.3, 9.4. HRMS (MALDI-TOF) m/z: [M+Na] ${ }^{+}$ Calcd for $\mathrm{C}_{34} \mathrm{H}_{36} \mathrm{~B}_{2} \mathrm{~F}_{4} \mathrm{~N}_{4} \mathrm{Na} 621.2954$, Found 621.2952 .

4c was obtained in $48 \%$ (310 mg) yield from 3c $(336 \mathrm{mg}, 1 \mathrm{mmol})$ using the same procedure described above for the synthesis of $\mathbf{4 a}$ and purified by chromatography (silica gel, hexane $/ \mathrm{CH}_{2} \mathrm{Cl}_{2}=$ 1/1.5, v/v). ${ }^{1} \mathrm{H}$ NMR (500 MHz, $\left.\mathrm{CDCl}_{3}\right) \delta 7.98(\mathrm{~d}, J=8.5 \mathrm{~Hz}, 2 \mathrm{H}), 7.32-7.35(\mathrm{~m}, 4 \mathrm{H}), 7.02(\mathrm{~s}, 2 \mathrm{H})$, $6.60(\mathrm{~s}, 2 \mathrm{H}), 5.27$ (s, 1H), 3.91 (s, 3H), 2.55 (s, 6H), 2.40 (q, J = 7.6 Hz, 4H), 2.17 (s, 6H), 1.08 (t, $J$ $=7.6 \mathrm{~Hz}, 6 \mathrm{H}) ;{ }^{13} \mathrm{C} \mathrm{NMR}\left(125 \mathrm{MHz}, \mathrm{CDCl}_{3}\right) \delta 167.0,163.5,149.2,141.0,137.0,136.3,134.8,133.5$, 132.4, 129.9, 128.5, 124.1, 123.2, 52.1, 42.1, 17.3, 14.2, 13.3, 9.5. HRMS (MALDI-TOF) m/z: $[\mathrm{M}+\mathrm{Na}]^{+}$Calcd for $\mathrm{C}_{35} \mathrm{H}_{36} \mathrm{~B}_{2} \mathrm{~F}_{4} \mathrm{~N}_{4} \mathrm{NaO}_{2}$ 665.2853, Found 665.2848.

4d was obtained in $62 \%(390 \mathrm{mg})$ yield from $3 d(321 \mathrm{mg}, 1 \mathrm{mmol})$ using the same procedure described above for the synthesis of $\mathbf{4 a}$ and purified by chromatography (silica gel, hexane $/ \mathrm{CH}_{2} \mathrm{Cl}_{2}=$ 1/2, v/v). ${ }^{1} \mathrm{H}$ NMR (500 MHz, $\left.\mathrm{CDCl}_{3}\right) \delta 8.16(\mathrm{~d}, J=8.5 \mathrm{~Hz}, 2 \mathrm{H}), 7.44(\mathrm{~d}, J=8.5 \mathrm{~Hz}, 2 \mathrm{H}), 7.30$ (s, 2H), 7.04 (s, 2H), $6.60(\mathrm{~s}, 2 \mathrm{H}), 5.33(\mathrm{~s}, 1 \mathrm{H}), 2.56(\mathrm{~s}, 6 \mathrm{H}), 2.40(\mathrm{q}, J=7.5 \mathrm{~Hz}, 4 \mathrm{H}), 2.17(\mathrm{~s}, 6 \mathrm{H}), 1.08$ $(\mathrm{t}, J=7.5 \mathrm{~Hz}, 6 \mathrm{H}) ;{ }^{13} \mathrm{C} \mathrm{NMR}\left(125 \mathrm{MHz}, \mathrm{CDCl}_{3}\right) \delta 164.3,151.6,146.6,141.4,136.6,136.3,135.1$, 132.5, 132.3, 129.3, 123.8, 123.6, 123.2, 41.9, 17.3, 14.2, 13.4, 9.5. HRMS (MALDI-TOF) m/z: $[\mathrm{M}+\mathrm{Na}]^{+}$Calcd for $\mathrm{C}_{33} \mathrm{H}_{33} \mathrm{~B}_{2} \mathrm{~F}_{4} \mathrm{~N}_{5} \mathrm{NaO}_{2} 652.2649$, Found 652.2644.

4e was obtained in $60 \%(401 \mathrm{mg}$ ) yield from $3 \mathbf{e}(368 \mathrm{mg}, 1 \mathrm{mmol})$ using the same procedure described above for the synthesis of $\mathbf{4 a}$ and purified by chromatography (silica gel, hexane $/ \mathrm{CH}_{2} \mathrm{Cl}_{2}=$ 1.5/1, v/v). ${ }^{1} \mathrm{H} \mathrm{NMR}\left(300 \mathrm{MHz}, \mathrm{CDCl}_{3}\right) \delta 7.42(\mathrm{~s}, 2 \mathrm{H}), 7.04(\mathrm{~s}, 2 \mathrm{H}), 6.73(\mathrm{~s}, 2 \mathrm{H}), 5.62(\mathrm{~s}, 1 \mathrm{H}), 2.56$ $(\mathrm{s}, 6 \mathrm{H}), 2.41(\mathrm{q}, J=6.0 \mathrm{~Hz}, 4 \mathrm{H}), 2.18(\mathrm{~s}, 6 \mathrm{H}), 1.13(\mathrm{t}, J=6.0 \mathrm{~Hz}, 6 \mathrm{H}) ;{ }^{13} \mathrm{C} \mathrm{NMR}(75 \mathrm{MHz}, \mathrm{CDCl} 3)$ $\delta 164.3,146.3,143.2,141.4,139.5,136.7,136.1,135.1,132.1,129.9,123.5,123.2,117.6,31.1,17.2$, 14.1, 13.4, 9.4. HRMS (ESI) m/z calcd for $\mathrm{C}_{33} \mathrm{H}_{30} \mathrm{~B}_{2} \mathrm{~F}_{9} \mathrm{~N}_{4}[\mathrm{M}+\mathrm{H}]^{+}: 675.2507$, found : 675.2515 . 

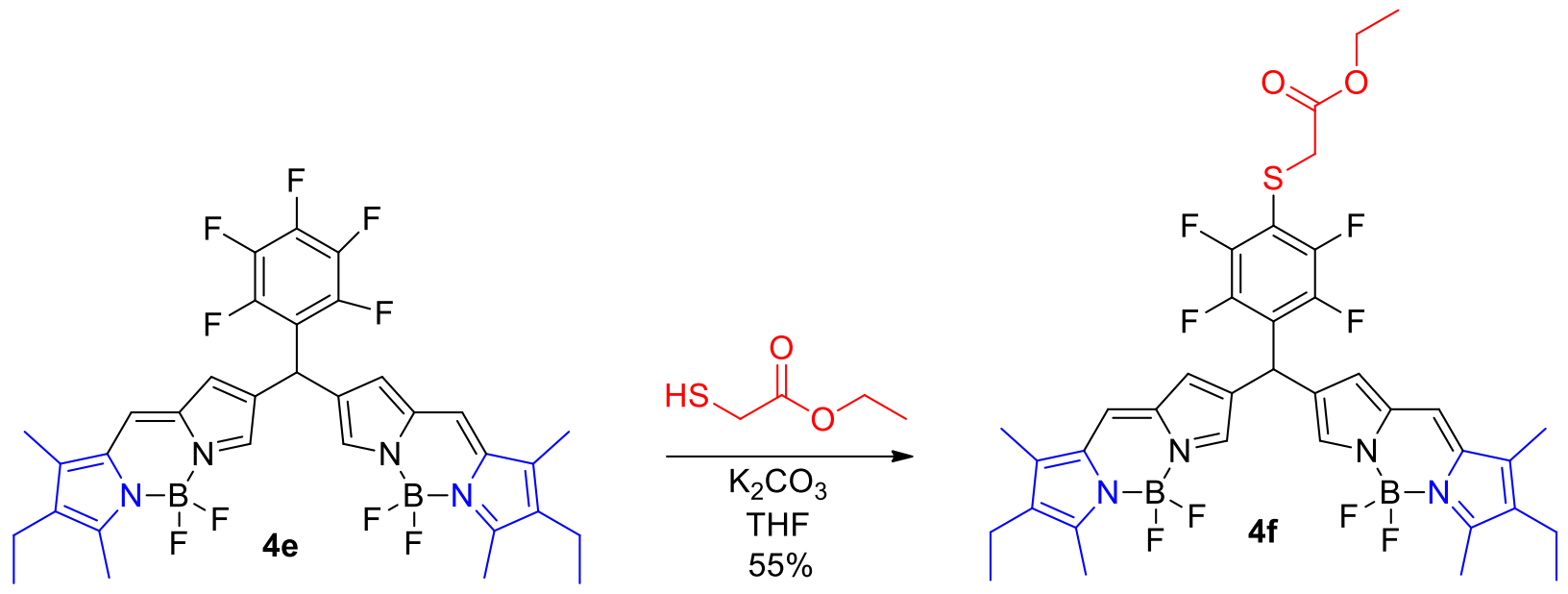

Syntheses of bisBODIPY 4f: In a $100 \mathrm{~mL}$ round bottom flask, $4 \mathbf{e}(674 \mathrm{mg}, 1 \mathrm{mmol})$ and $\mathrm{K}_{2} \mathrm{CO}_{3}$ (1.38 g, $10 \mathrm{mmol})$ were dissolved in THF (30 mL). Ethyl 2-mercaptoacetate $(0.55 \mathrm{~mL}, 5 \mathrm{mmol})$ was then added, and the mixture was stirred for $30 \mathrm{~min}$ at $80^{\circ} \mathrm{C}$ in oil bath. After being cooled to room temperature, the reaction mixture was poured into water $(150 \mathrm{~mL})$, and extracted with dichloromethane $(150 \mathrm{~mL})$. The organic layer was dried over anhydrous $\mathrm{Na}_{2} \mathrm{SO}_{4}$. Upon removal of solvents under vacuo, the residual was purified by silica gel column chromatography (silica gel, hexane $/ \mathrm{CH}_{2} \mathrm{Cl}_{2}=1 / 1$, v/v) to afford $4 \mathbf{f}$ in $55 \%(416 \mathrm{mg})$ yield. ${ }^{1} \mathrm{H} \mathrm{NMR}\left(300 \mathrm{MHz}, \mathrm{CDCl}_{3}\right) \delta 7.43(\mathrm{~s}$, 2H), 7.04 (s, 2H), $6.74(\mathrm{~s}, 2 \mathrm{H}), 5.66(\mathrm{~s}, 1 \mathrm{H}), 4.13(\mathrm{q}, J=7.1 \mathrm{~Hz}, 2 \mathrm{H}), 3.60(\mathrm{~s}, 2 \mathrm{H}), 2.56(\mathrm{~s}, 6 \mathrm{H}), 2.41$ $(\mathrm{q}, J=7.4 \mathrm{~Hz}, 4 \mathrm{H}), 2.17(\mathrm{~s}, 6 \mathrm{H}), 1.17(\mathrm{t}, J=7.1 \mathrm{~Hz}, 3 \mathrm{H}), 1.13(\mathrm{t}, J=7.5 \mathrm{~Hz}, 6 \mathrm{H}),{ }^{13} \mathrm{C}$ NMR $(75$ $\left.\mathrm{MHz}_{\mathrm{CDCl}}\right) \delta 168.6,164.2,148.9,145.6,141.3,136.7,136.3,135.1,132.2,129.8,123.9,123.6$, 123.3, 61.9, 36.0, 31.7, 17.3, 14.1, 13.9, 13.4, 9.5. HRMS (ESI) m/z calcd for $\mathrm{C}_{37} \mathrm{H}_{36} \mathrm{~B}_{2} \mathrm{~F}_{7} \mathrm{~N}_{4} \mathrm{O}_{2} \mathrm{~S}$ [M-F] $]^{+}$755.2633, found: 755.2618 . 


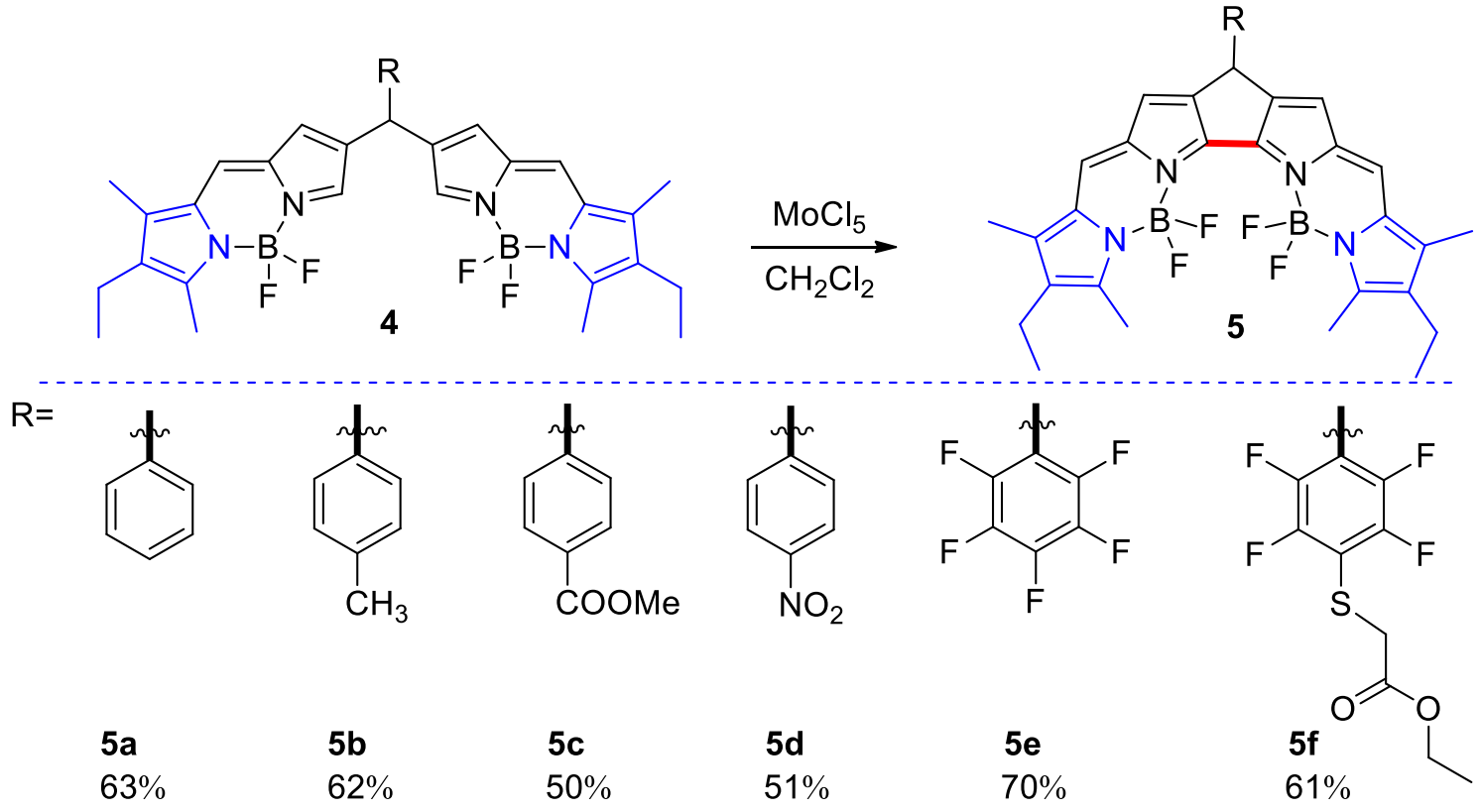

Syntheses of bisBODIPY 5a: To a solution of $4 \mathbf{a}(58 \mathrm{mg}, 0.1 \mathrm{mmol})$ in dry dichloromethane (20 $\mathrm{mL})$ at $0{ }^{\circ} \mathrm{C}$ was added $\mathrm{MoCl}_{5}(205 \mathrm{mg}, 0.75 \mathrm{mmol})$. The reaction mixture was stirred at $0{ }^{\circ} \mathrm{C}$ for 30 min, and was quenched by adding saturated aqueous solution of $\mathrm{NaHCO}_{3}$. The reaction mixture was diluted with dichloromethane $(50 \mathrm{~mL})$, and washed twice with water (100 mL each). The organic layer was dried over anhydrous $\mathrm{Na}_{2} \mathrm{SO}_{4}$, filtered, and evaporated under vacuum. The residue was purified by chromatography (silica gel, hexane $/ \mathrm{CH}_{2} \mathrm{Cl}_{2}=1 / 1.5$, v/v) as eluent to give $\mathbf{5 a}$ (36 $\mathrm{mg}$, 63\%). ${ }^{1} \mathrm{H}$ NMR (300 MHz, $\left.\mathrm{CDCl}_{3}\right) \delta 7.32-7.26(\mathrm{~m}, 5 \mathrm{H}), 6.88(\mathrm{~s}, 2 \mathrm{H}), 6.56(\mathrm{~s}, 2 \mathrm{H}), 4.68(\mathrm{~s}, 1 \mathrm{H})$, $2.70(\mathrm{~s}, 6 \mathrm{H}), 2.41(\mathrm{q}, J=7.3 \mathrm{~Hz}, 4 \mathrm{H}), 2.15(\mathrm{~s}, 6 \mathrm{H}), 1.13(\mathrm{t}, J=7.4 \mathrm{~Hz}, 6 \mathrm{H}) ;{ }^{13} \mathrm{C} \mathrm{NMR}(75 \mathrm{MHz}$, $\left.\mathrm{CDCl}_{3}\right) \delta 167.0,163.5,149.2,141.0,137.0,136.3,134.8,133.5,132.4,129.9,128.5,124.1,123.2$, 42.1, 17.3, 14.2, 13.4, 9.5. HRMS (MALDI-TOF) $\mathrm{m} / \mathrm{z}$ : $[\mathrm{M}+\mathrm{Na}]^{+}$Calcd for $\mathrm{C}_{33} \mathrm{H}_{32} \mathrm{~B}_{2} \mathrm{~F}_{4} \mathrm{~N}_{4} \mathrm{Na}$ 605.2641, Found 605.2639.

5b was obtained in $62 \%$ (37 mg) yield from $\mathbf{4 b}(60 \mathrm{mg}, 0.1 \mathrm{mmol})$ using the same procedure described above for the synthesis of $\mathbf{5 a}$ and purified by chromatography (silica gel, hexane $/ \mathrm{CH}_{2} \mathrm{Cl}_{2}=$ 1/1, v/v). ${ }^{1} \mathrm{H}$ NMR $\left(500 \mathrm{MHz}, \mathrm{CDCl}_{3}\right) \delta 7.15(\mathrm{~d}, J=6.0 \mathrm{~Hz}, 4 \mathrm{H}), 7.11(\mathrm{~d}, J=6.0 \mathrm{~Hz}, 4 \mathrm{H}), 6.88(\mathrm{~s}$, 2H), $6.56(\mathrm{~s}, 2 \mathrm{H}), 4.65(\mathrm{~s}, 1 \mathrm{H}), 2.70(\mathrm{~s}, 6 \mathrm{H}), 2.41(\mathrm{q}, J=7.6 \mathrm{~Hz}, 4 \mathrm{H}), 2.33(\mathrm{~s}, 3 \mathrm{H}), 2.16(\mathrm{~s}, 6 \mathrm{H}), 1.07$ $(\mathrm{t}, J=7.6 \mathrm{~Hz}, 6 \mathrm{H}) ;{ }^{13} \mathrm{C} \mathrm{NMR}\left(125 \mathrm{MHz}, \mathrm{CDCl}_{3}\right) \delta 161.6,151.4,146.4,141.2,137.7,137.4,136.6$, 136.3, 134.7, 129.4, 127.6, 120.7, 118.6, 40.7, 21.1, 17.4, 14.3, 138, 9.4. HRMS (MALDI-TOF) m/z: $[\mathrm{M}+\mathrm{Na}]^{+}$Calcd for $\mathrm{C}_{34} \mathrm{H}_{34} \mathrm{~B}_{2} \mathrm{~F}_{4} \mathrm{~N}_{4} \mathrm{Na}$ 619.2798, Found 619.2795. 
5c was obtained in 50\% (32 mg) yield from 4 c $(64 \mathrm{mg}, 0.1 \mathrm{mmol})$ using the same procedure described above for the synthesis of $\mathbf{5 a}$ and purified by chromatography (silica gel, hexane $/ \mathrm{CH}_{2} \mathrm{Cl}_{2}=$ 1/1, v/v). ${ }^{1} \mathrm{H}$ NMR (300 MHz, $\left.\mathrm{CDCl}_{3}\right) \delta 7.97(\mathrm{~d}, J=8.0 \mathrm{~Hz}, 2 \mathrm{H}), 7.32(\mathrm{~d}, J=8.0 \mathrm{~Hz}, 2 \mathrm{H}), 6.89$ (s, 2H), $6.55(\mathrm{~s}, 2 \mathrm{H}), 4.70(\mathrm{~s}, 1 \mathrm{H}), 3.90(\mathrm{~s}, 3 \mathrm{H}), 2.71(\mathrm{~s}, 6 \mathrm{H}), 2.47$ (q, J = 7.4 Hz, 4H), $2.16(\mathrm{~s}, 6 \mathrm{H}), 1.08$ $(\mathrm{t}, J=7.4 \mathrm{~Hz}, 6 \mathrm{H}) ;{ }^{13} \mathrm{C} \mathrm{NMR}\left(75 \mathrm{MHz}, \mathrm{CDCl}_{3}\right) \delta 166.9,162.2,150.1,146.2,146.0,140.9,138.0$, $136.4,134.9,129.5,128.9,127.7,120.7,118.5,52.1,41.0,17.4,15.9,13.8,9.4$. HRMS (MALDI-TOF) m/z: [M+Na] ${ }^{+}$Calcd for $\mathrm{C}_{35} \mathrm{H}_{34} \mathrm{~B}_{2} \mathrm{~F}_{4} \mathrm{~N}_{4} \mathrm{NaO}_{2}$ 663.2696, Found 663.2695.

5d was obtained in 51\% (32 mg) yield from 4d $(63 \mathrm{mg}, 0.1 \mathrm{mmol})$ using the same procedure described above for the synthesis of $\mathbf{5 a}$ and purified by chromatography (silica gel, hexane $/ \mathrm{CH}_{2} \mathrm{Cl}_{2}=$ 1/1, v/v). ${ }^{1} \mathrm{H}$ NMR $\left(500 \mathrm{MHz}, \mathrm{CDCl}_{3}\right) \delta 8.16(\mathrm{~d}, J=8.7 \mathrm{~Hz}, 2 \mathrm{H}), 7.42(\mathrm{~d}, J=8.6 \mathrm{~Hz}, 2 \mathrm{H}), 6.90$ (s, 2H), $6.54(\mathrm{~s}, 2 \mathrm{H}), 4.74(\mathrm{~s}, 1 \mathrm{H}), 2.72$ (s, 6H), 2.42 (q, J= $7.5 \mathrm{~Hz}, 4 \mathrm{H}), 2.17$ (s, 6H), 1.09 (t, J = 7.6 Hz, $6 \mathrm{H}) ;{ }^{13} \mathrm{C}$ NMR $\left(125 \mathrm{MHz}, \mathrm{CDCl}_{3}\right) \delta 162.7,149.1,148.6,147.0,145.8,140.7,138.3,136.6,135.2$, 128.6, 124.0, 120.7, 118.2, 40.7, 17.4, 14.3, 13.9, 9.4. HRMS (MALDI-TOF) m/z: $[\mathrm{M}+\mathrm{Na}]^{+} \mathrm{Calcd}$ for $\mathrm{C}_{33} \mathrm{H}_{31} \mathrm{~B}_{2} \mathrm{~F}_{4} \mathrm{~N}_{5} \mathrm{NaO}_{2}$ 605.2492, Found 605.2486.

5e was obtained in $70 \%$ (47 mg) yield from 4 e $(67 \mathrm{mg}, 0.1 \mathrm{mmol})$ using the same procedure described above for the synthesis of $\mathbf{5 a}$ and purified by chromatography (silica gel, hexane $/ \mathrm{CH}_{2} \mathrm{Cl}_{2}=$ 1/1, v/v). ${ }^{1} \mathrm{H}$ NMR (300 MHz, $\left.\mathrm{CDCl}_{3}\right) \delta 6.90$ (s, 2H), 6.55 (s, 2H), 5.01 (s, 1H), $2.71(\mathrm{~s}, 6 \mathrm{H}), 2.42(\mathrm{q}$, $J=6.8 \mathrm{~Hz}, 4 \mathrm{H}), 2.17(\mathrm{~s}, 6 \mathrm{H}), 1.08(\mathrm{t}, J=7.3 \mathrm{~Hz}, 6 \mathrm{H}) ;{ }^{13} \mathrm{C} \mathrm{NMR}\left(75 \mathrm{MHz}, \mathrm{CDCl}_{3}\right) \delta 162.7,146.7$, 146.1, 140.5, 138.3, 136.6, 135.2, 120.8, 117.8, 29.9, 17.4, 14.3, 13.8, 9.4. HRMS (MALDI-TOF) $\mathrm{m} / \mathrm{z}:[\mathrm{M}]^{+}$Calcd for $\mathrm{C}_{33} \mathrm{H}_{27} \mathrm{~B}_{2} \mathrm{~F}_{9} \mathrm{~N}_{4} 672.2273$, Found 672.2278.

5f was obtained in $61 \%(46 \mathrm{mg})$ yield from 4 f $(76 \mathrm{mg}, 0.1 \mathrm{mmol})$ using the same procedure described above for the synthesis of $\mathbf{5 a}$ and purified by chromatography (silica gel, hexane $/ \mathrm{CH}_{2} \mathrm{Cl}_{2}=$ 1/1, v/v). ${ }^{1} \mathrm{H}$ NMR (500 MHz, $\left.\mathrm{CDCl}_{3}\right) \delta 6.90$ (s, 2H), 6.57 (s, 2H), 5.04 (s, 1H), 4.15 (q, J = 7.1 Hz, 2H), $3.59(\mathrm{~s}, 2 \mathrm{H}), 2.70(\mathrm{~s}, 6 \mathrm{H}), 2.41(\mathrm{q}, J=7.5 \mathrm{~Hz}, 4 \mathrm{H}), 2.16(\mathrm{~s}, 6 \mathrm{H}), 1.21(\mathrm{t}, J=7.1 \mathrm{~Hz}, 4 \mathrm{H}), 1.07$ $(\mathrm{d}, J=7.5 \mathrm{~Hz}, 6 \mathrm{H}) ;{ }^{13} \mathrm{C} \mathrm{NMR}\left(75 \mathrm{MHz}, \mathrm{CDCl}_{3}\right) \delta 167.6,164.5,148.1,145.3,140.3,136.5,136.7$, $135.6,132.4$, 129.1, 123.9, 123.5, 123.0, 60.2, 36.3, 31.7, 17.2, 14.1, 13.8, 13.4, 9.5. HRMS (MALDI-TOF) m/z: [M+Na $]^{+}$Calcd for $\mathrm{C}_{37} \mathrm{H}_{34} \mathrm{~B}_{2} \mathrm{~F}_{8} \mathrm{~N}_{4} \mathrm{NaO}_{2} \mathrm{~S}$ 795.2353, Found 795.2345. 


\section{Crystal data}
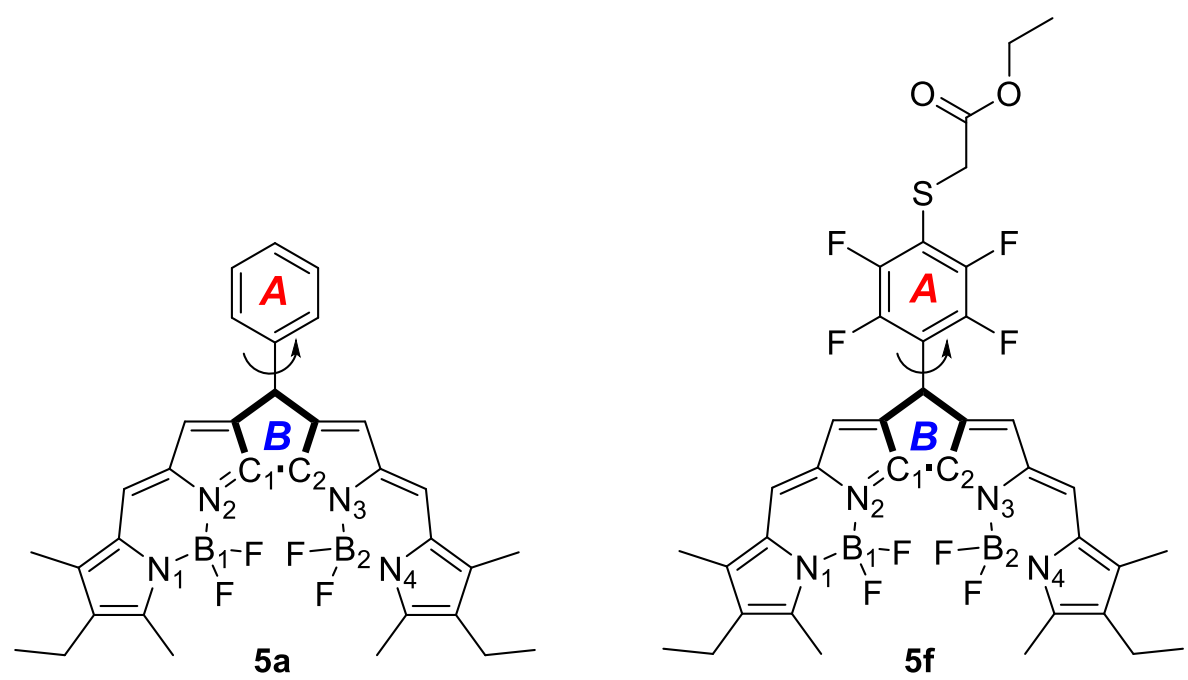

Table S2: Elected geometrical parameters of $\mathbf{5 a}$ and $\mathbf{5 f}$ obtained from crystallography

\begin{tabular}{ccc}
\hline & $\mathbf{5 a}$ & $\mathbf{5 f}$ \\
\hline the $\mathrm{B}_{1}-\mathrm{N}_{1}$ bond length $(\AA)$ & 1.561 & 1.561 \\
the $\mathrm{B}_{1}-\mathrm{N}_{2}$ bond length $(\AA)$ & 1.567 & 1.553 \\
the $\mathrm{B}_{2}-\mathrm{N}_{3}$ bond length $(\AA)$ & 1.552 & 1.564 \\
the $\mathrm{B}_{2}-\mathrm{N}_{4}$ bond length $(\AA)$ & 1.557 & 1.568 \\
the $\mathrm{C}_{1}-\mathrm{C}_{2}$ bond length $(\AA)$ in the \\
$\quad \begin{array}{l}\text { five-membered-ring } \\
\text { dihedral angles between ring } A\end{array}$
\end{tabular}


Table S3. Crystal data and structure refinement for $\mathbf{5 a}$ and $\mathbf{5 f}$.

\begin{tabular}{|c|c|c|}
\hline Compound & $\mathbf{5 a}(+$ solvent $)$ & $\mathbf{5 f}(+$ solvent $)$ \\
\hline Empirical formula & $\begin{array}{c}\mathrm{C}_{33} \mathrm{H}_{32} \mathrm{~B}_{2} \mathrm{~F}_{4} \mathrm{~N}_{4} \\
\left(+\mathrm{HCCl}_{3}\right)\end{array}$ & $\begin{array}{c}\mathrm{C}_{37} \mathrm{H}_{34} \mathrm{~B}_{2} \mathrm{~F}_{8} \mathrm{~N}_{4} \mathrm{O}_{2} \mathrm{~S} \\
\left(+\mathrm{HCCl}_{3}\right)\end{array}$ \\
\hline Formula weight & 701.61 & 891.73 \\
\hline Temperature/K & 293(2) & 293(2) \\
\hline Crystal system & triclinic & triclinic \\
\hline Space group & P-1 & P-1 \\
\hline $\mathrm{a} / \AA$ & $12.431(2)$ & $11.7754(4)$ \\
\hline $\mathrm{b} / \AA$ & $15.750(5)$ & $13.4210(4)$ \\
\hline $\mathrm{c} / \AA$ & $17.538(3)$ & $14.9920(5)$ \\
\hline$\alpha /{ }^{\circ}$ & $84.608(4)$ & $69.2810(10)$ \\
\hline$\beta /{ }^{\circ}$ & $82.88(5)$ & $68.4440(10)$ \\
\hline$\gamma /{ }^{\circ}$ & $79.796(4)$ & $75.0370(10)$ \\
\hline Volume $/ \AA^{3}$ & $3344.1(14)$ & $2038.57(12)$ \\
\hline Z & 4 & 2 \\
\hline$\rho_{\text {calc }} \mathrm{g} / \mathrm{cm}^{3}$ & 1.394 & 1.453 \\
\hline$\mu / \mathrm{mm}^{-1}$ & 0.328 & 0.353 \\
\hline $\mathrm{F}(000)$ & 1448.0 & 912.0 \\
\hline Crystal size $/ \mathrm{mm}^{3}$ & $0.23 \times 0.18 \times 0.15$ & $0.25 \times 0.15 \times 0.12$ \\
\hline Radiation & $\operatorname{MoK} \alpha(\lambda=0.71073)$ & $\operatorname{MoK} \alpha(\lambda=0.71073)$ \\
\hline $\begin{array}{l}2 \Theta \text { range for data } \\
\text { collection }^{\circ}\end{array}$ & 5.92 to 49.998 & 6.038 to 50.814 \\
\hline Index ranges & $\begin{array}{c}-14 \leq \mathrm{h} \leq 14,-18 \leq \mathrm{k} \leq 18 \\
-20 \leq 1 \leq 20\end{array}$ & $\begin{array}{c}-14 \leq \mathrm{h} \leq 14,-16 \leq \mathrm{k} \leq 16 \\
-18 \leq 1 \leq 18\end{array}$ \\
\hline Reflections collected & 101928 & 43074 \\
\hline Independent reflections & $\begin{array}{c}11451\left[\mathrm{R}_{\text {int }}=0.0579\right. \\
\left.\mathrm{R}_{\text {sigma }}=0.0341\right]\end{array}$ & $\begin{array}{c}7488\left[R_{\text {int }}=0.0429\right. \\
\left.R_{\text {sigma }}=0.0272\right]\end{array}$ \\
\hline Data/restraints/parameters & $11451 / 834 / 859$ & $7488 / 0 / 530$ \\
\hline Goodness-of-fit on $\mathrm{F}^{2}$ & 1.026 & 1.032 \\
\hline Final $R$ indexes $[\mathrm{I}>=2 \sigma(\mathrm{I})]$ & \multicolumn{2}{|c|}{$\mathrm{R}_{1}=0.0853, \mathrm{wR}_{2}=0.2322 \mathrm{R}_{1}=0.0661, \mathrm{wR}_{2}=0.1719$} \\
\hline Final $\mathrm{R}$ indexes [all data] & \multicolumn{2}{|c|}{$\mathrm{R}_{1}=0.1190, \mathrm{wR}_{2}=0.2477 \mathrm{R}_{1}=0.0954, \mathrm{wR}_{2}=0.1983$} \\
\hline $\begin{array}{l}\text { Largest diff. peak/hole / e } \\
\qquad \AA^{-3}\end{array}$ & $0.77 /-0.73$ & $0.80 /-0.67$ \\
\hline
\end{tabular}


(a)

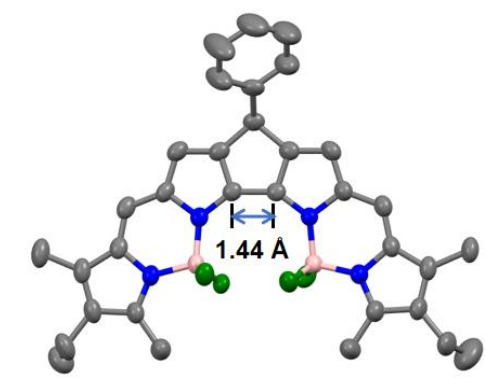

top view

(e)
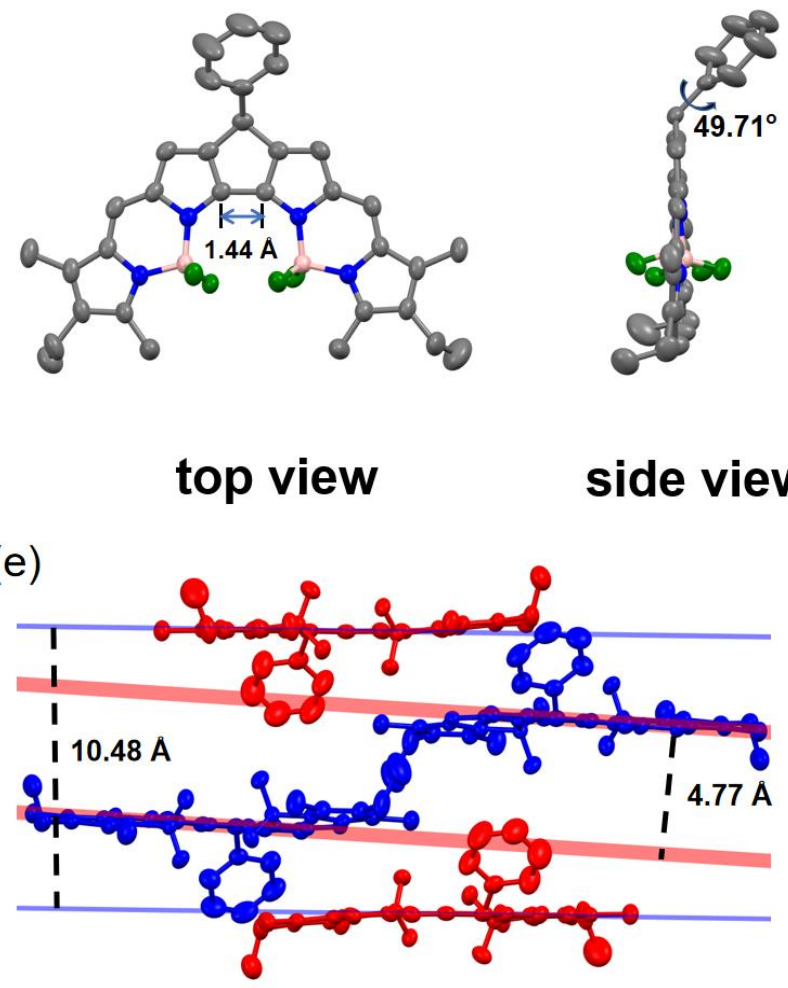

(c)

side view

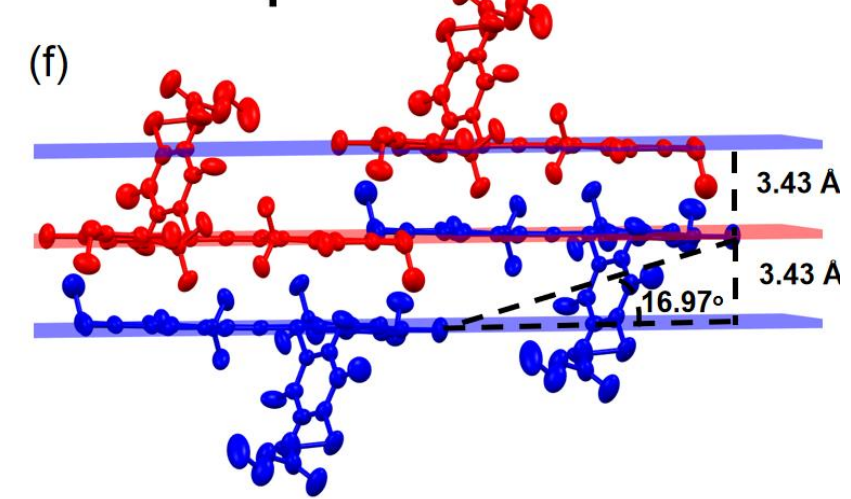

Figure S1. Top and side views of X-Ray structures of 5a (a-b), $\mathbf{5 f}(\mathrm{c}-\mathrm{d})$ and their crystal packing (e-f). C, gray; N, blue; B, pink; F, green. Hydrogen atoms have been removed for clarity. Thermal ellipsoids are shown at the $50 \%$ probability level 


\section{Photophysical properties}
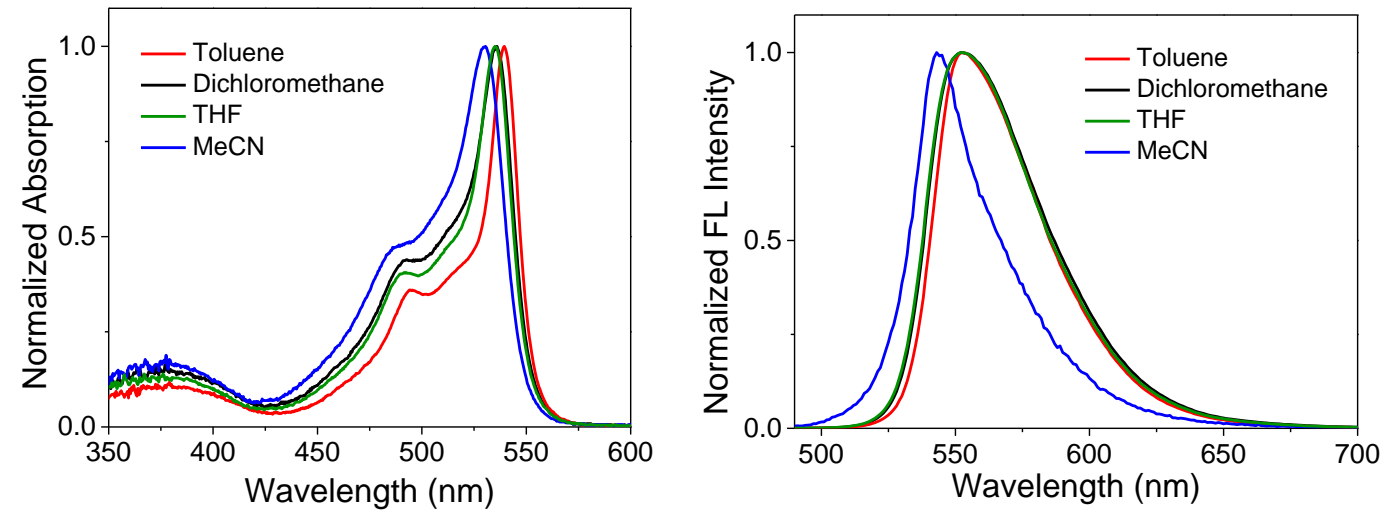

Figure S2. Absorption (left) and emission (right) spectra of compound 4a recorded in different solvents. Excited at $480 \mathrm{~nm}$.
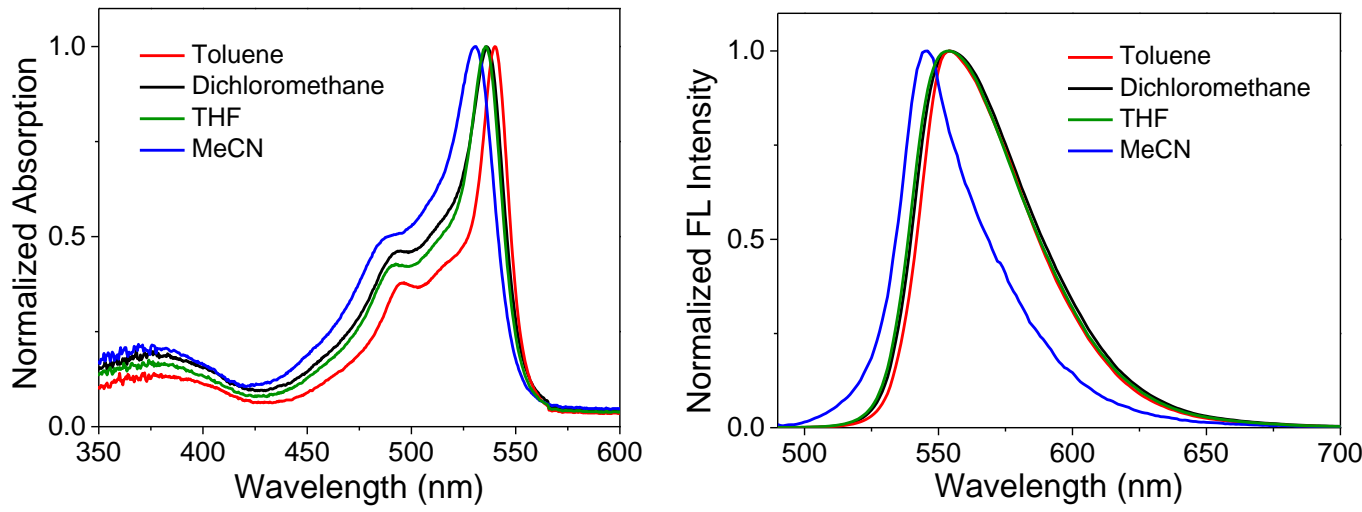

Figure S3. Absorption (left) and emission (right) spectra of compound $\mathbf{4 b}$ recorded in different solvents. Excited at $480 \mathrm{~nm}$.
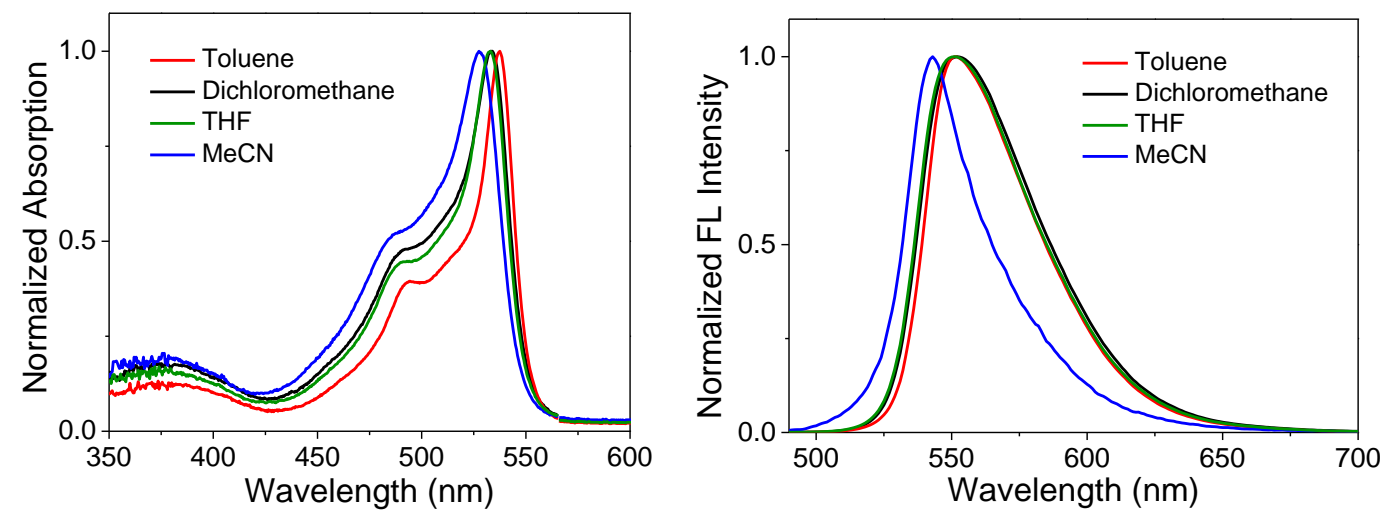

Figure S4. Absorption (left) and emission (right) spectra of compound $\mathbf{4 c}$ recorded in different solvents. Excited at $480 \mathrm{~nm}$. 

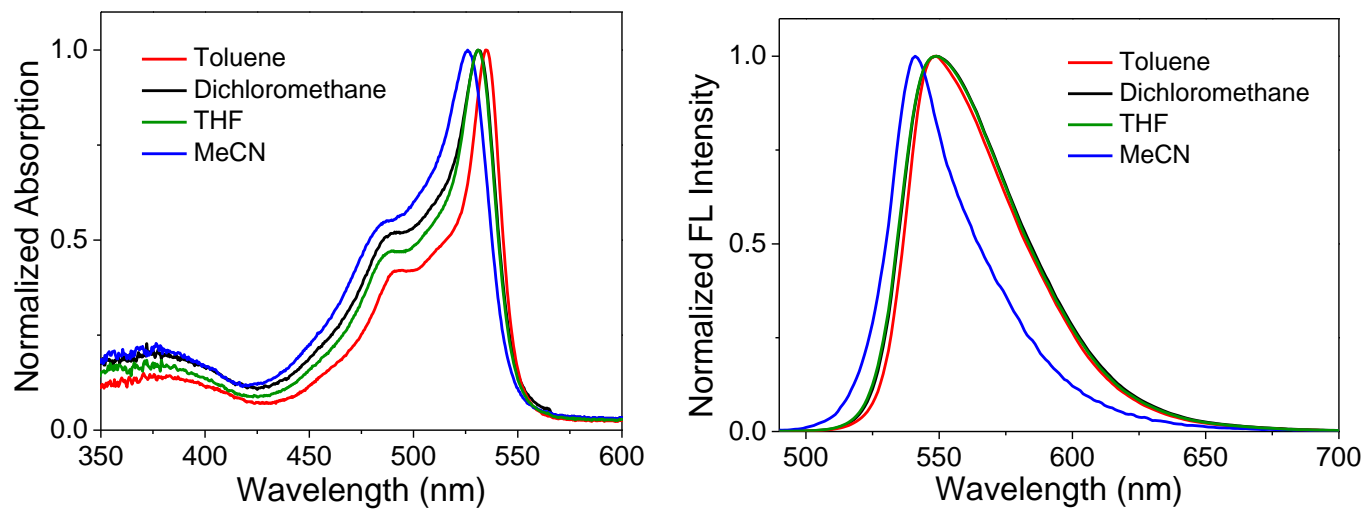

Figure S5. Absorption (left) and emission (right) spectra of compound 4d recorded in different solvents. Excited at $480 \mathrm{~nm}$.
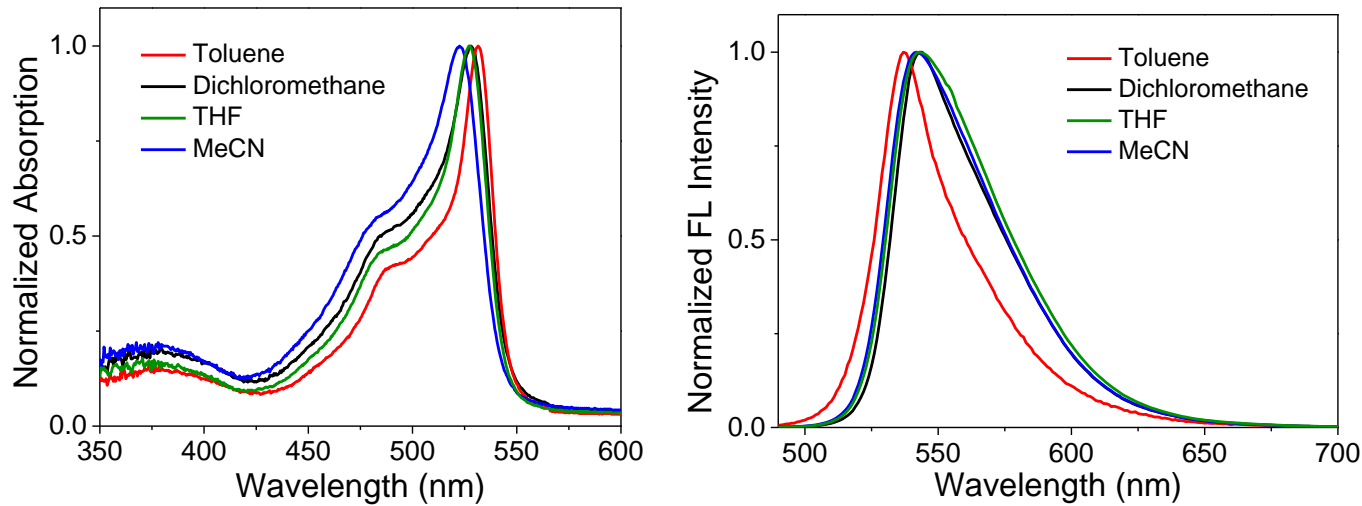

Figure S6. Absorption (left) and emission (right) spectra of compound $4 \mathbf{e}$ recorded in different solvents. Excited at $480 \mathrm{~nm}$.
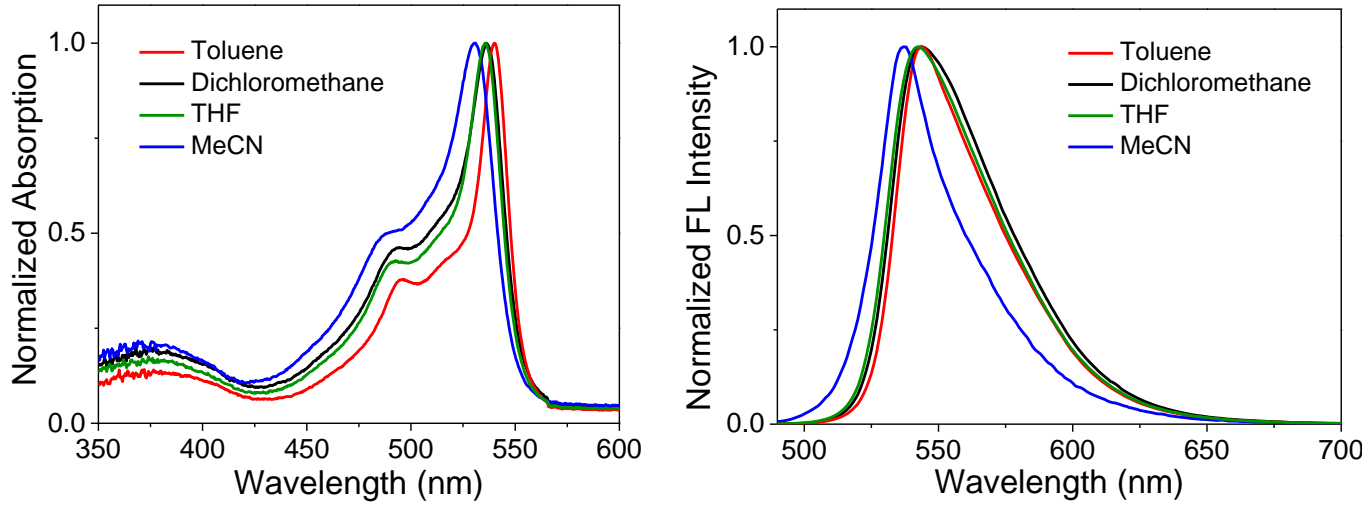

Figure S7. Absorption (left) and emission (right) spectra of compound $4 \mathbf{f}$ recorded in different solvents. Excited at $480 \mathrm{~nm}$. 

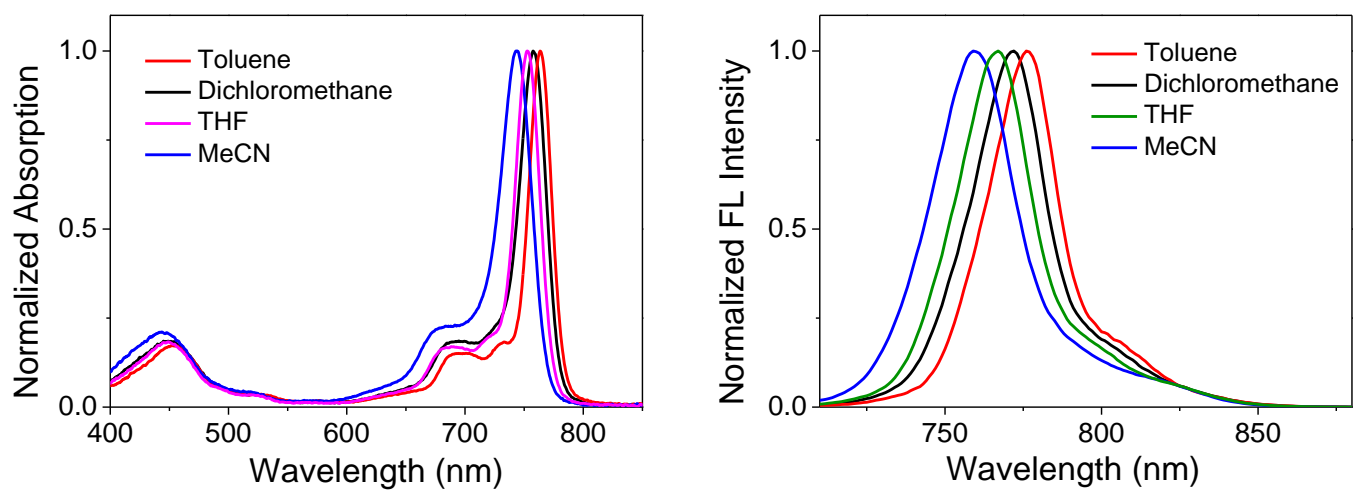

Figure S8. Absorption (left) and emission (right) spectra of compound 5a recorded in different solvents. Excited at $700 \mathrm{~nm}$.
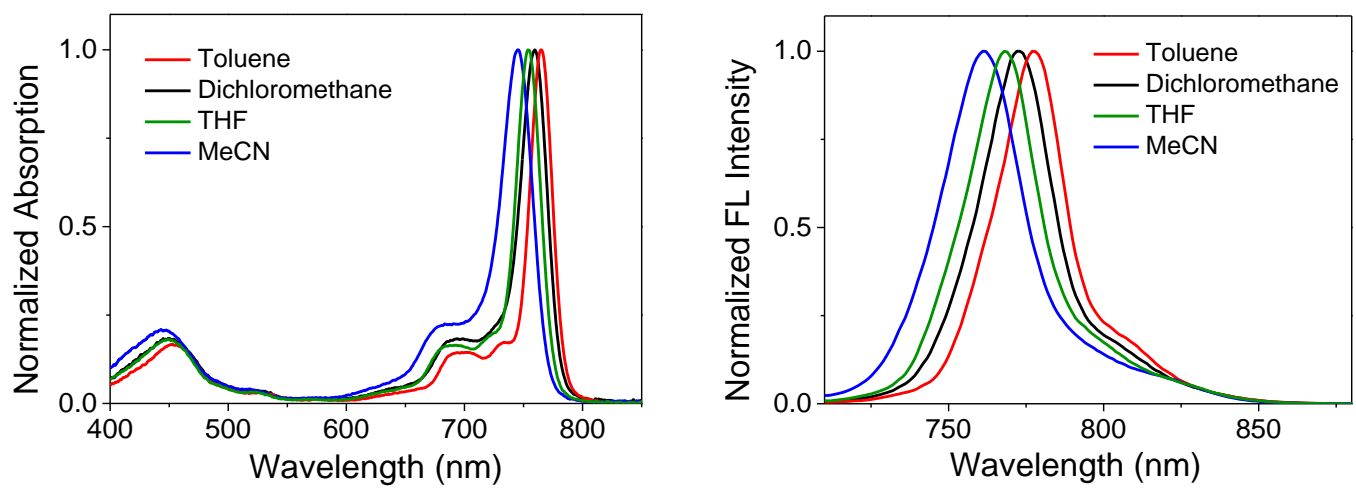

Figure S9. Absorption (left) and emission (right) spectra of compound $\mathbf{5 b}$ recorded in different solvents. Excited at $700 \mathrm{~nm}$.
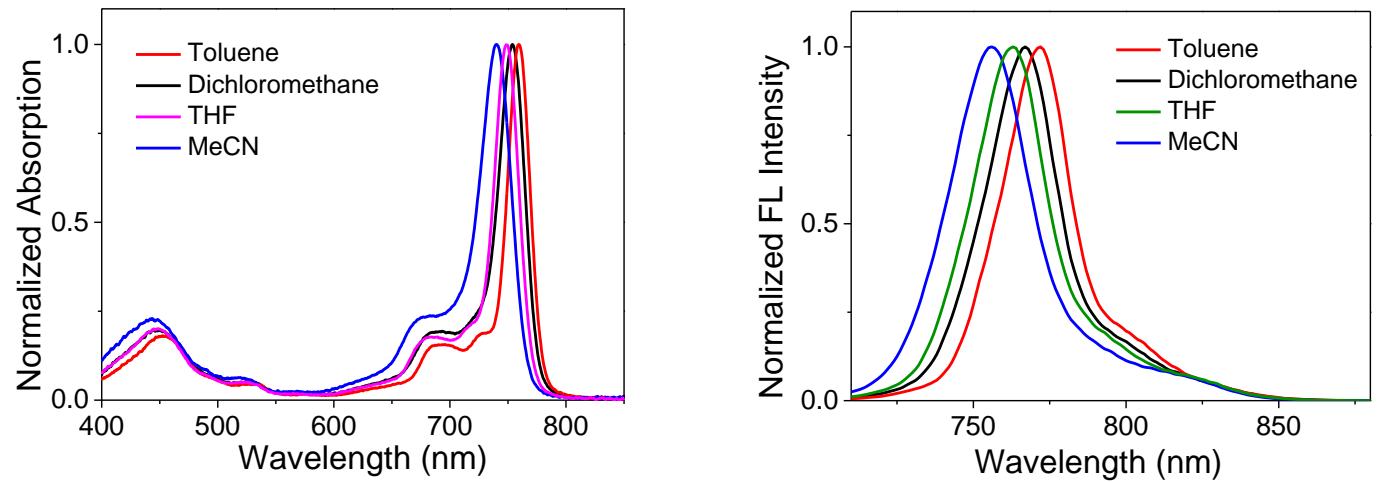

Figure S10. Absorption (left) and emission (right) spectra of compound 5c recorded in different solvents. Excited at $700 \mathrm{~nm}$. 

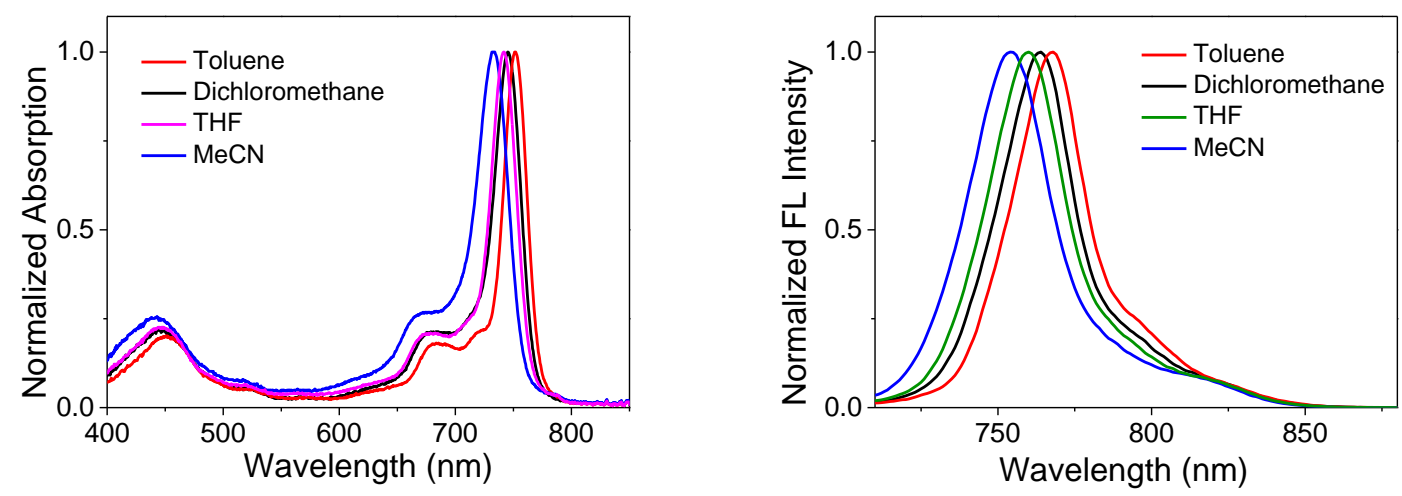

Figure S11. Absorption (left) and emission (right) spectra of compound 5d recorded in different solvents. Excited at $700 \mathrm{~nm}$.
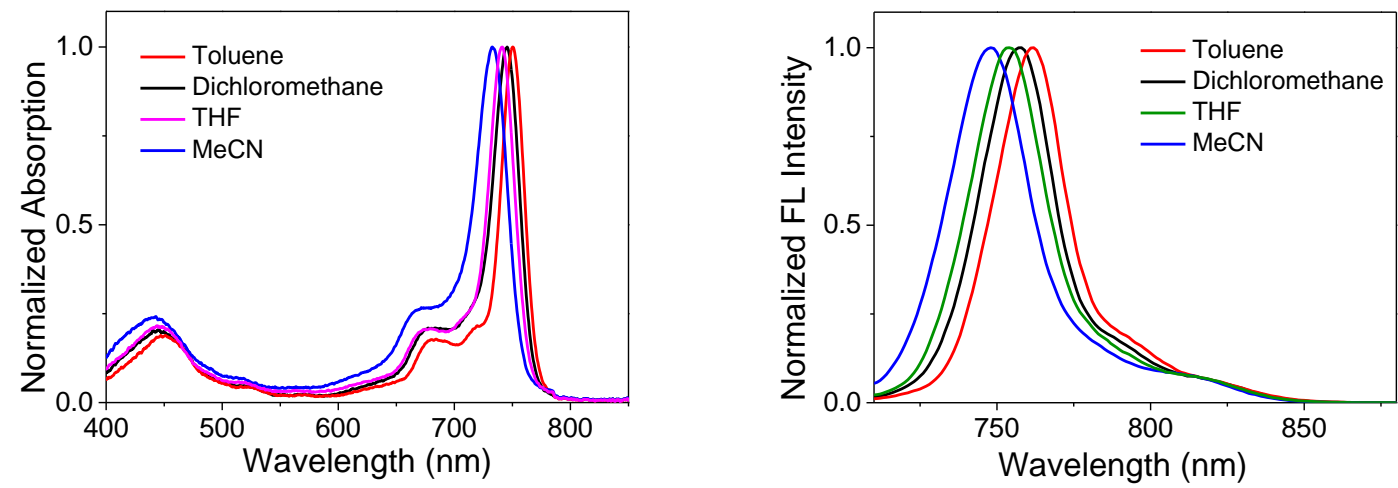

Figure S12. Absorption (left) and emission (right) spectra of compound 5e recorded in different solvents. Excited at $700 \mathrm{~nm}$.
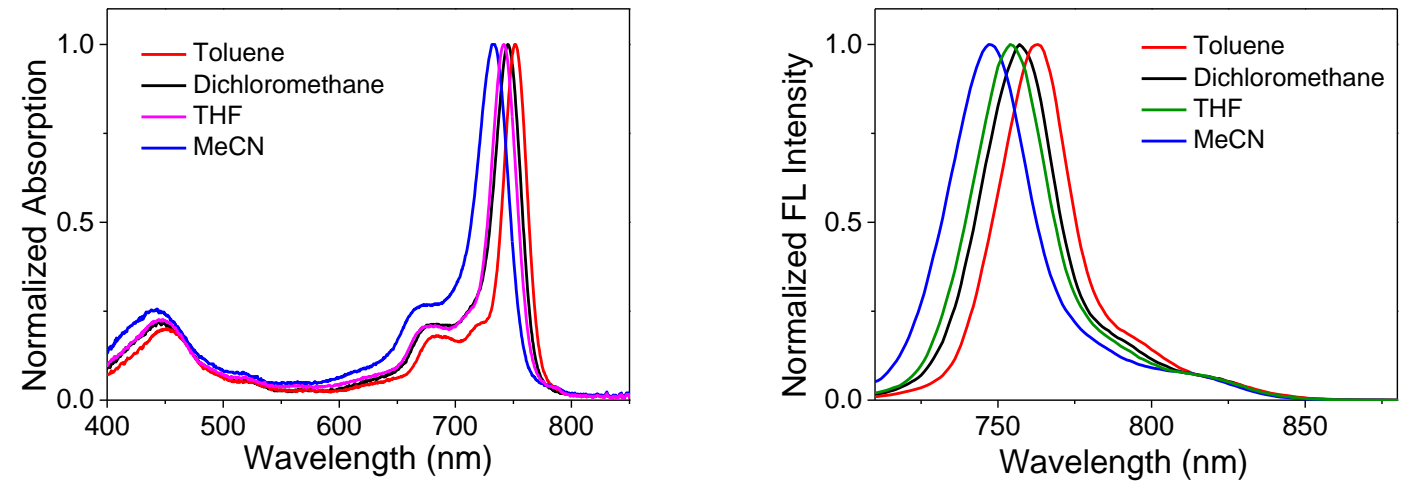

Figure S13. Absorption (left) and emission (right) spectra of compound $\mathbf{5 f}$ recorded in different solvents. Excited at $700 \mathrm{~nm}$. 


\section{DFT calculation}
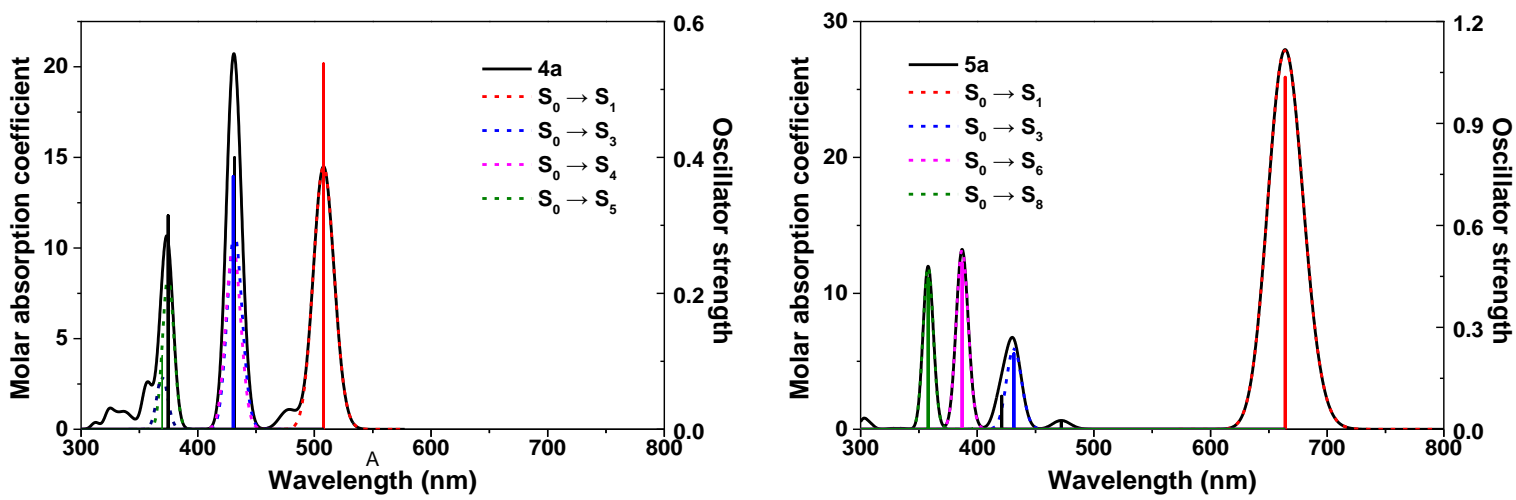

Figure S14. Calculated UV-vis absorption of energy-minimized calculated (Gaussian) 4a (left) and 5a (right). The unit for molar absorption coefficient is $10^{4} \mathrm{~L} / \mathrm{mol} / \mathrm{cm}$. Calculation was performed at B3LYP/6-31+G(d,p) level with Gaussian 09.

Table S4. Selected electronic excitation energies $(\mathrm{eV})$ and oscillator strengths (f), configurations of the low-lying excited states of $\mathbf{M}, \mathbf{4 a}$ and $\mathbf{5 a}$ calculated by TDDFT//B3LYP/6-31+G(d,p), based on the optimized ground state geometries.

\begin{tabular}{|c|c|c|c|c|c|}
\hline \multirow{2}{*}{ dyes } & \multirow{2}{*}{$\begin{array}{c}\text { Electronic } \\
\text { transition }\end{array}$} & \multicolumn{4}{|c|}{ TD//B3LYP/6-31+G (d, p) } \\
\hline & & Energy/ eV ${ }^{[a]}$ & $f^{[\mathrm{b}]}$ & Composition $^{[\mathrm{c}]}$ & $\mathrm{CI}^{[\mathrm{d}]}$ \\
\hline \multirow[t]{5}{*}{$\mathbf{M}$} & $\mathrm{S} 0 \rightarrow \mathrm{S} 1$ & $2.8692 \mathrm{eV} \quad 432.12 \mathrm{~nm}$ & 0.5730 & HOMO - $1 \rightarrow$ LUMO & 0.1830 \\
\hline & & & & HOMO $\rightarrow$ LUMO & 0.6820 \\
\hline & $\mathrm{S} 0 \rightarrow \mathrm{S} 2$ & $3.3698 \mathrm{eV} 367.93 \mathrm{~nm}$ & 0.1826 & HOMO - $1 \rightarrow$ LUMO & 0.6803 \\
\hline & & & & $\mathrm{HOMO} \rightarrow$ LUMO & 0.1847 \\
\hline & $\mathrm{S} 0 \rightarrow \mathrm{S} 3$ & $3.7746 \mathrm{eV} \quad 328.47 \mathrm{~nm}$ & 0.0760 & HOMO -2 $\rightarrow$ LUMO & 0.6994 \\
\hline \multirow[t]{5}{*}{$4 \mathbf{a}$} & $\mathrm{S} 0 \rightarrow \mathrm{S} 1$ & $2.4430 \mathrm{eV} 507.51 \mathrm{~nm}$ & 0.5377 & HOMO $\rightarrow$ LUMO & 0.6981 \\
\hline & $\mathrm{S} 0 \rightarrow \mathrm{S} 2$ & $2.5964 \mathrm{eV} \quad 477.52 \mathrm{~nm}$ & 0.0397 & HOMO $-1 \rightarrow$ LUMO & 0.4113 \\
\hline & & & & $\mathrm{HOMO} \rightarrow \mathrm{LUMO}+1$ & 0.5704 \\
\hline & $\mathrm{S} 0 \rightarrow \mathrm{S} 3$ & $2.8752 \mathrm{eV} \quad 431.22 \mathrm{~nm}$ & 0.3997 & HOMO -1 $\rightarrow$ LUMO & 0.5474 \\
\hline & & & & $\mathrm{HOMO} \rightarrow \mathrm{LUMO}+1$ & 0.3825 \\
\hline \multirow[t]{5}{*}{$5 \mathbf{a}$} & $\mathrm{S} 0 \rightarrow \mathrm{S} 1$ & $1.8686 \mathrm{eV} \quad 663.51 \mathrm{~nm}$ & 1.0362 & HOMO $\rightarrow$ LUMO & 0.7111 \\
\hline & $\mathrm{S} 0 \rightarrow \mathrm{S} 2$ & $2.6284 \mathrm{eV} \quad 471.71 \mathrm{~nm}$ & 0.0240 & HOMO - $1 \rightarrow$ LUMO & 0.4406 \\
\hline & & & & $\mathrm{HOMO} \rightarrow \mathrm{LUMO}+1$ & 0.5483 \\
\hline & $\mathrm{S} 0 \rightarrow \mathrm{S} 3$ & $2.8758 \mathrm{eV} \quad 431.13 \mathrm{~nm}$ & 0.2228 & HOMO - $1 \rightarrow$ LUMO & 0.4070 \\
\hline & & & & $\mathrm{HOMO} \rightarrow \mathrm{LUMO}+1$ & 0.2771 \\
\hline
\end{tabular}

[a] Only the selected low-lying excited states are presented. [b] Oscillator strength. [c] Only the main configurations are presented. [d] The CI coefficients are in absolute values. 


\section{Electrochemical properties}

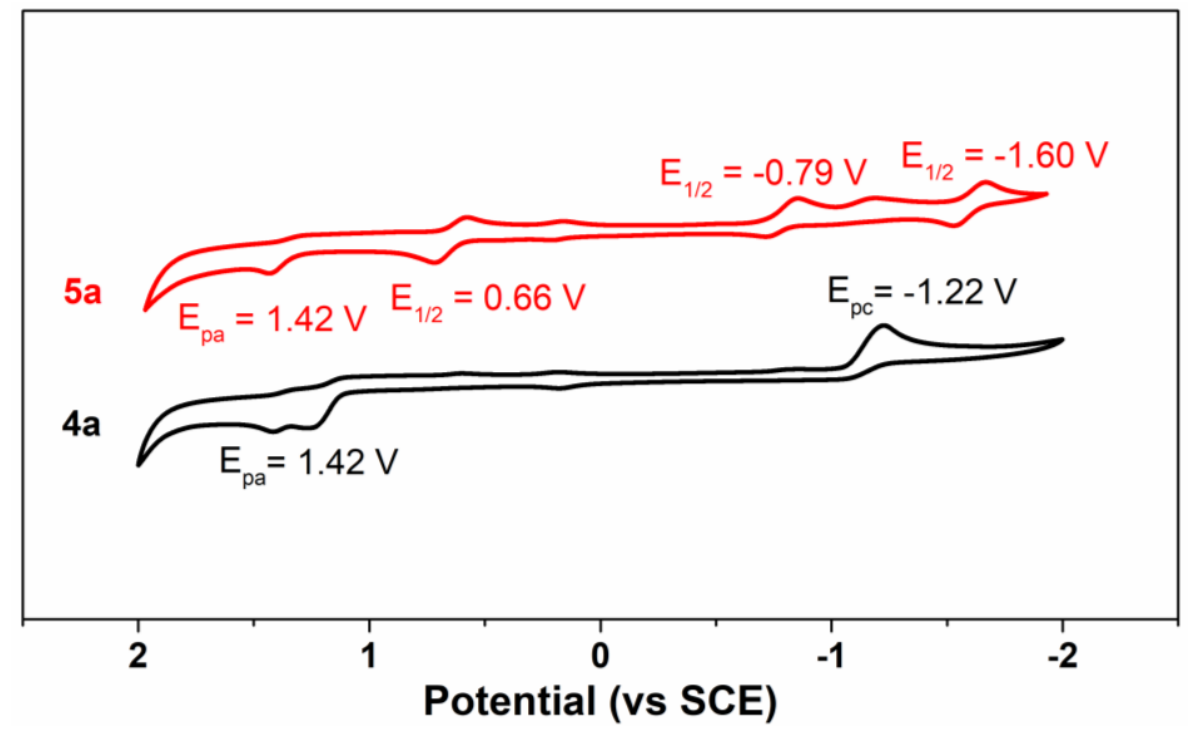

Figure S15. Cyclic voltammograms of $\mathbf{4 a}$ and $5 \mathbf{a}$ in anhydrous dichloromethane.

Table S5. Electrochemical data and HOMO-LUMO band gaps of 4 a and $5 a$.

\begin{tabular}{|c|c|c|c|c|c|c|c|c|c|}
\hline Dyes & $\begin{array}{c}E_{\mathrm{B} / \mathrm{B}}^{\mathrm{o}} \\
(\mathrm{v})\end{array}$ & $\begin{array}{l}E_{\mathrm{p}}^{\text {ox }} \\
(\mathrm{v})\end{array}$ & $\begin{array}{c}E_{\text {ox }}{ }^{\text {onset }} \\
\text { (v) }\end{array}$ & $\begin{array}{c}E_{\mathrm{B} / \mathrm{B}^{-}}^{\mathrm{o}} \\
(\mathrm{v})\end{array}$ & $\begin{array}{l}E_{\mathrm{p}}^{\text {red }} \\
(\mathrm{v})\end{array}$ & $\begin{array}{c}E_{\text {red }}{ }^{\text {onset }} \\
\text { (v) }\end{array}$ & $\begin{array}{c}\text { HOMO } \\
(\mathrm{ev})\end{array}$ & $\begin{array}{c}\text { LUMO } \\
(\mathrm{ev})\end{array}$ & $\begin{array}{l}E \mathrm{~g}^{\mathrm{e}} \\
(\mathrm{ev})\end{array}$ \\
\hline $4 a$ & - & 1.42 & 1.12 & - & -1.22 & -1.07 & -5.52 & -3.33 & 2.19 \\
\hline $5 a$ & 0.66 & 1.42 & 0.58 & $\begin{array}{l}-0.79 \\
-1.60\end{array}$ & - & -0.68 & -4.98 & -3.72 & 1.26 \\
\hline $\begin{array}{l}E^{\mathrm{o}_{\mathrm{B}}^{+} / \mathrm{B}} \\
\text { oxidati } \\
E_{\text {red }} \text { onse } \\
\text { bandga }\end{array}$ & tent & ${ }^{O} \mathrm{~B} /$ & tent & $F^{\text {ox }}=$ & 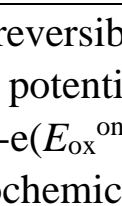 & $4.4)$ & $\begin{array}{l}\text { potent } \\
\text { eversi } \\
\text { MO }=\end{array}$ & $\begin{array}{l}\text { onset } \\
\text { ductic } \\
\text { donset }+\end{array}$ & $\begin{array}{l}\text { ons } \\
\text { entia } \\
E \mathrm{~g}^{\mathrm{e}}\end{array}$ \\
\hline
\end{tabular}




\section{Characterization and properties of 5a micelles}
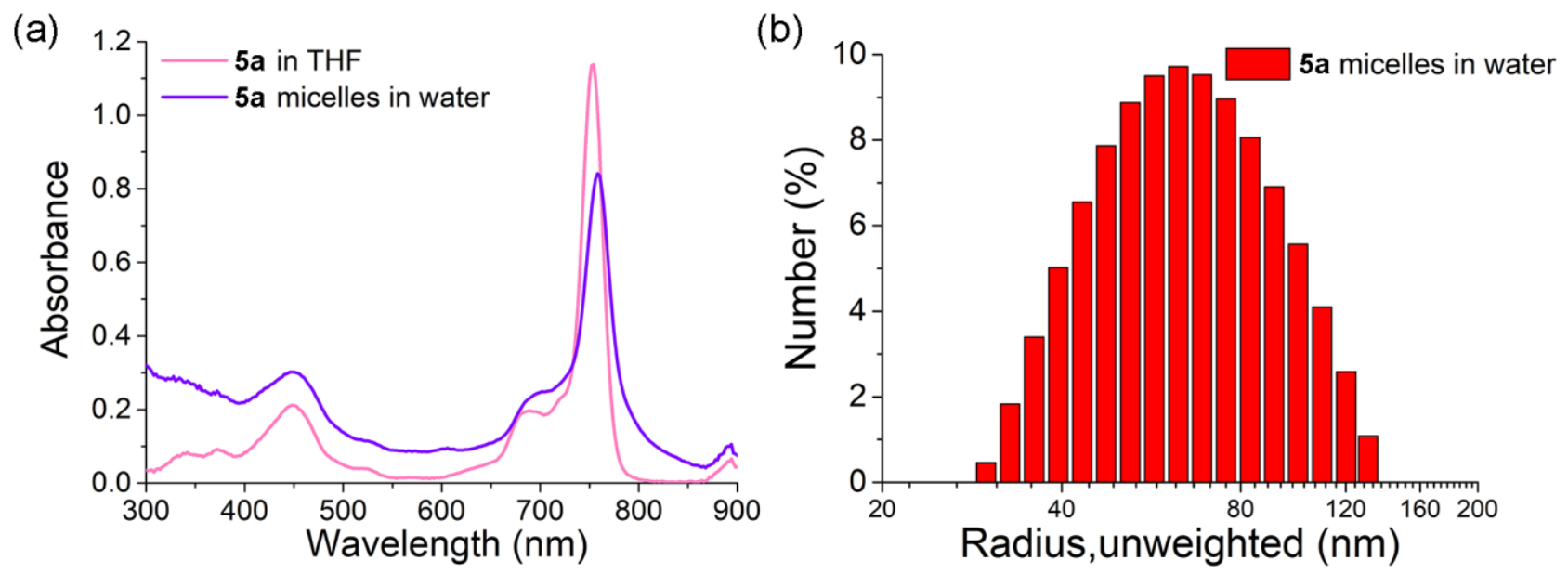

Figure S16. (a) UV-vis spectra of 5a $(5 \mu \mathrm{M})$ in different solvents. (b) The hydrodynamic diameter of 5a \& Cremophor EL micelles in water via DLS, the hydrodynamic sizes of 5a micelles were measured to be $\approx 61 \mathrm{~nm}$.

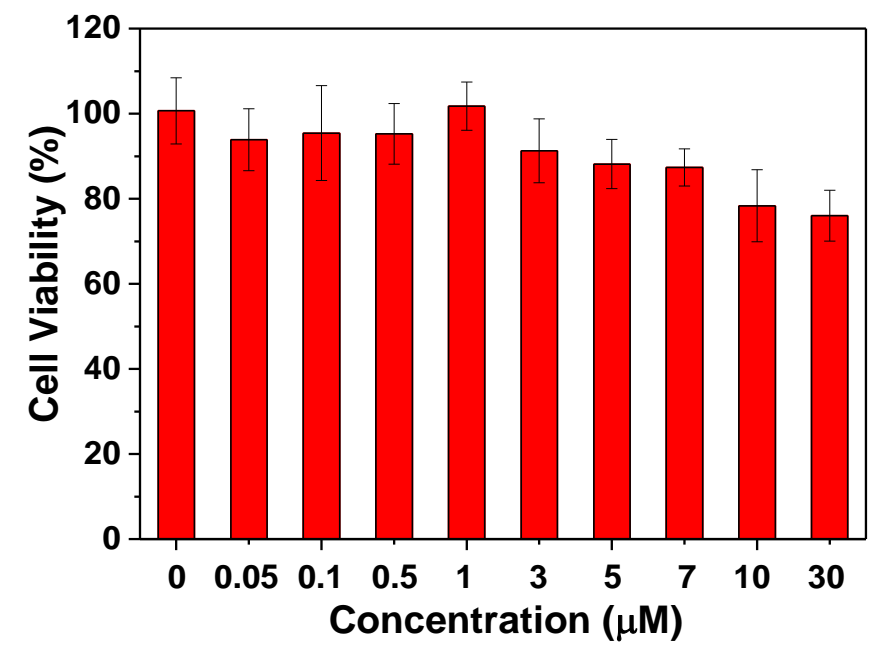

Figure S17. Ex vivo survival rate of Hela cells incubation with 5a micelles at different concentrations in the dark for $24 \mathrm{~h}$ as demonstrated by CCK-8 assay. 

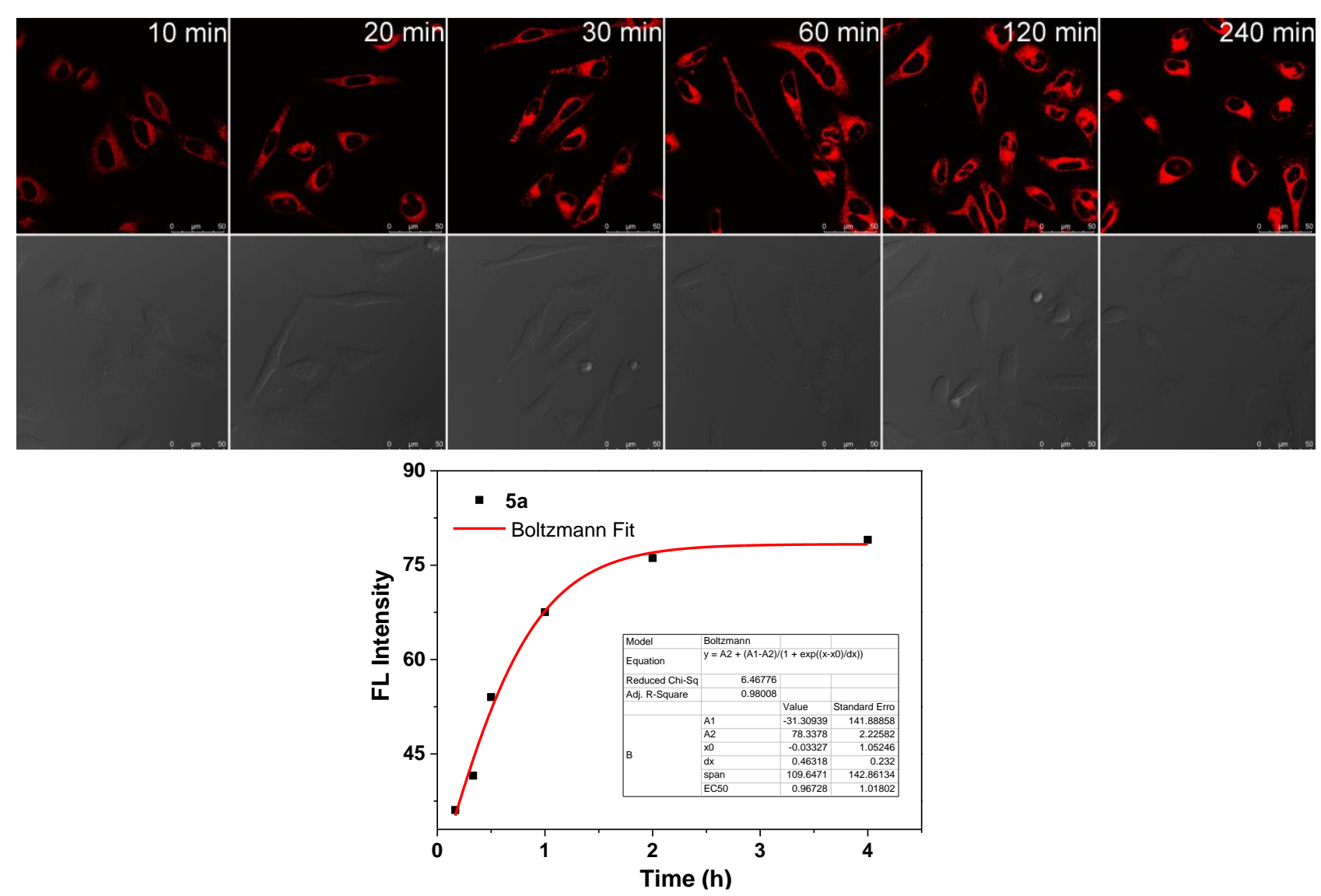

Figure S18. Fluorescence images of time-dependent uptake of $\mathbf{5 a}$ micelles at $5 \mu \mathrm{M}$ by HeLa cells (top) and fluorescence intensity quantitation analyzed by the above fluorescence images (bottom).

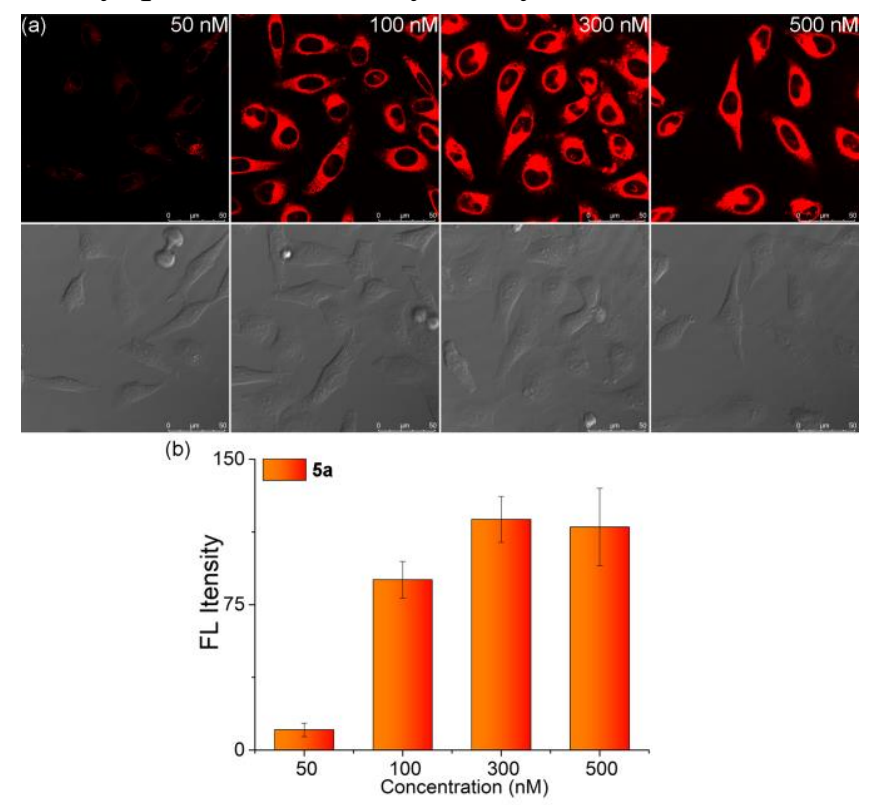

Figure S19. Fluorescence imaging of living HeLa cells with different concentrations of $\mathbf{5 a}$ micelles for $2 \mathrm{~h}$ at $37{ }^{\circ} \mathrm{C}$. Laser channel: $\lambda_{\mathrm{ex}}=638 \mathrm{~nm}, \lambda_{\mathrm{em}}=650-800 \mathrm{~nm}$. Scale bars $=50 \mu \mathrm{m}$. 

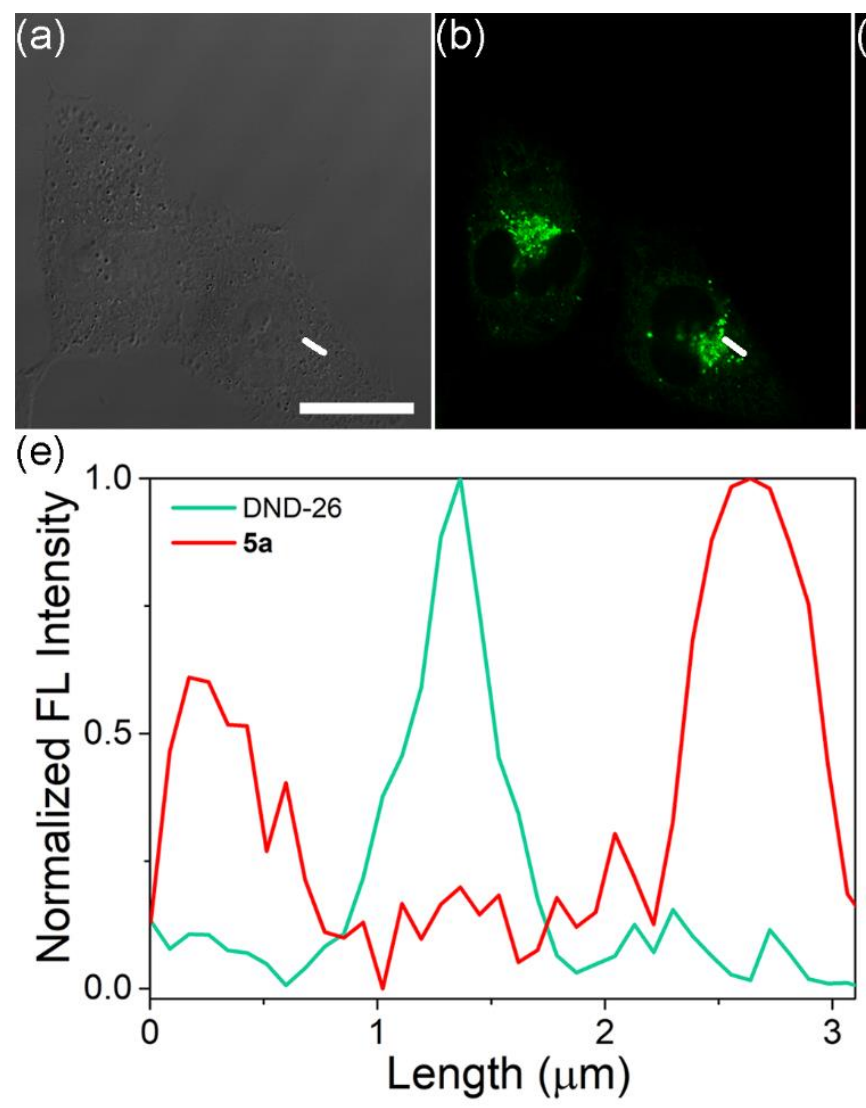
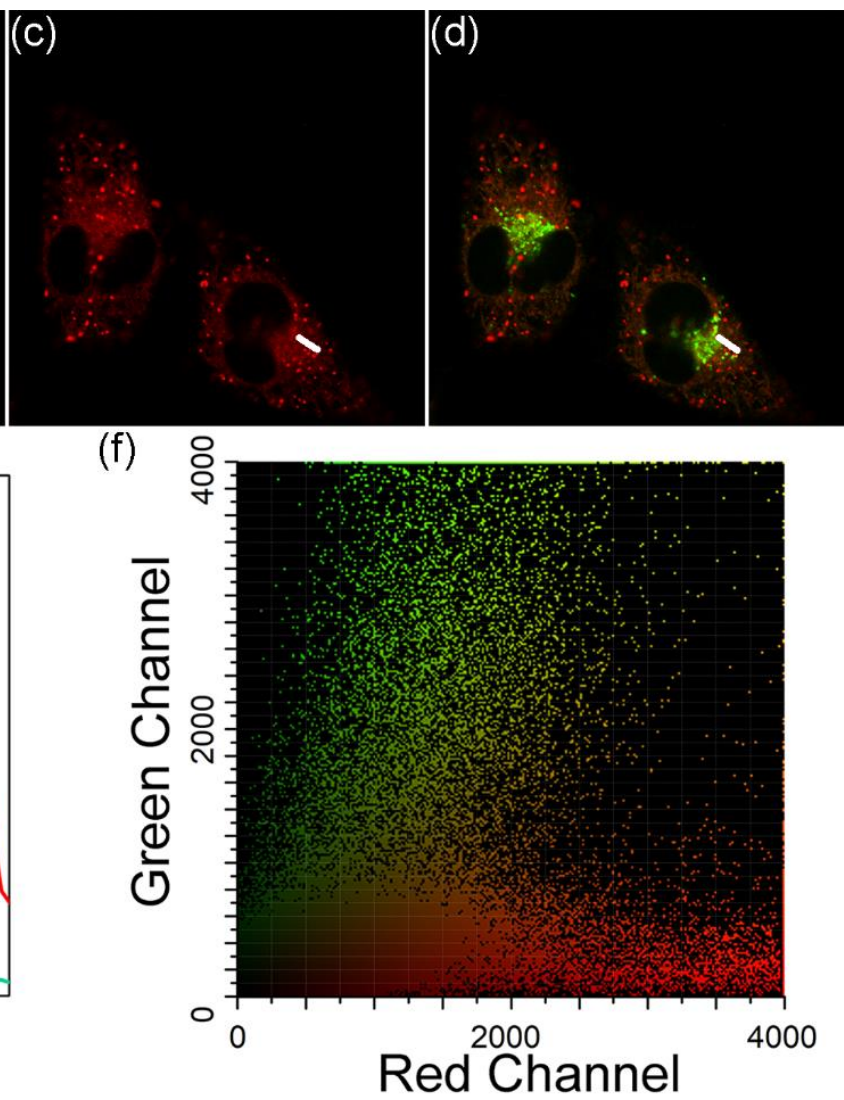

Figure S20. Lysosome-targeting properties of 5a micelles $(1 \mu \mathrm{M})$ in Hela cells. (a) Bright field; (b) DND-26 (LysoTracker® Green DND-26, $1 \mu \mathrm{M}$ ) fluorescence, using excitation wavelengths of 488 $\mathrm{nm}$, and recording over the 500-550 $\mathrm{nm}$ spectral regions; (c) 5a micelles fluorescence after incubation for $1 \mathrm{~h}$, using excitation wavelengths of $638 \mathrm{~nm}$, and recording over the 750-800 $\mathrm{nm}$ spectral regions; (d) merged images of parts b and c; (e) Intensity profiles within the regions of interests (ROIs) of 5a micelles and DND-26 across Hela cells, Pearson's correlation $\mathrm{Rr}=0.36$; (f) Correlation plot of 5a micelles and DND-26 intensities, Pearson's correlation $\mathrm{Rr}=0.49$; Overlap coefficient $\mathrm{R}=0.64$; Scale bars $=25 \mu \mathrm{m}$. 

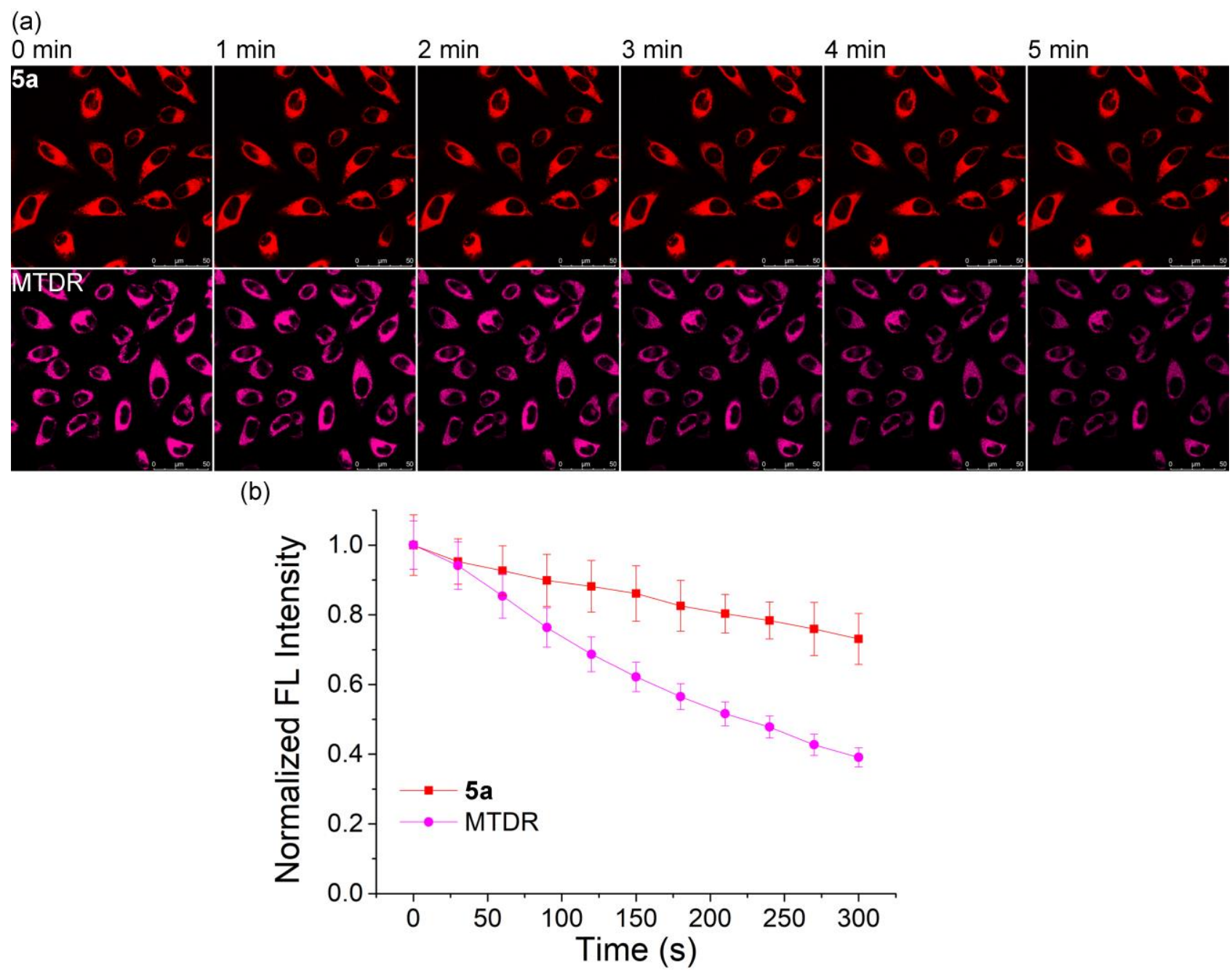

Figure S21. (a) Fluorescent images and (b) fluorescence intensity of 5a micelles $(5 \mu \mathrm{M})$ and MTDR $(500 \mathrm{nM})$ by continuous irradiation with $638 \mathrm{~nm}$ laser at different time. The image was scanned about every 60 s. Scale bar: $50 \mu \mathrm{m}$. 

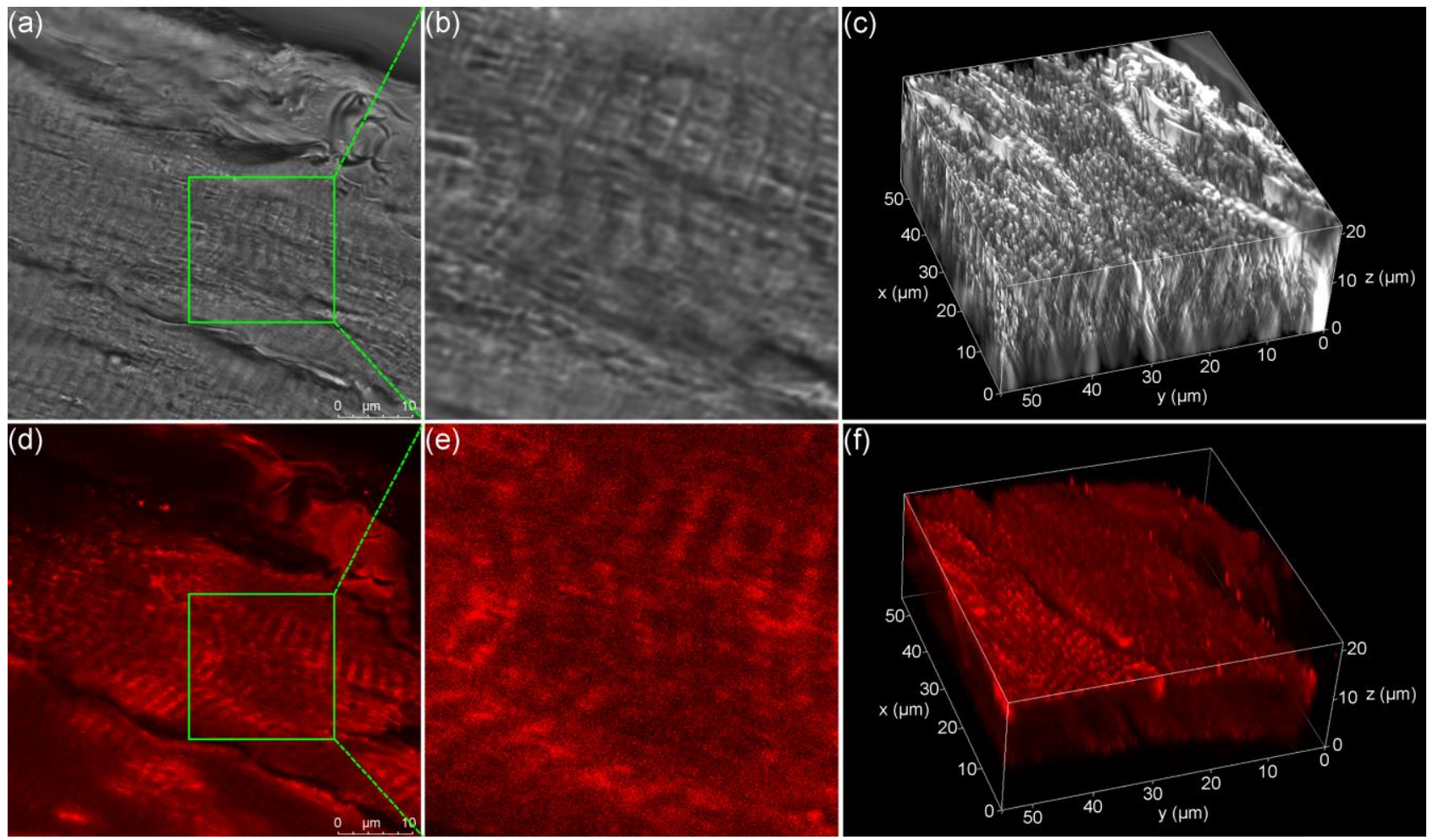

Figure S22. Ex vivo one-photon imaging in live deep tissues. (a) bright fields images of the domestic cat skeletal muscle tissue stained with 5a micelles $(5 \mu \mathrm{M})$; (b) enlarged image of a; (c) reconstructed 3D bright fields image; (d) 5a micelles fluorescence after incubation for 20 min, using excitation wavelengths of $638 \mathrm{~nm}$; (e) enlarged image of d; (f) reconstructed 3D fluorescent microscopic images. 


\section{9. ${ }^{1} \mathrm{H}$ and ${ }^{13} \mathrm{C}$ NMR spectra for all new compounds}

${ }^{1} \mathrm{H}$ NMR (300 MHz) spectrum of compound $4 \mathbf{a}$ in $\mathrm{CDCl}_{3}$.
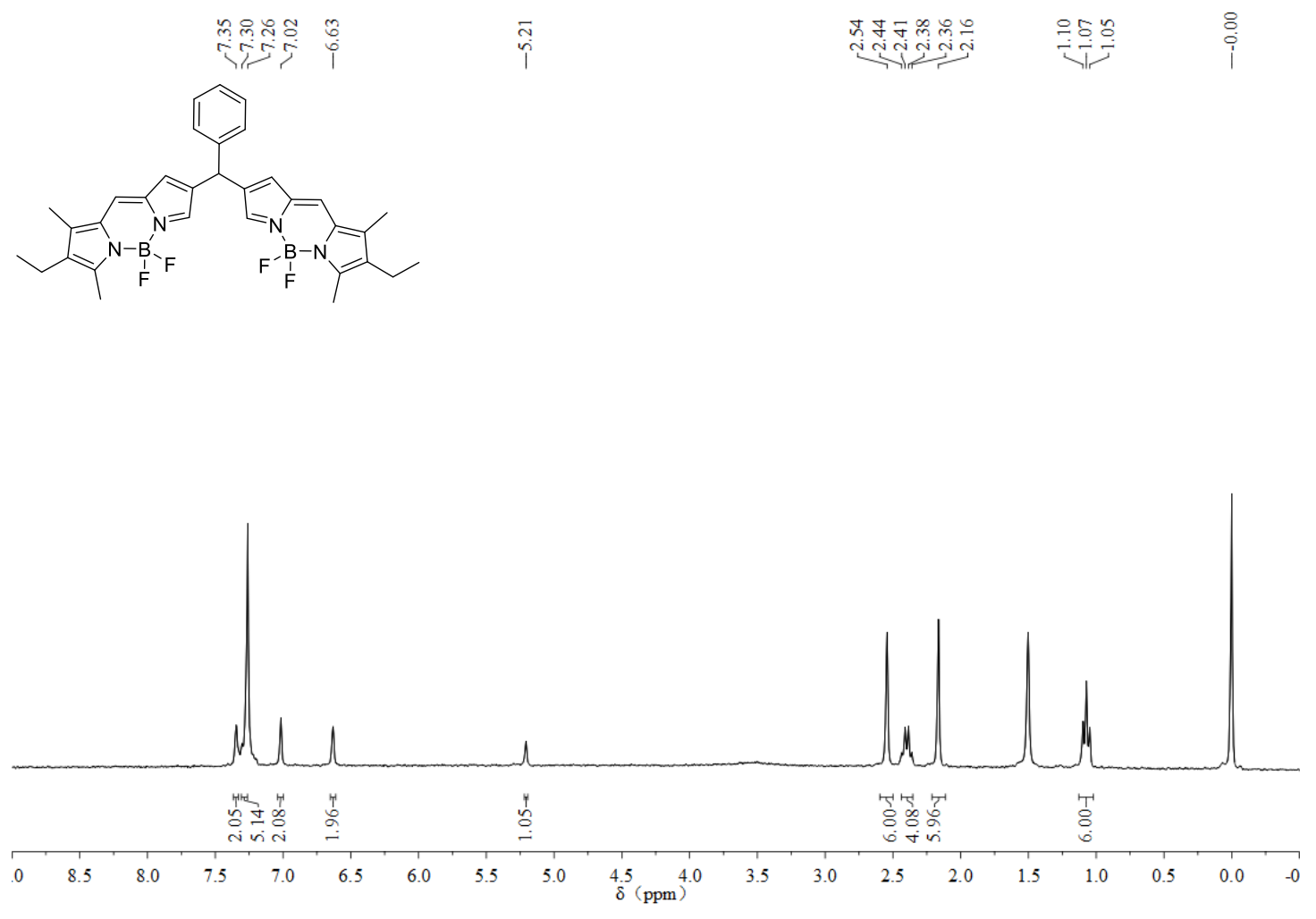

${ }^{13} \mathrm{C}$ NMR (300 MHz) spectrum of compound $4 \mathbf{a}$ in $\mathrm{CDCl}_{3}$.

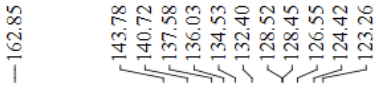

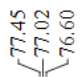

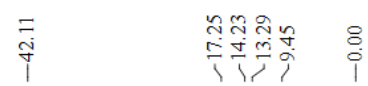
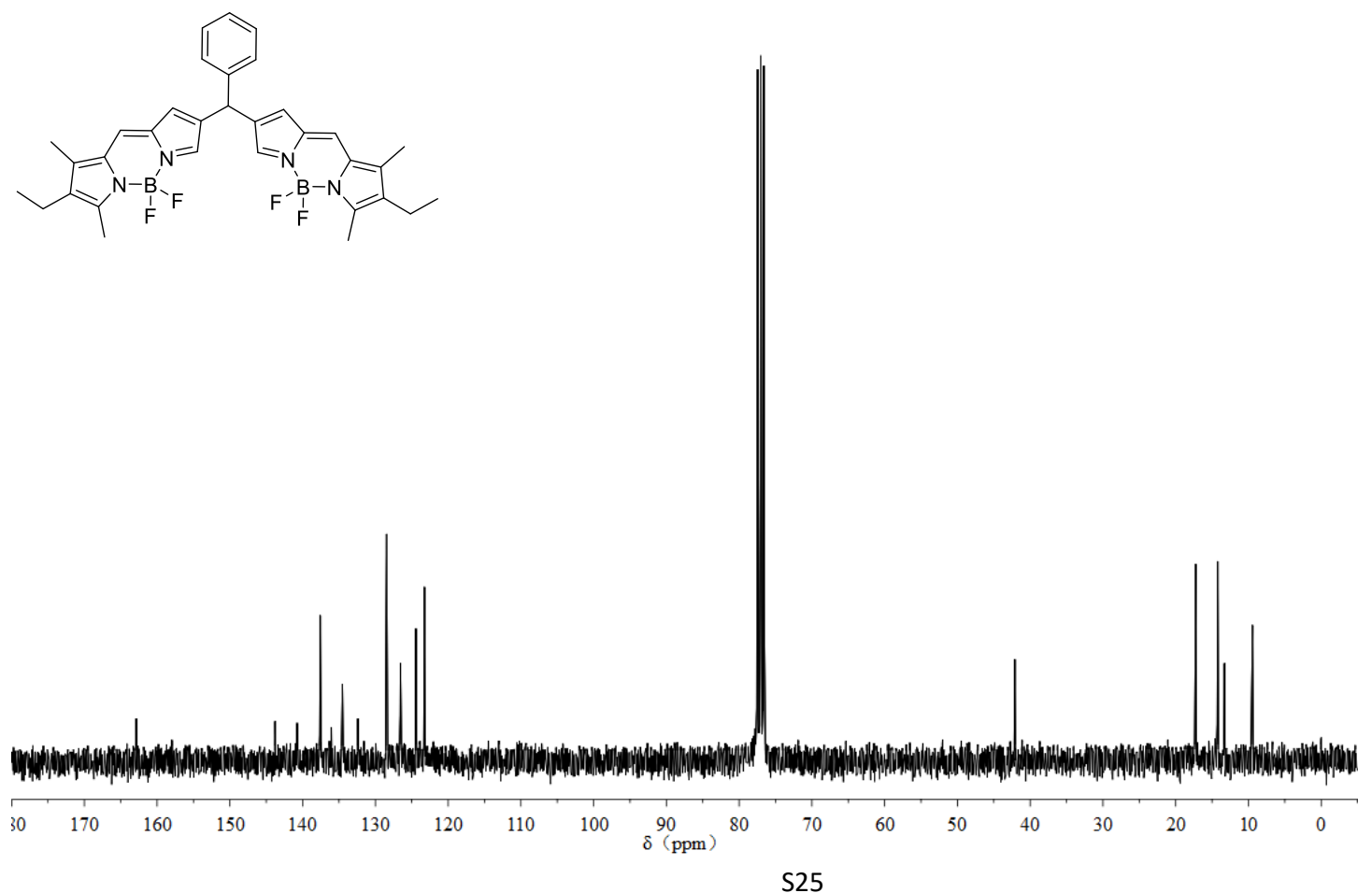
${ }^{1} \mathrm{H}$ NMR (500 MHz) spectrum of compound $\mathbf{4 b}$ in $\mathrm{CDCl}_{3}$.
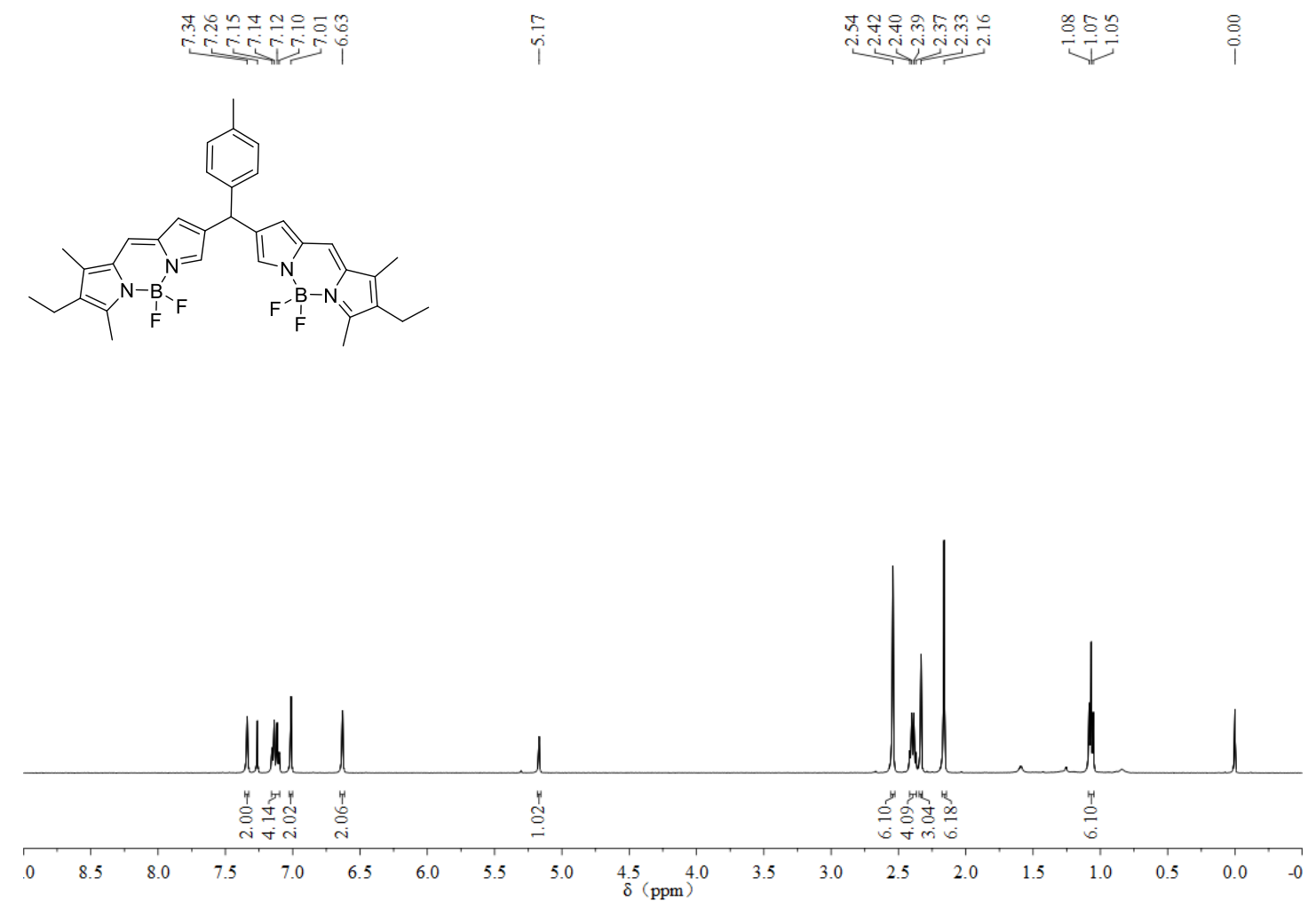

${ }^{13} \mathrm{C}$ NMR $(500 \mathrm{MHz})$ spectrum of compound $\mathbf{4 b}$ in $\mathrm{CDCl}_{3}$.
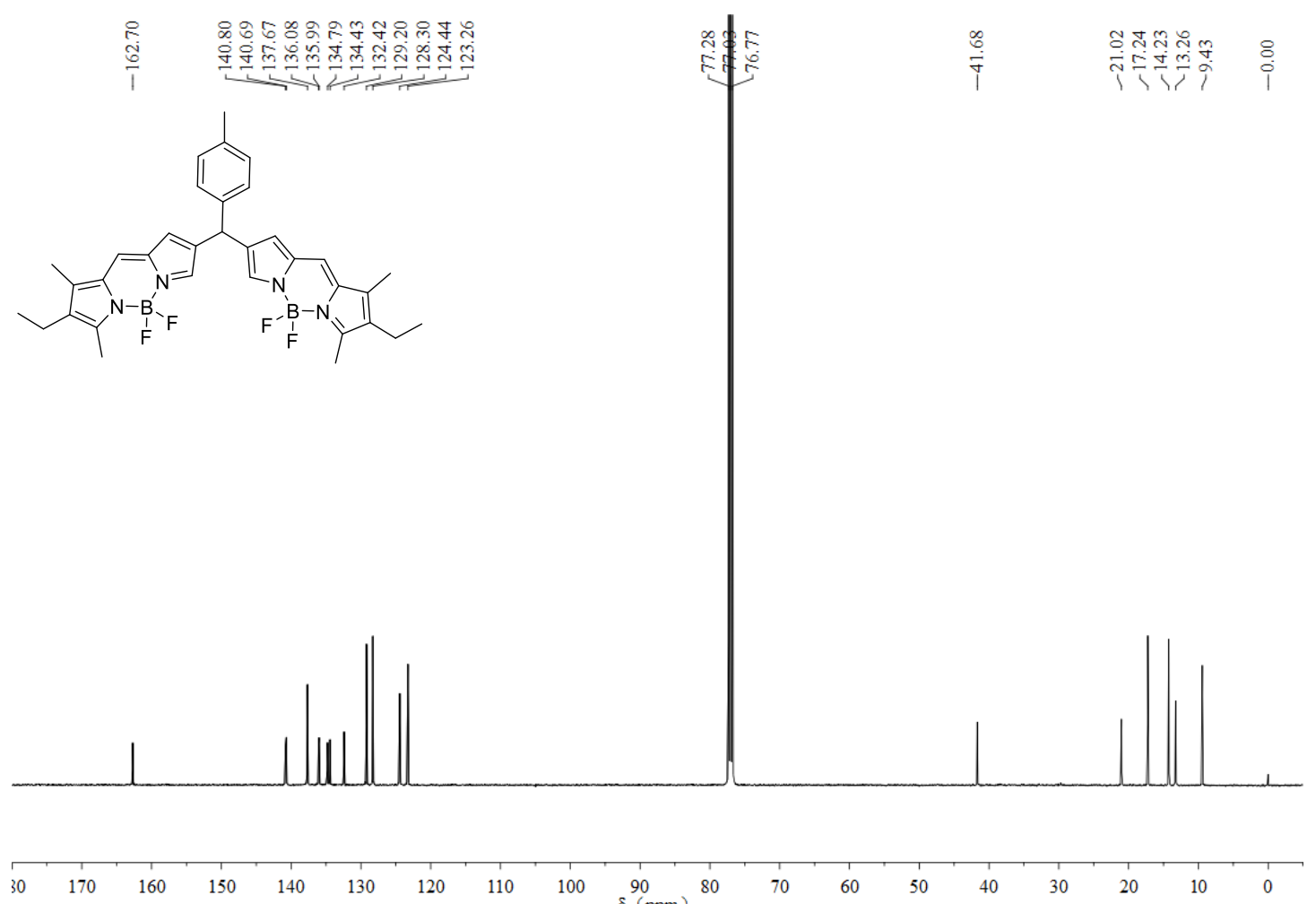
${ }^{1} \mathrm{H}$ NMR (500 MHz) spectrum of compound $\mathbf{4 c}$ in $\mathrm{CDCl}_{3}$.

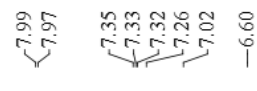

în

i

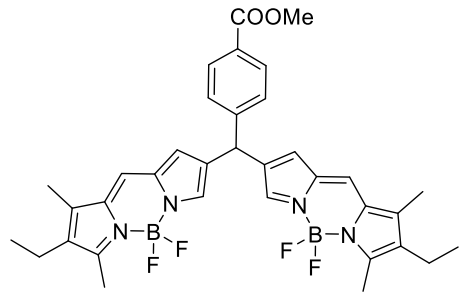

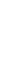


${ }^{1} \mathrm{H}$ NMR (500 MHz) spectrum of compound $\mathbf{4 d}$ in $\mathrm{CDCl}_{3}$.

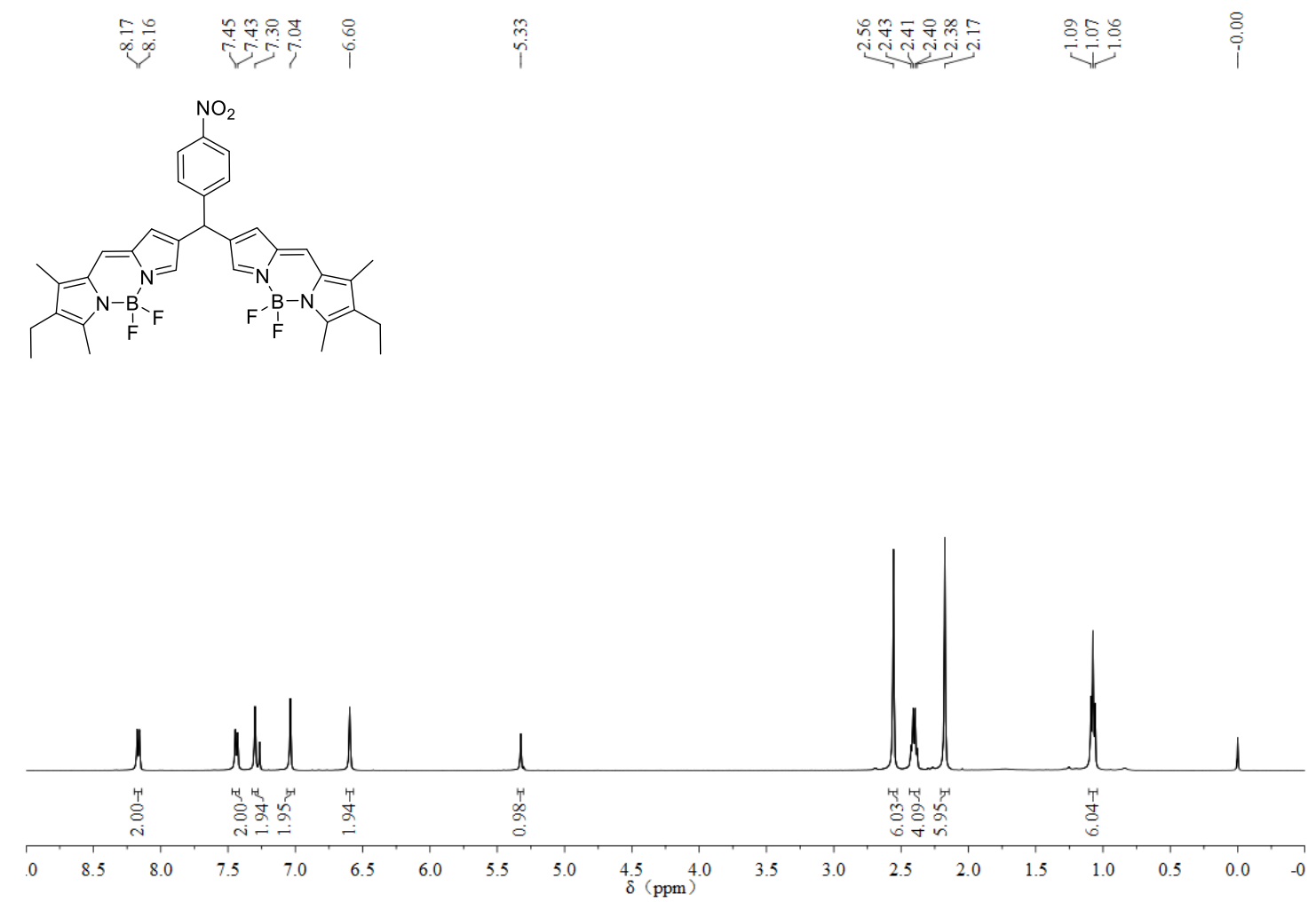

${ }^{13} \mathrm{C}$ NMR (500 MHz) spectrum of compound $\mathbf{4 d}$ in $\mathrm{CDCl}_{3}$.

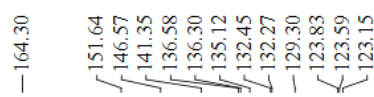
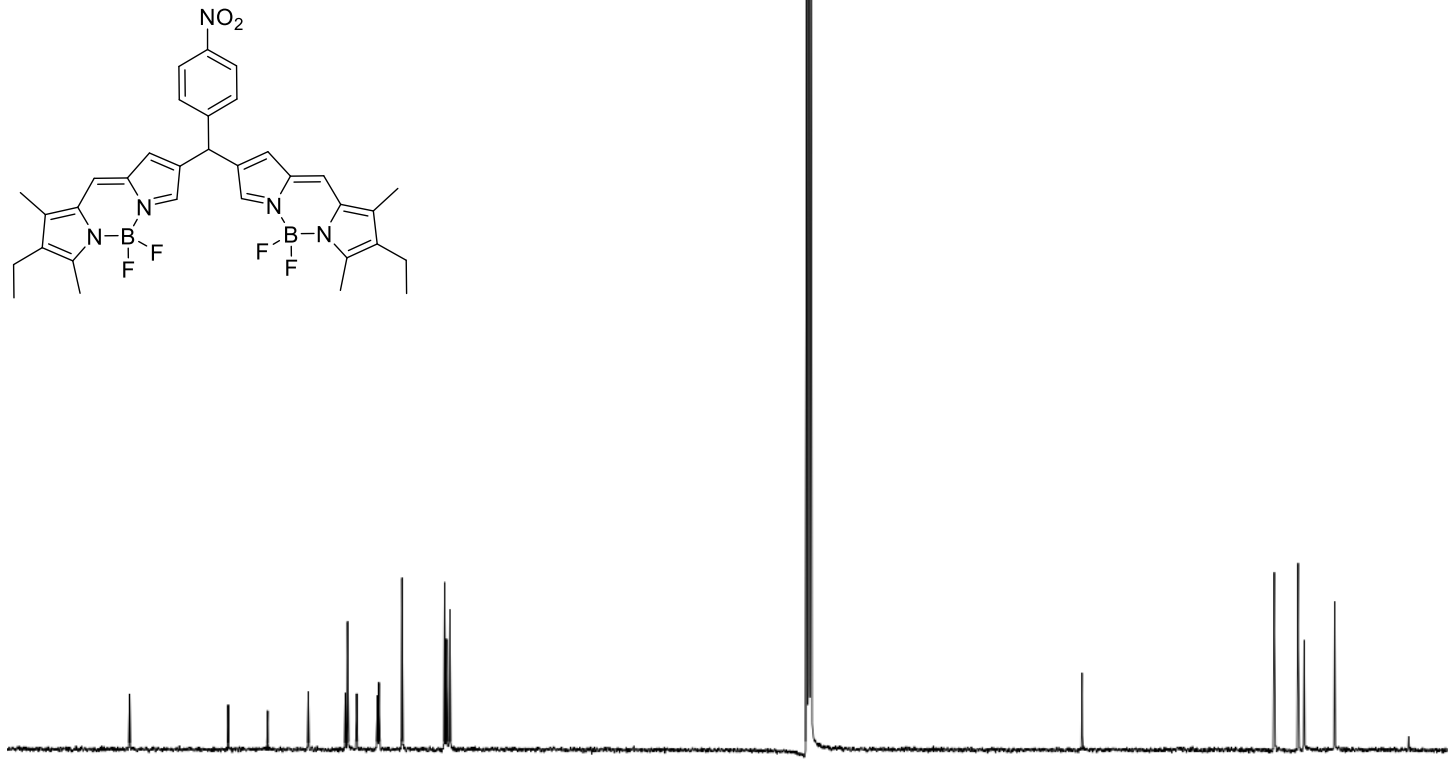

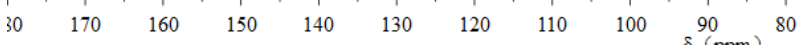


${ }^{1} \mathrm{H}$ NMR (300 MHz) spectrum of compound $4 \mathbf{e}$ in $\mathrm{CDCl}_{3}$.

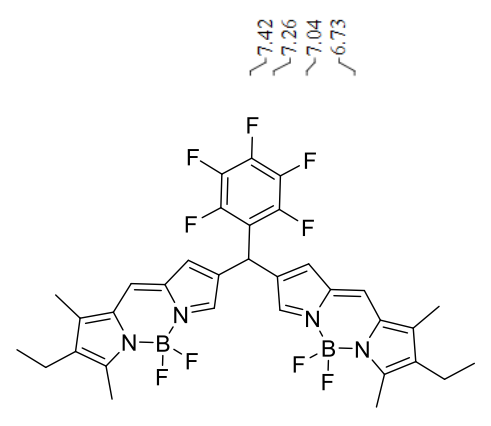

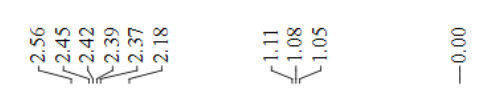

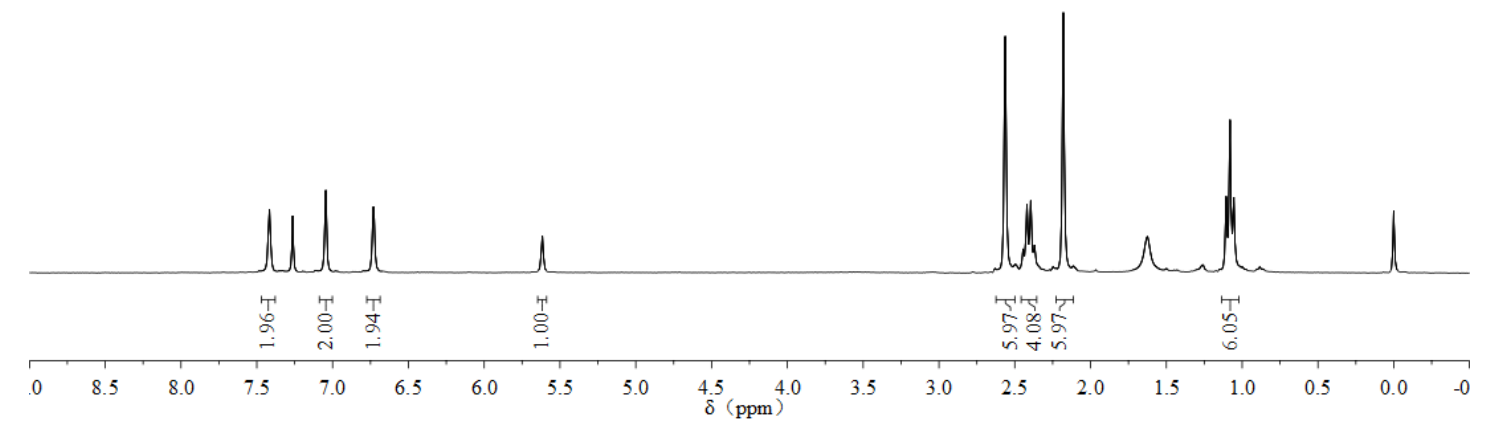

${ }^{13} \mathrm{C}$ NMR (300 MHz) spectrum of compound $4 \mathbf{e}$ in $\mathrm{CDCl}_{3}$.

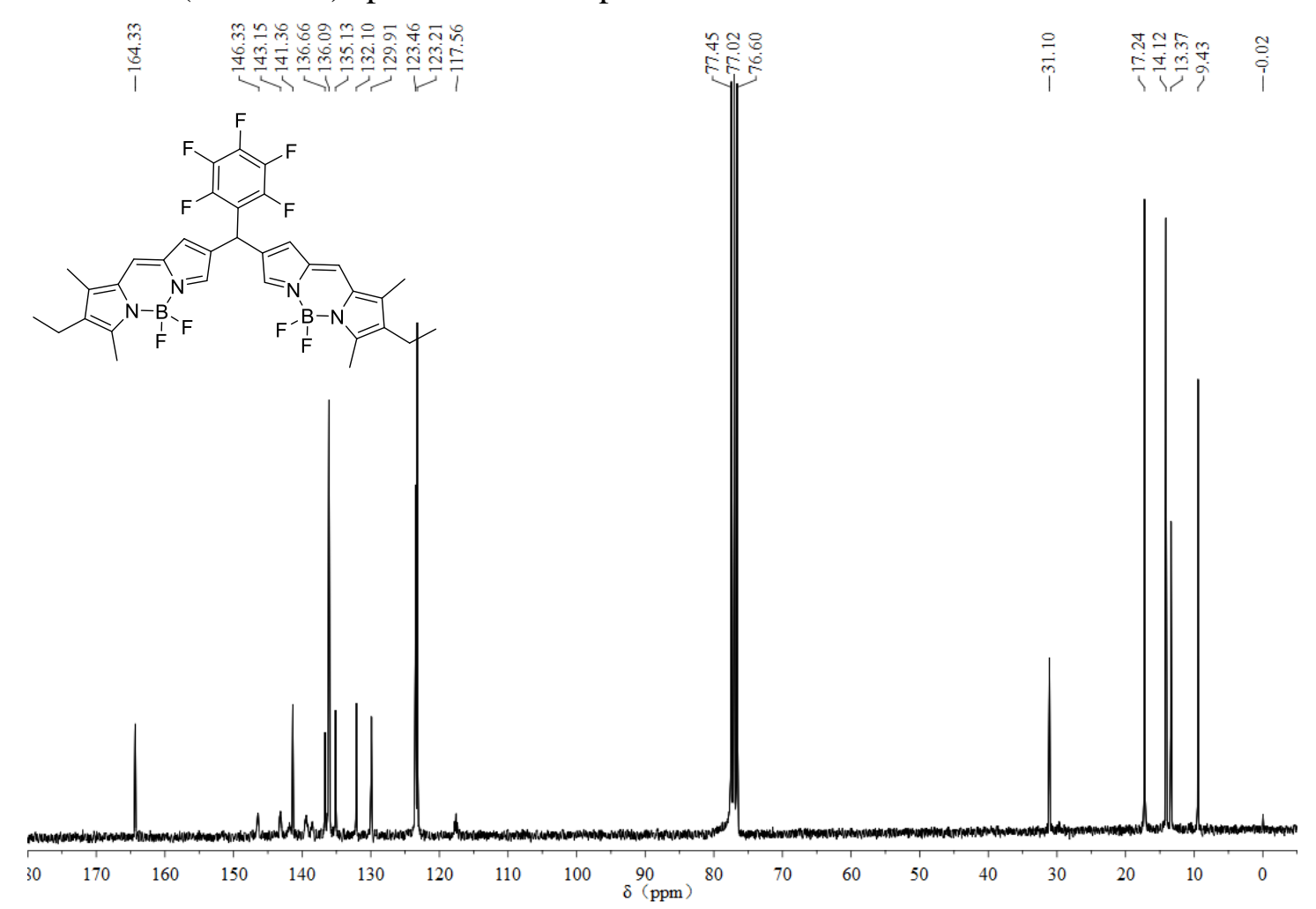


${ }^{1} \mathrm{H}$ NMR (300 MHz) spectrum of compound $\mathbf{4 f}$ in $\mathrm{CDCl}_{3}$.

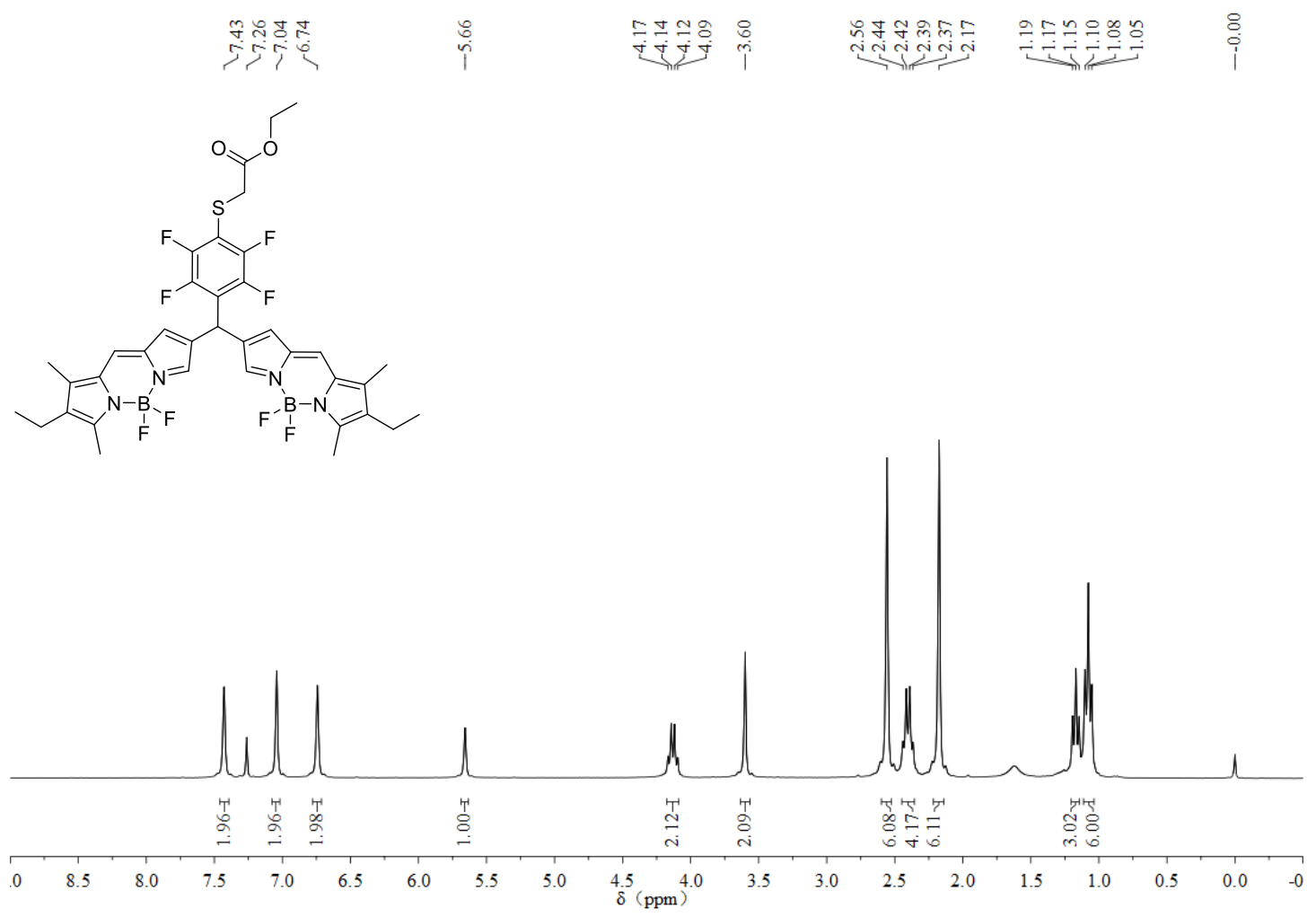

${ }^{13} \mathrm{C}$ NMR (300 MHz) spectrum of compound $\mathbf{4 f}$ in $\mathrm{CDCl}_{3}$.

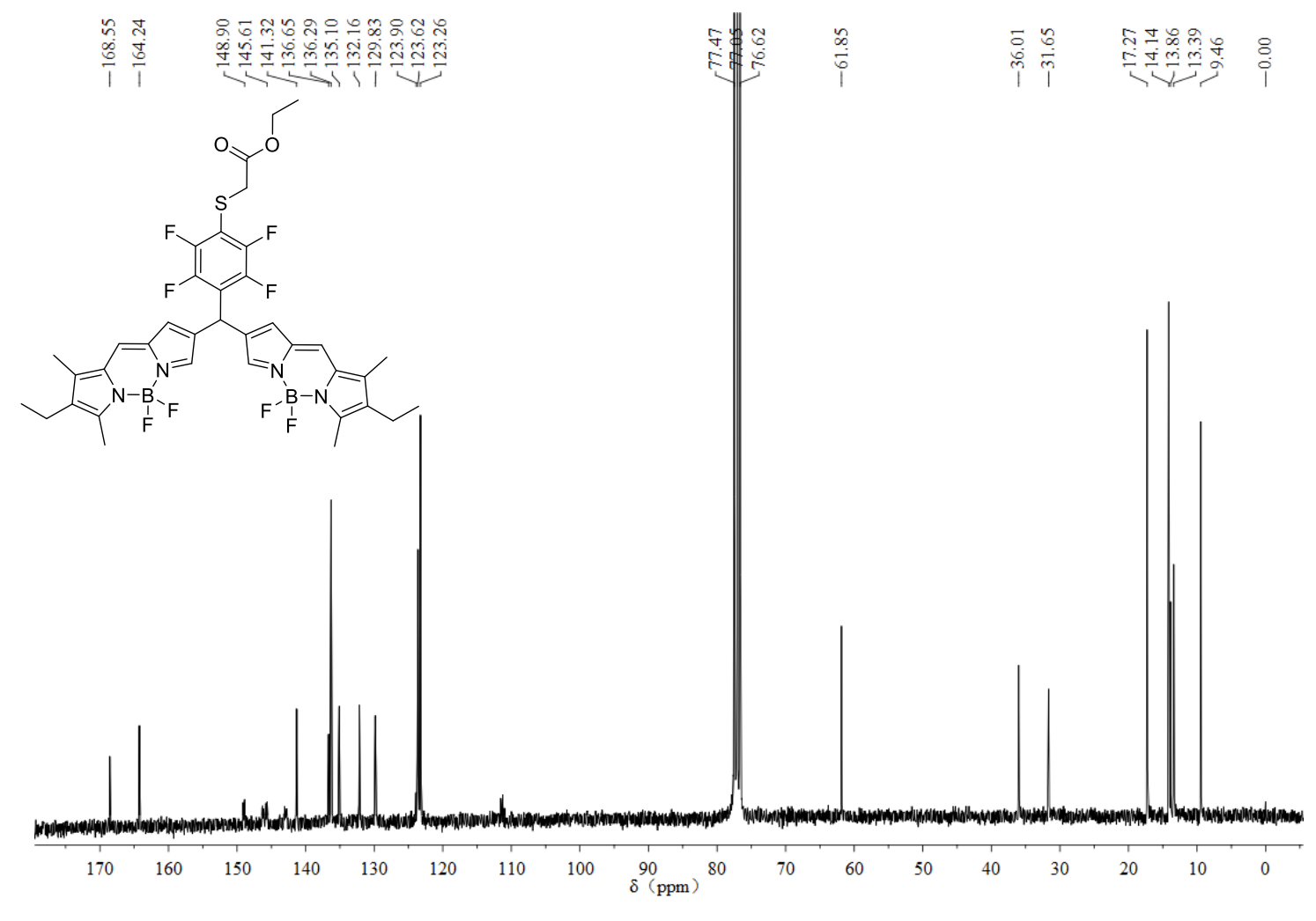

S30 
${ }^{1} \mathrm{H}$ NMR (300 MHz) spectrum of compound sa in $\mathrm{CDCl}_{3}$.
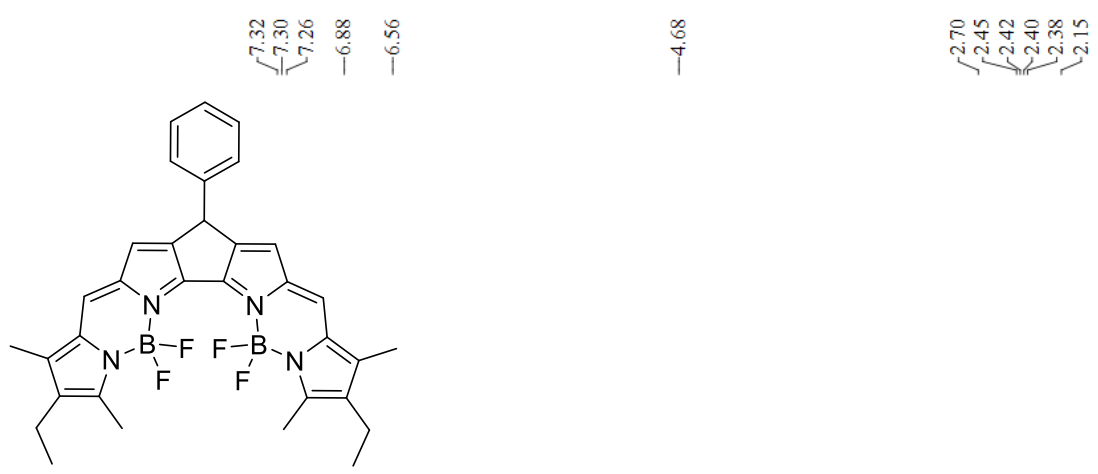

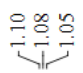

$\stackrel{8}{i}$

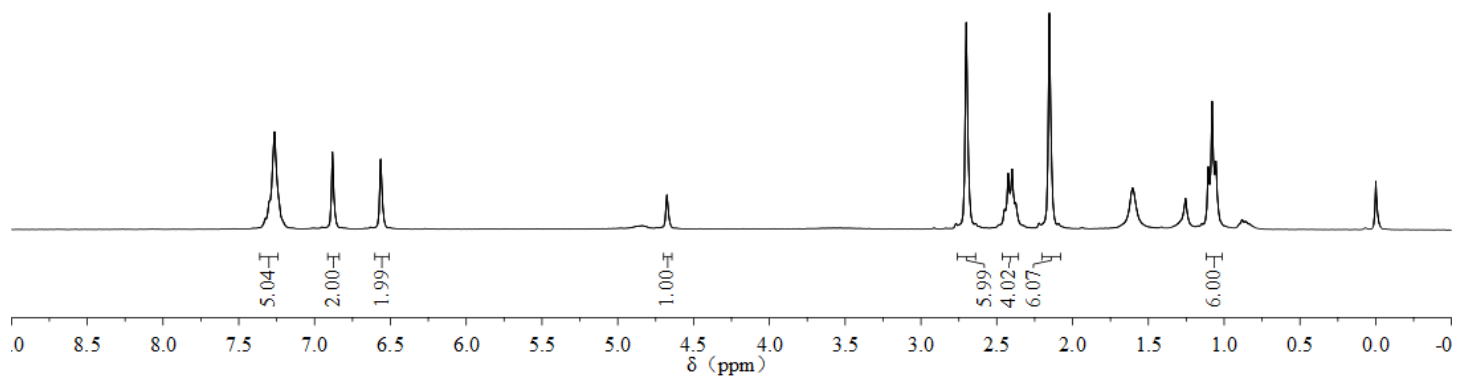

${ }^{13} \mathrm{C}$ NMR (300 MHz) spectrum of compound $\mathbf{5 a}$ in $\mathrm{CDCl}_{3}$.
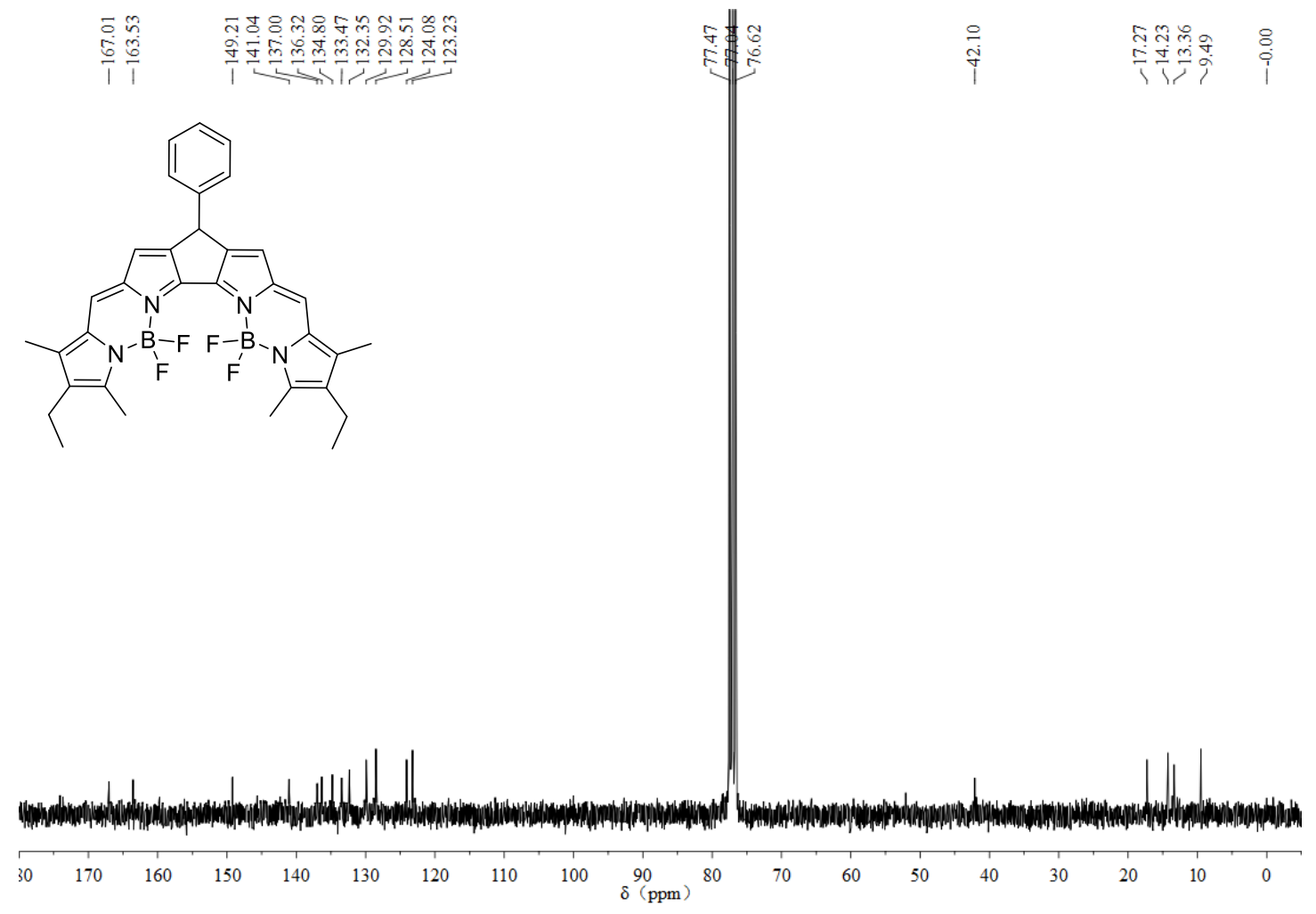

S31 
${ }^{1} \mathrm{H}$ NMR (500 MHz) spectrum of compound $\mathbf{5 b}$ in $\mathrm{CDCl}_{3}$.
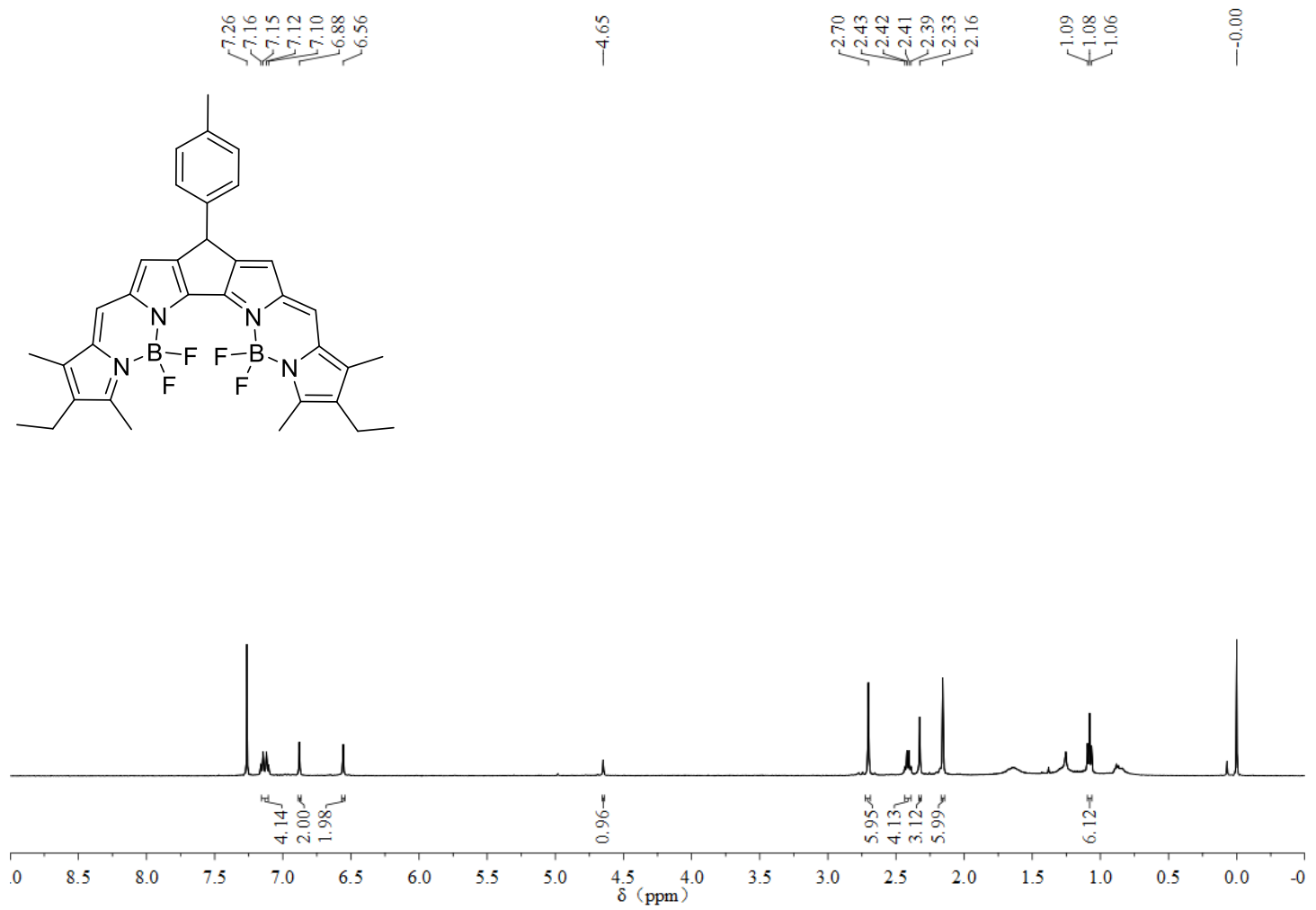

${ }^{13} \mathrm{C}$ NMR (500 MHz) spectrum of compound $\mathbf{5 b}$ in $\mathrm{CDCl}_{3}$.

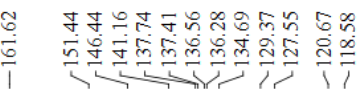
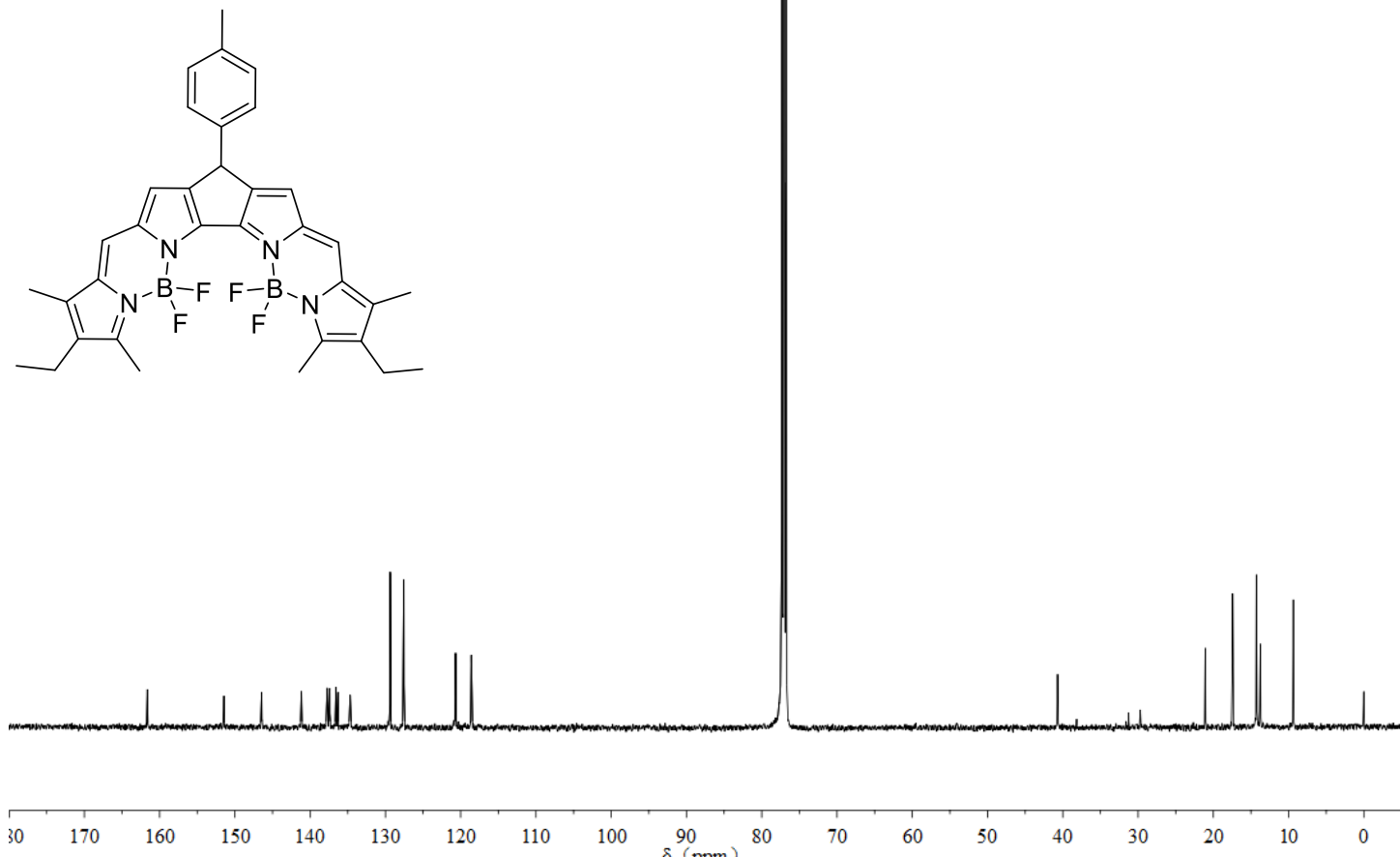
${ }^{1} \mathrm{H}$ NMR (300 MHz) spectrum of compound $\mathbf{5 c}$ in $\mathrm{CDCl}_{3}$.

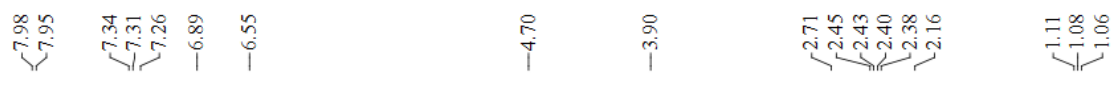
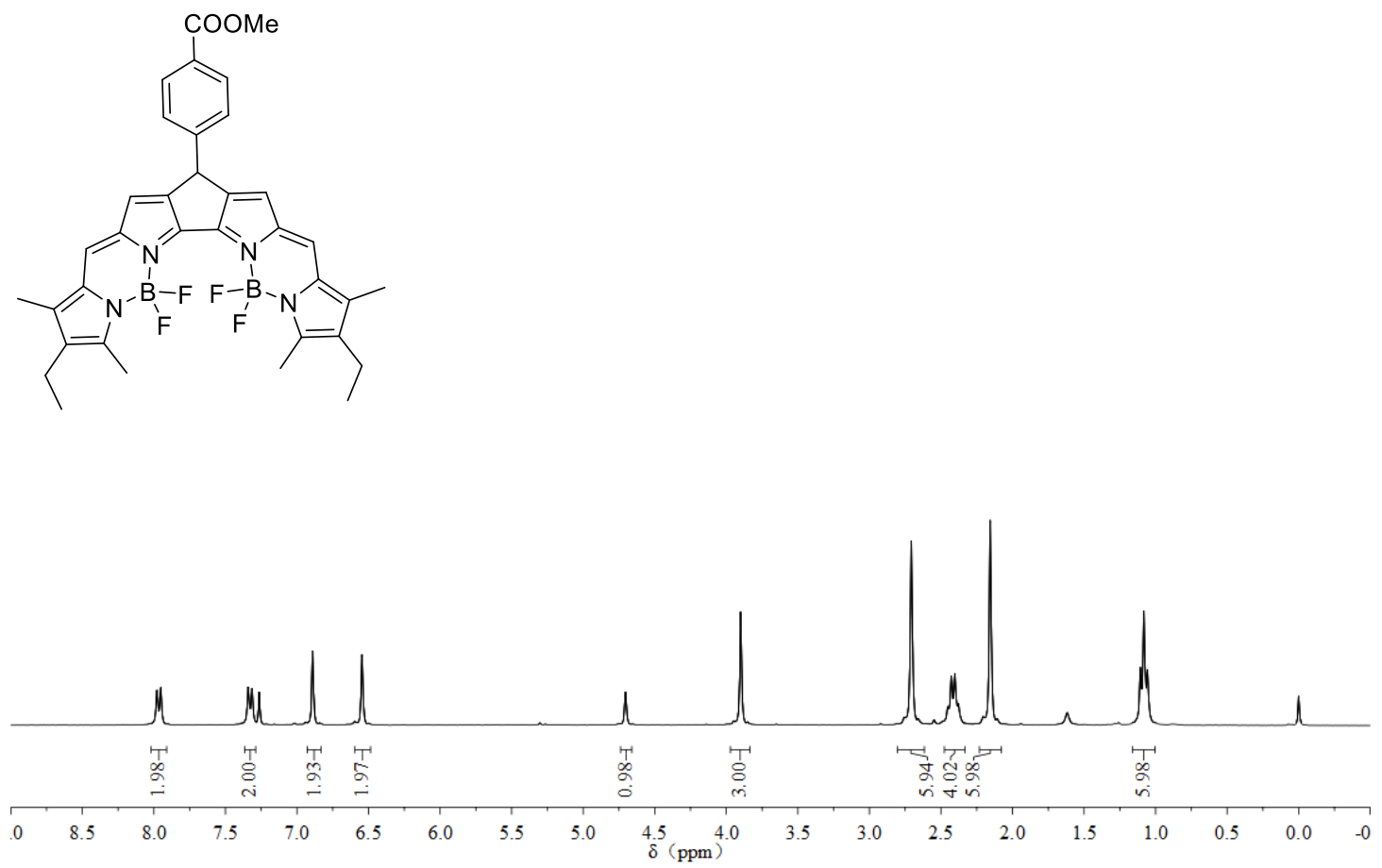

${ }^{13} \mathrm{C}$ NMR $(300 \mathrm{MHz})$ spectrum of compound $\mathbf{5 c}$ in $\mathrm{CDCl}_{3}$.
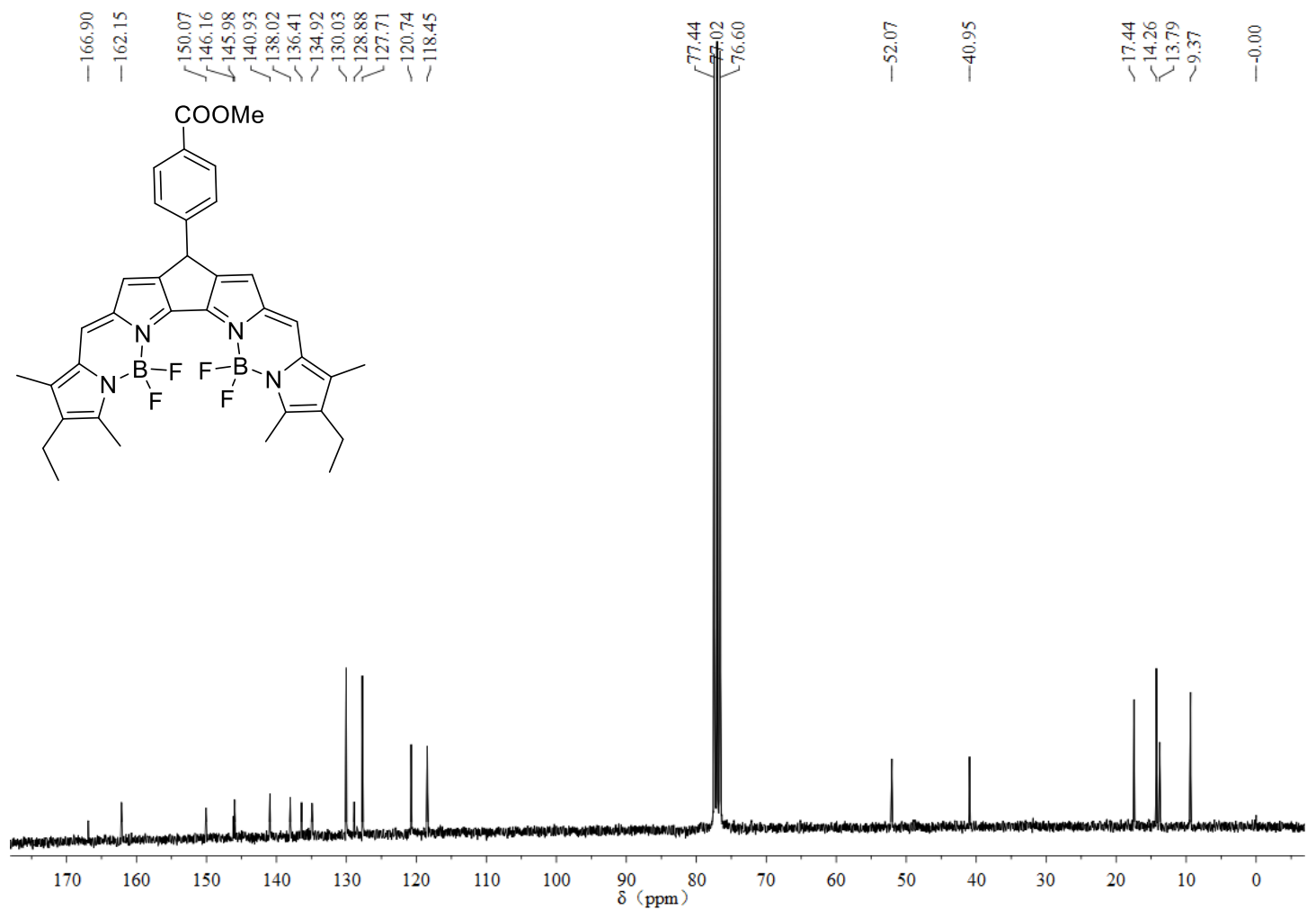
${ }^{1} \mathrm{H}$ NMR (500 MHz) spectrum of compound $\mathbf{5 d}$ in $\mathrm{CDCl}_{3}$.

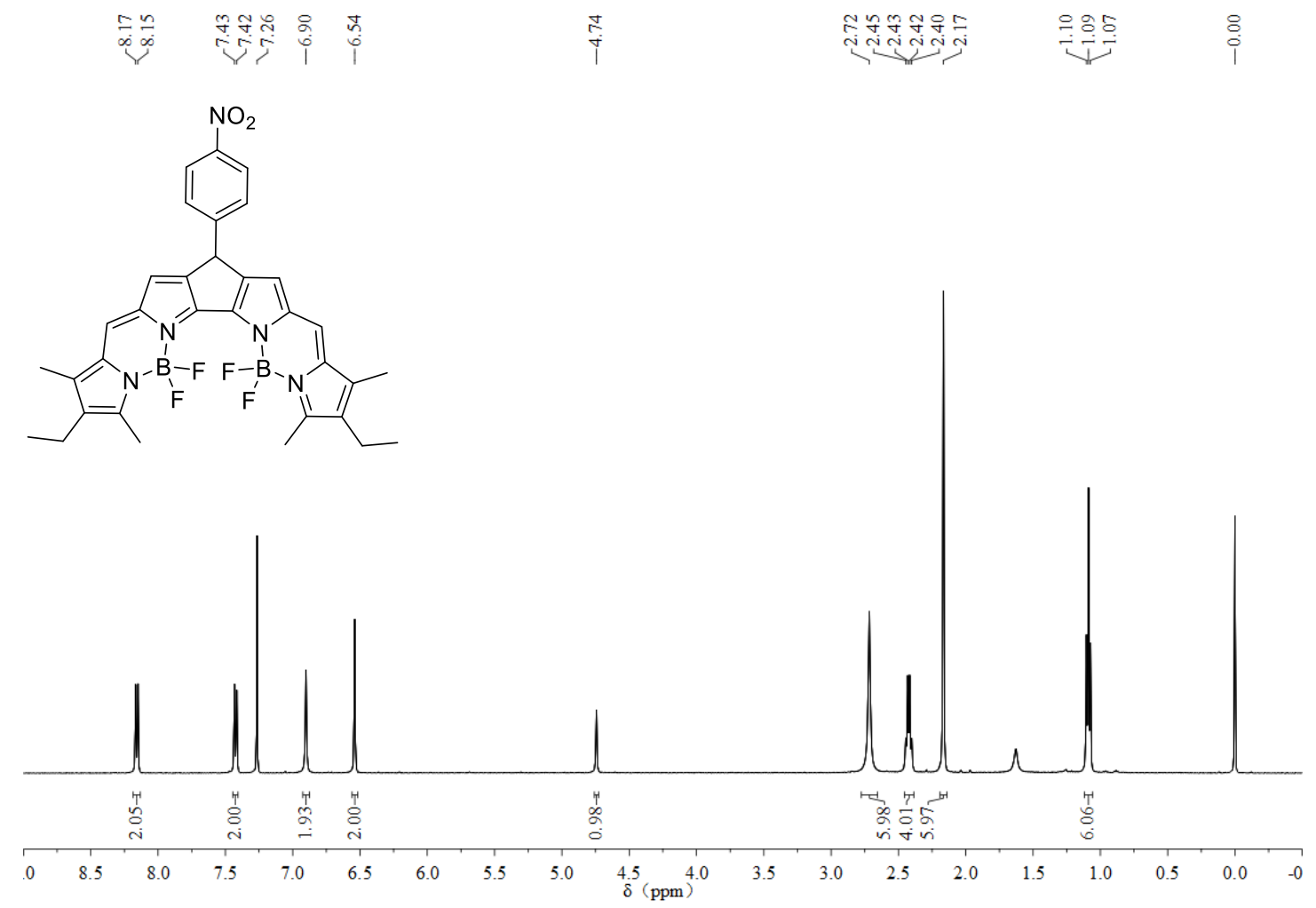

${ }^{13} \mathrm{C}$ NMR (500 MHz) spectrum of compound $\mathbf{5 d}$ in $\mathrm{CDCl}_{3}$.

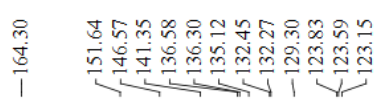
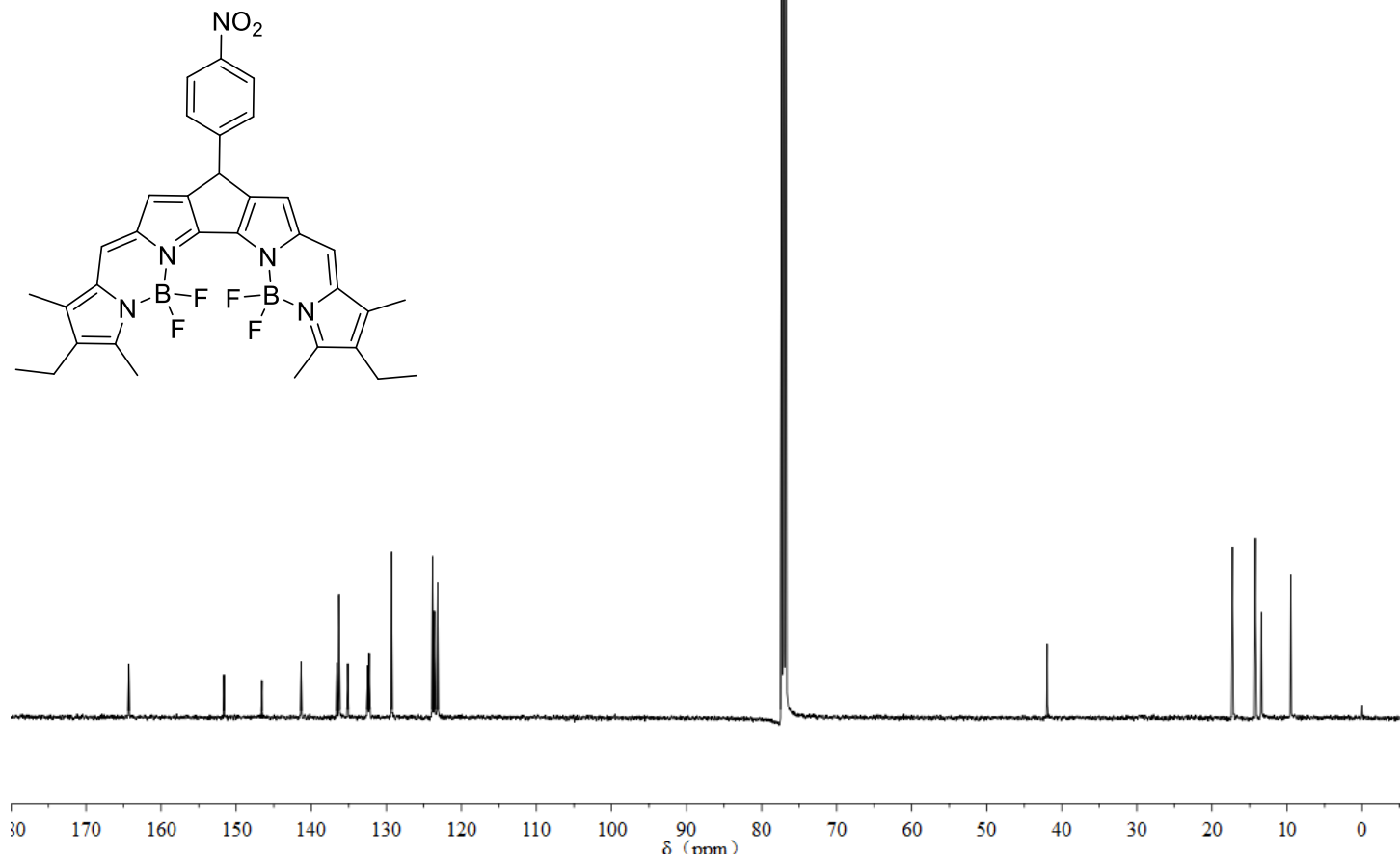
${ }^{1} \mathrm{H}$ NMR (300 MHz) spectrum of compound $\mathbf{5 e}$ in $\mathrm{CDCl}_{3}$.

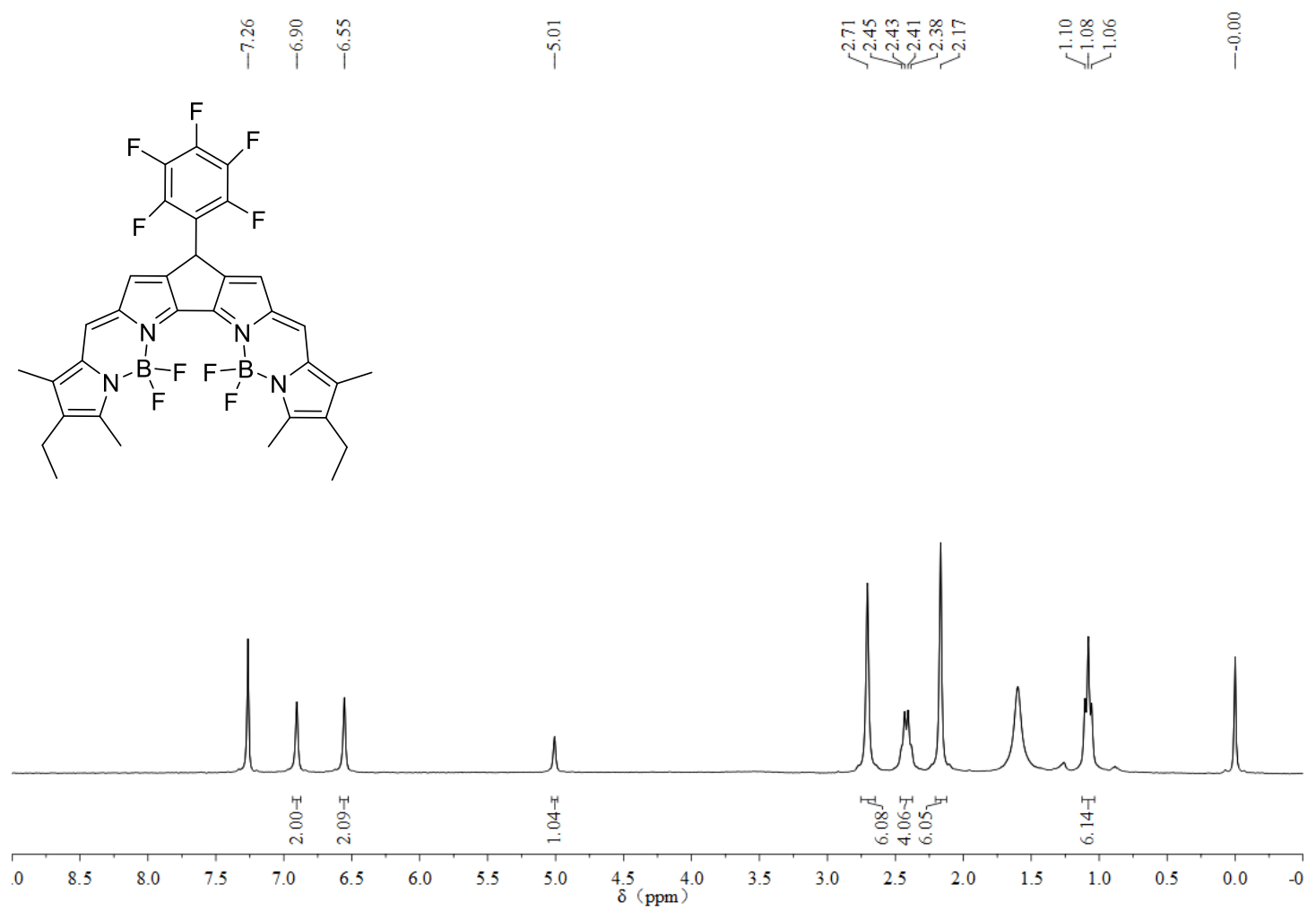

${ }^{13} \mathrm{C}$ NMR (300 MHz) spectrum of compound $\mathbf{5 e}$ in $\mathrm{CDCl}_{3}$.
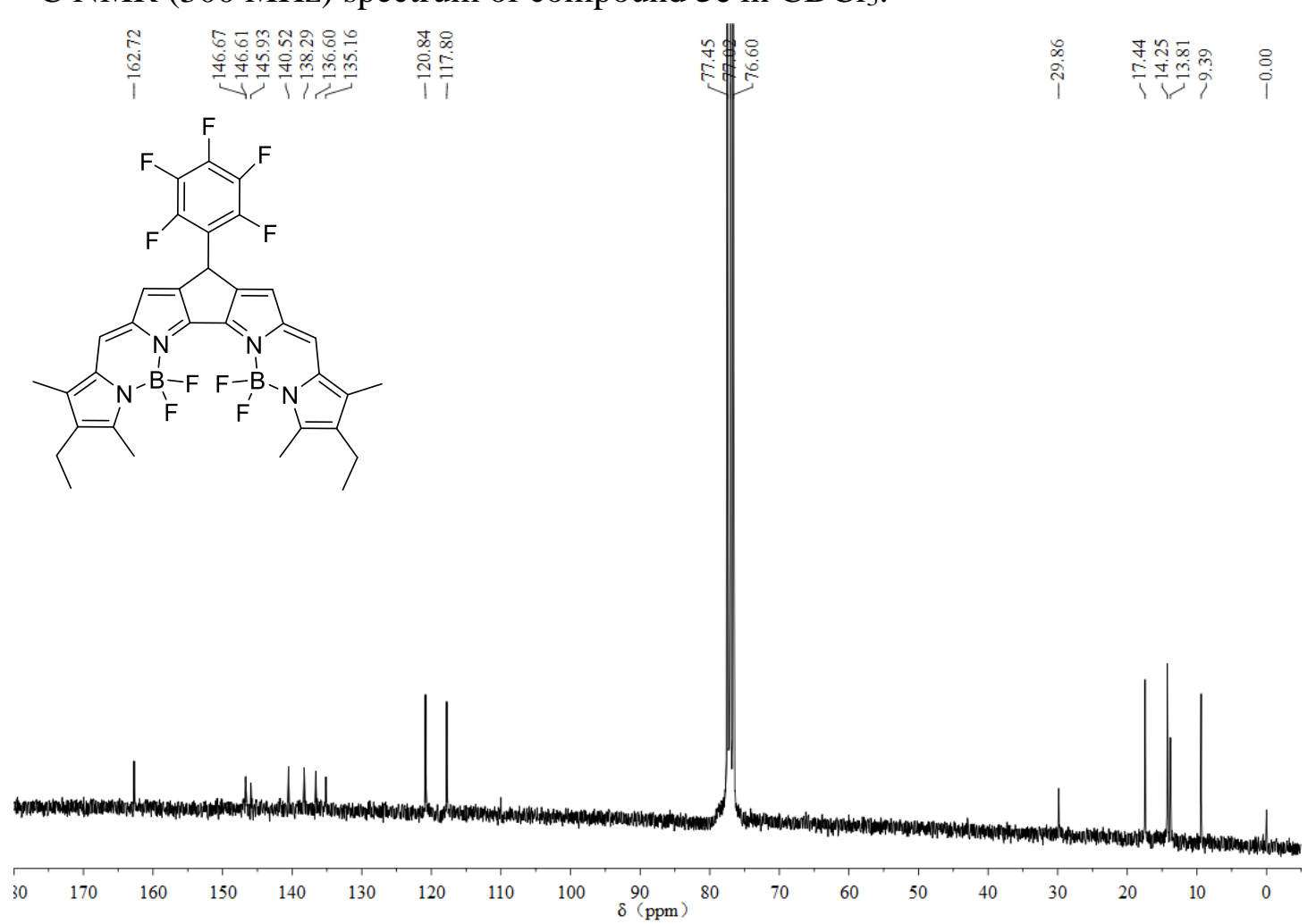
${ }^{1} \mathrm{H}$ NMR (500 MHz) spectrum of compound $\mathbf{5 f}$ in $\mathrm{CDCl}_{3}$.
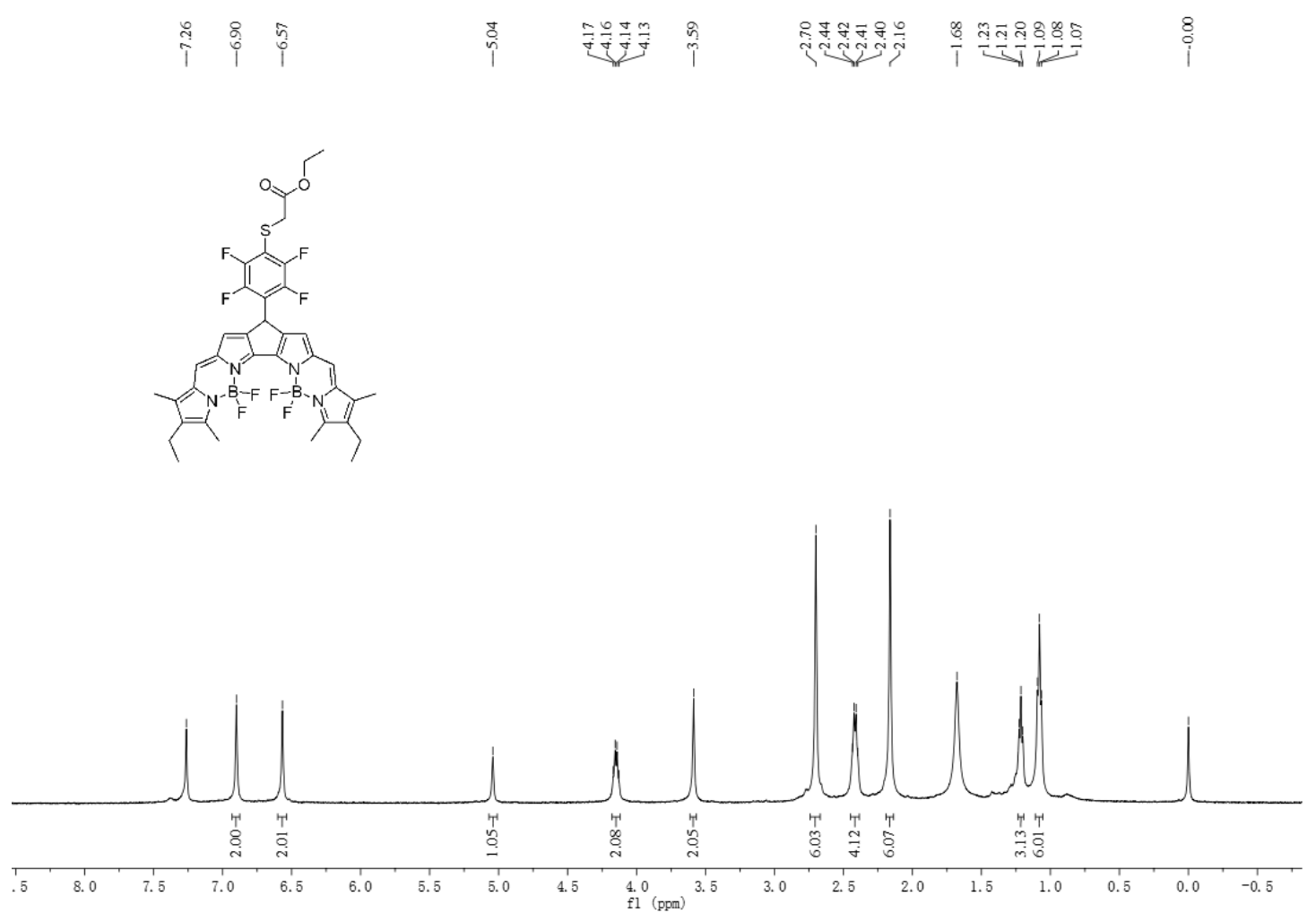

${ }^{13} \mathrm{C}$ NMR (300 MHz) spectrum of compound $\mathbf{5 f}$ in $\mathrm{CDCl}_{3}$.

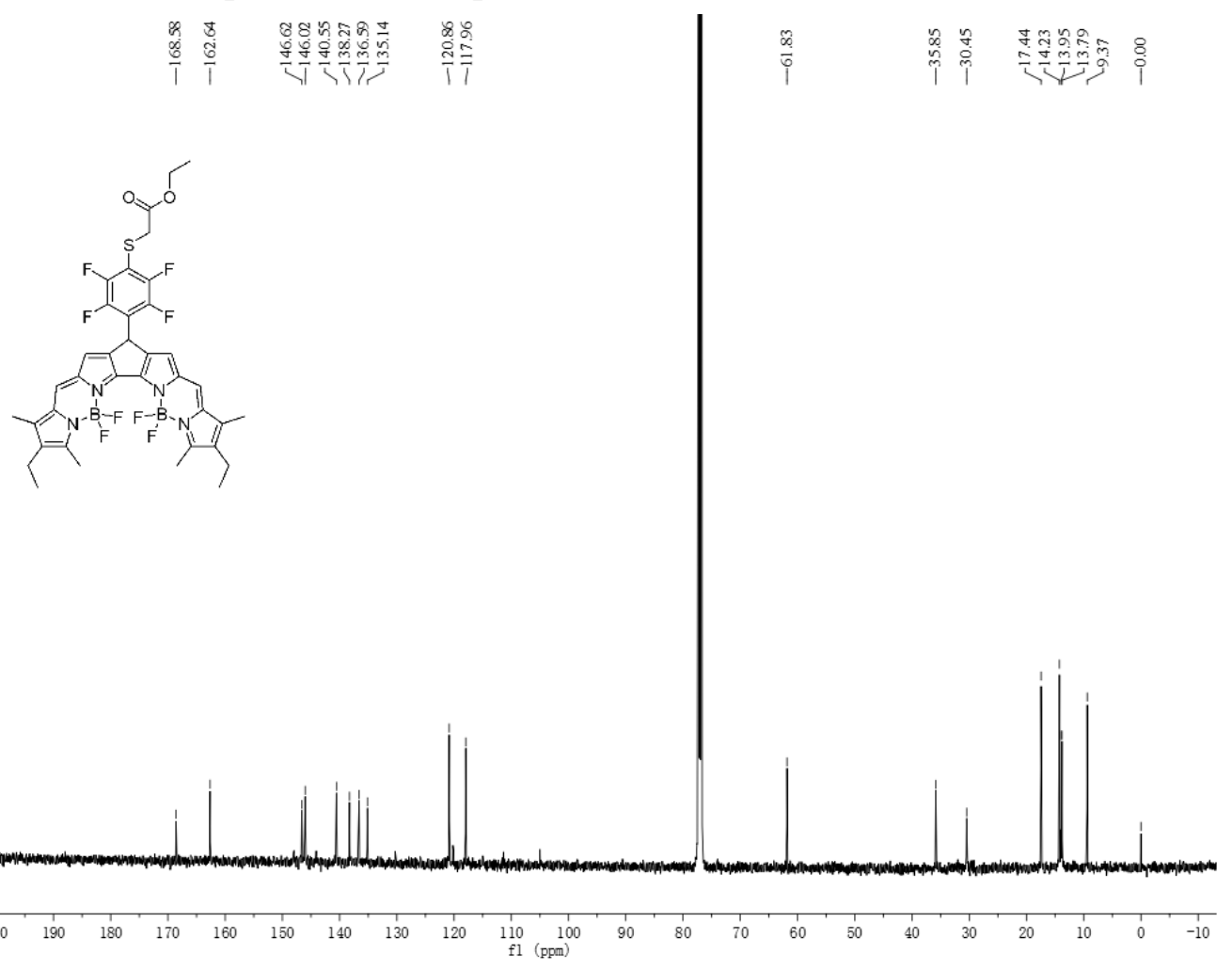




\section{HRMS spectra for all new compounds}

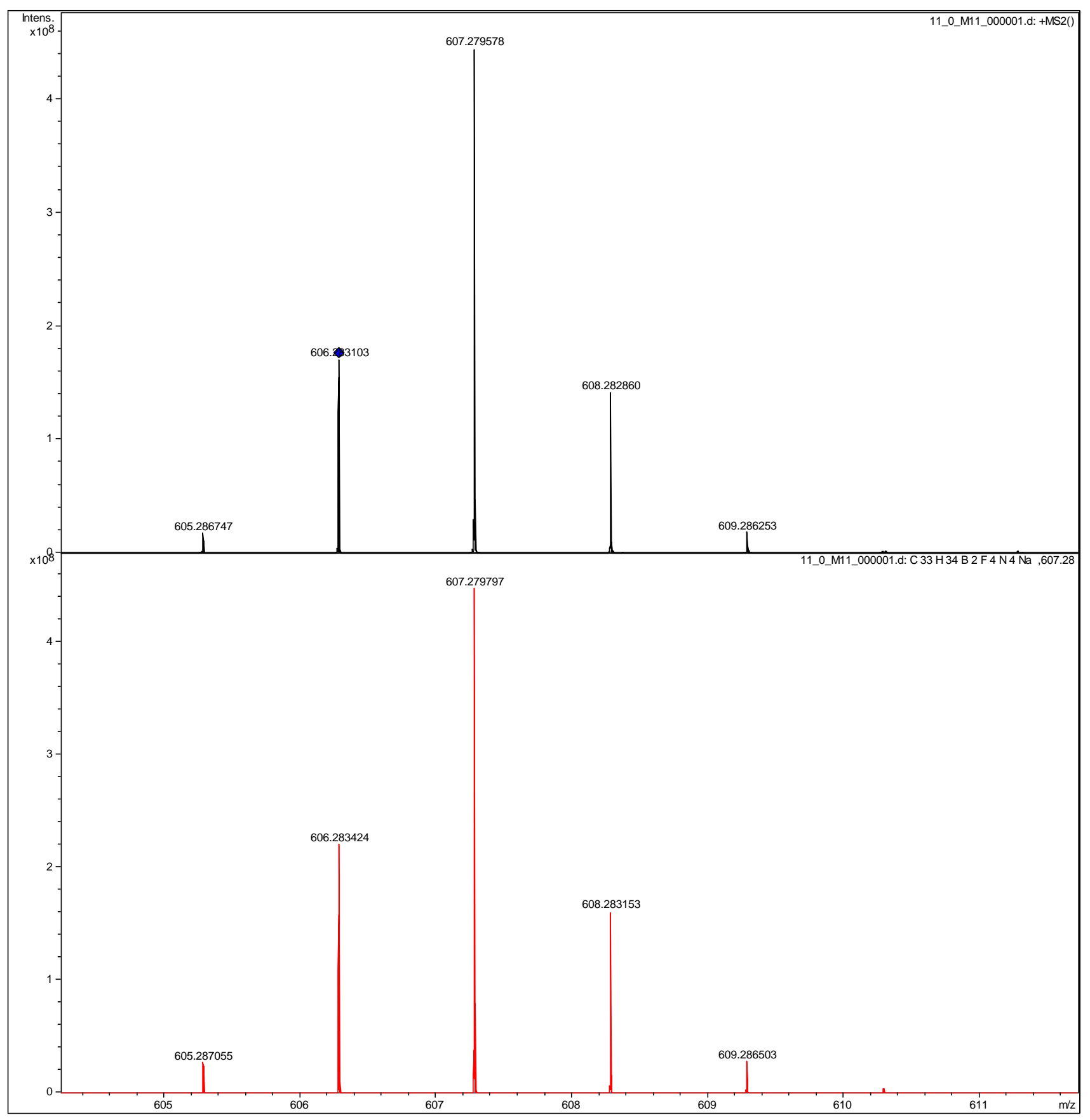

Observed (top) and calculated (bottom) HRMS for $\mathbf{4 a}$. 


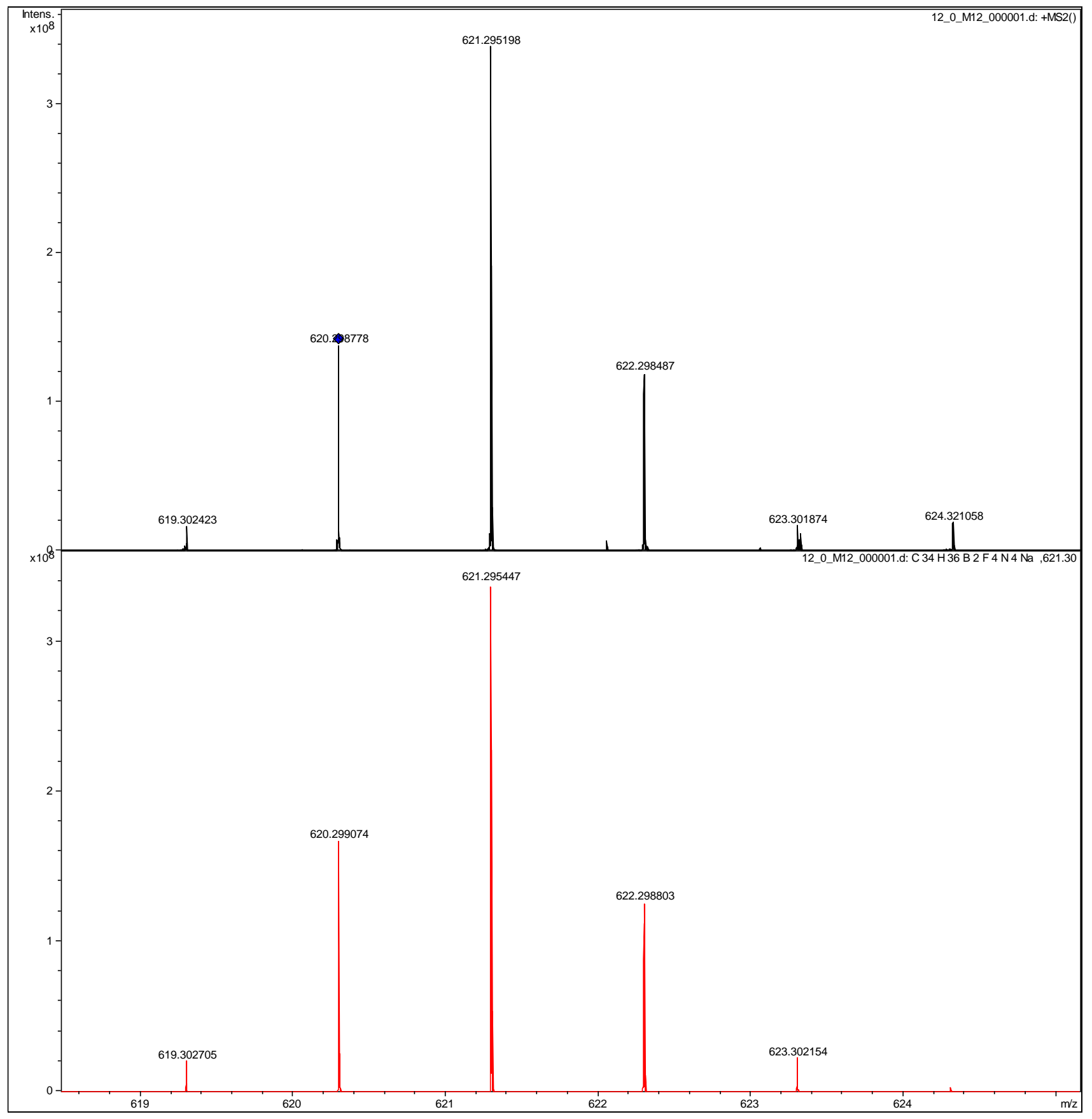

Observed (top) and calculated (bottom) HRMS for $\mathbf{4 b}$. 


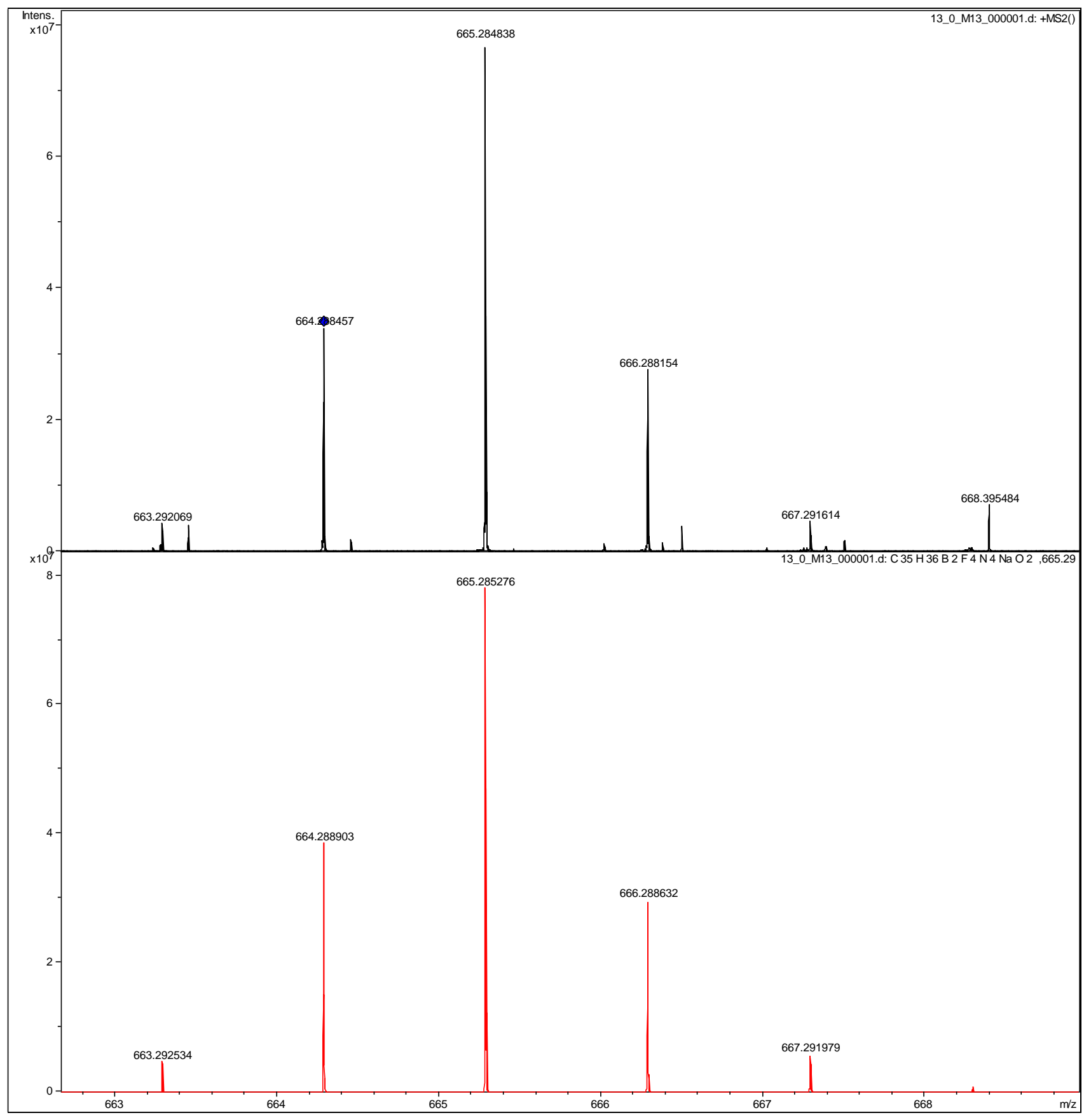

Observed (top) and calculated (bottom) HRMS for $\mathbf{4 c}$ 


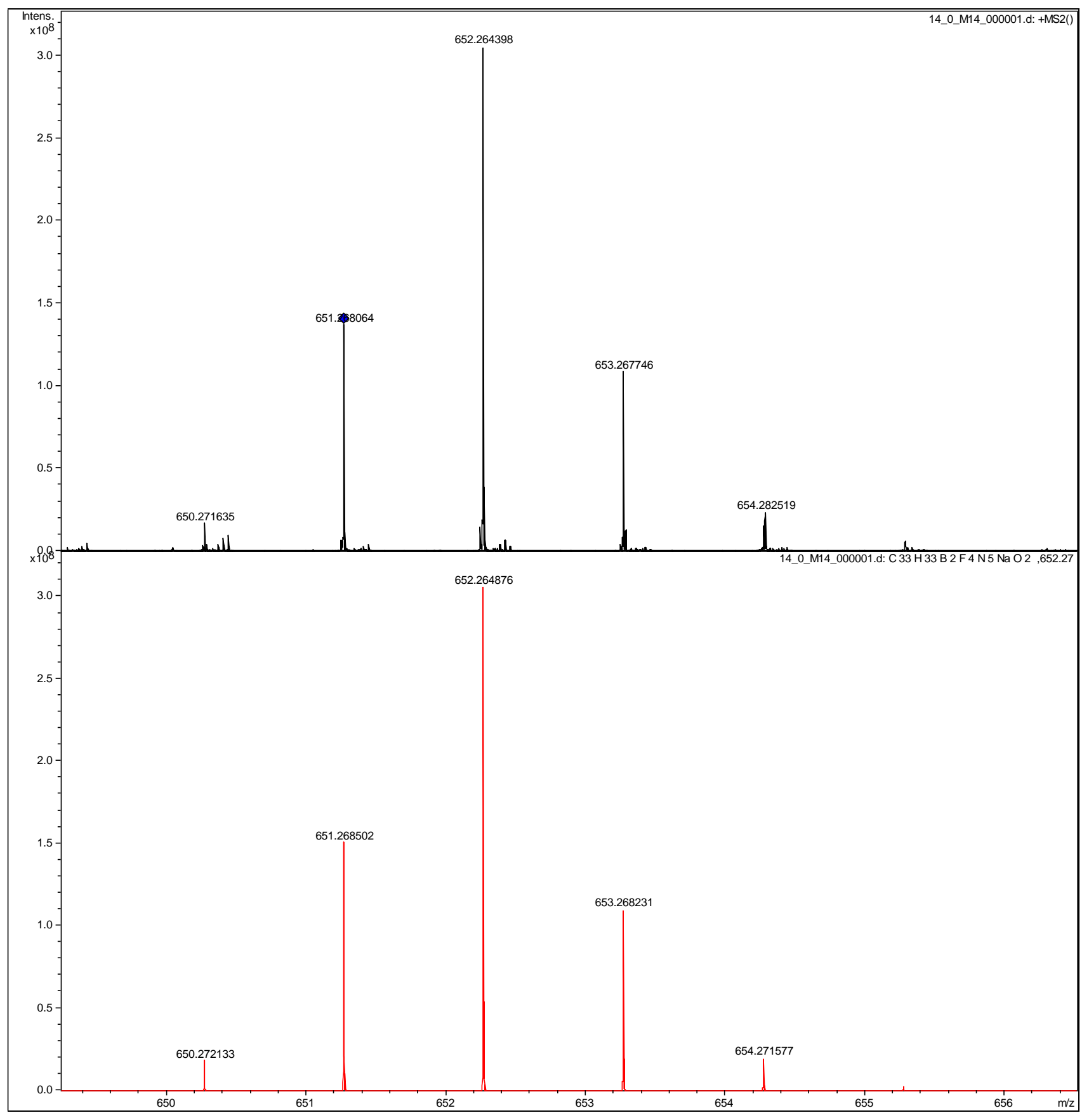

Observed (top) and calculated (bottom) HRMS for $\mathbf{4 d}$. 
103 \#17 RT: 0.25 AV: 1 NL: 8.75E 4

T: FTMS + p ESIFull ms [150.00-2000.00]

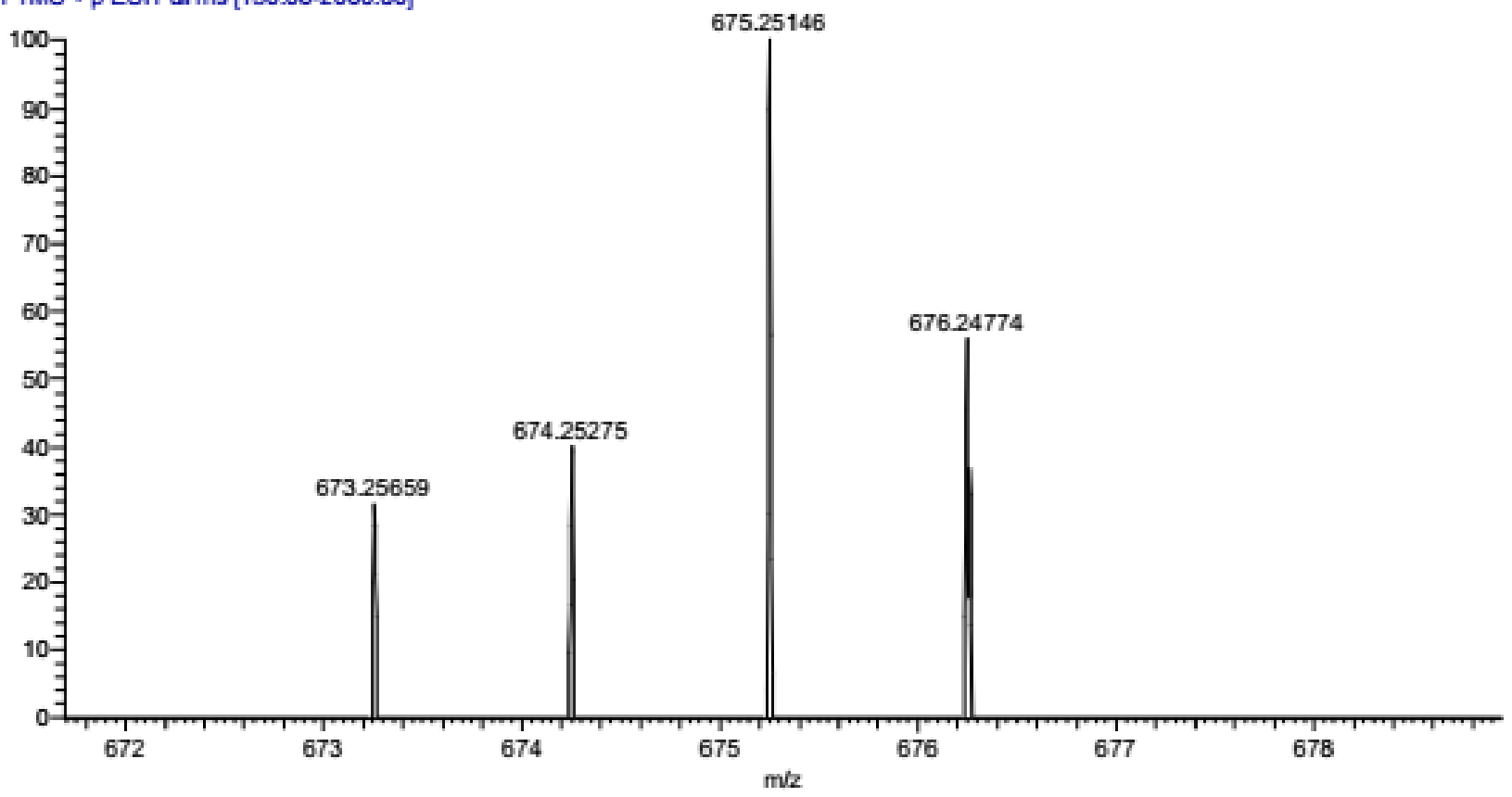

Observed HRMS of compound $\mathbf{4 e}$

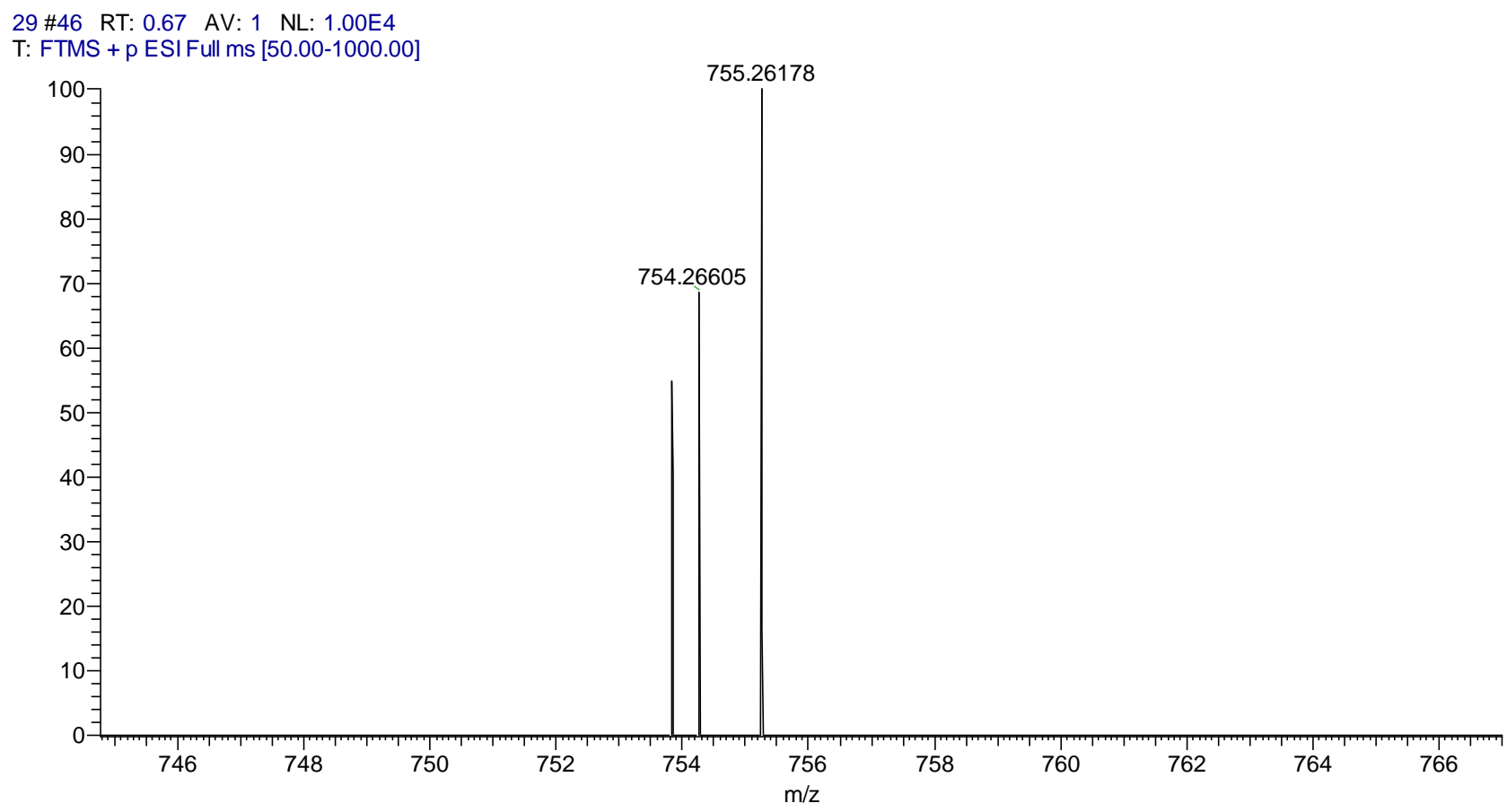

Observed HRMS of compound $\mathbf{4 f}$ 


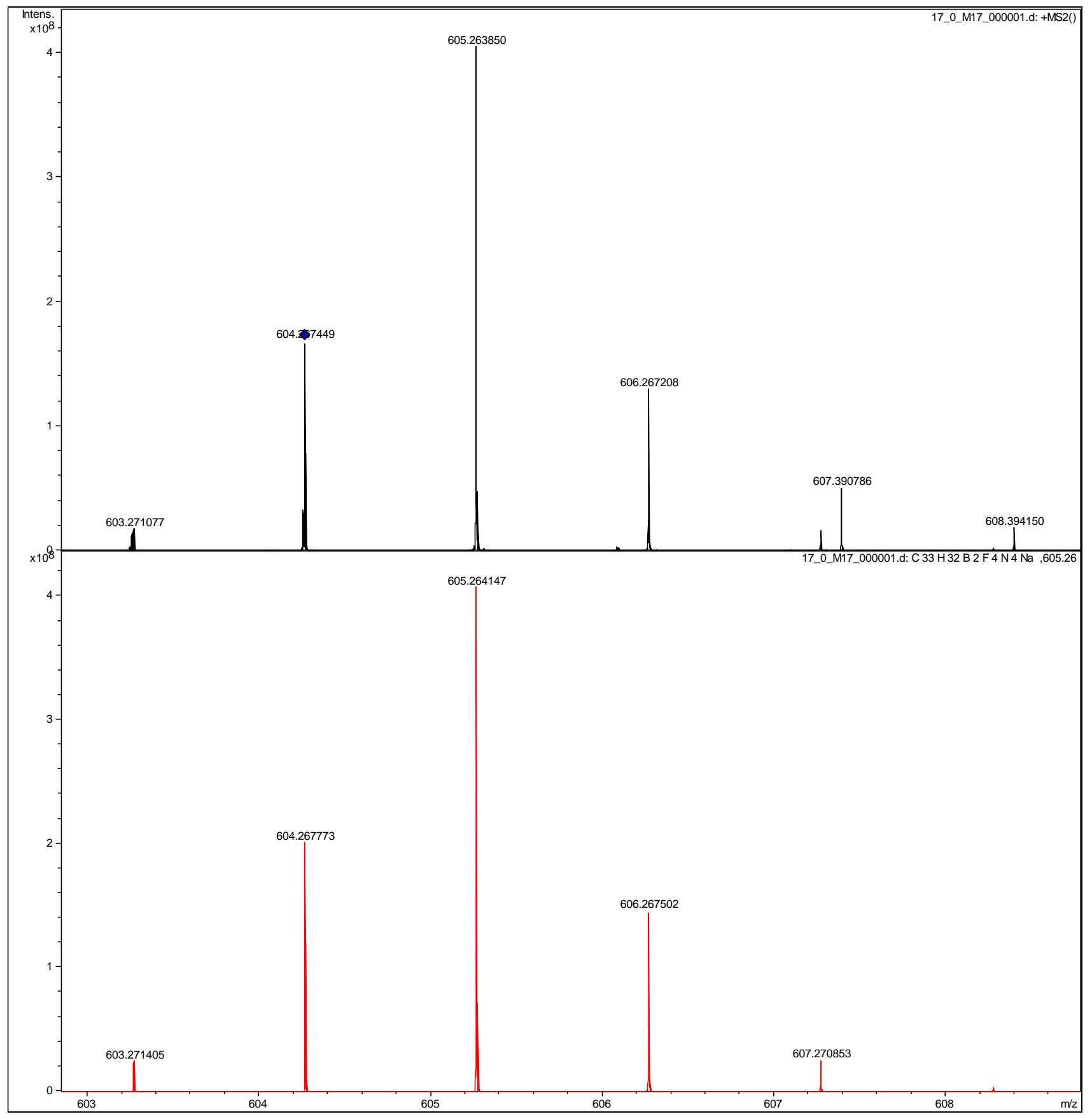

Observed (top) and calculated (bottom) HRMS for 5a. 


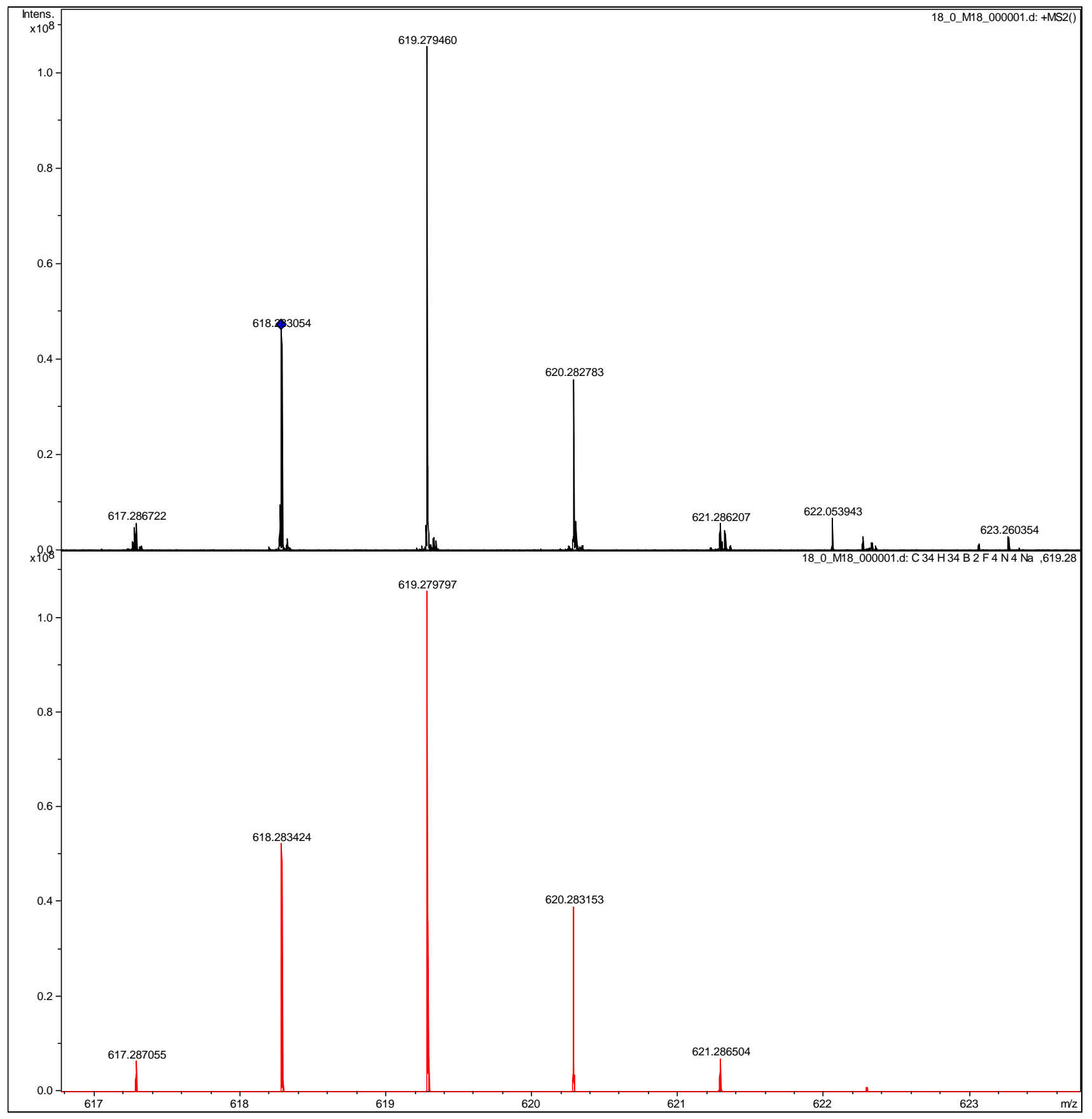

Observed (top) and calculated (bottom) HRMS for $\mathbf{5 b}$. 


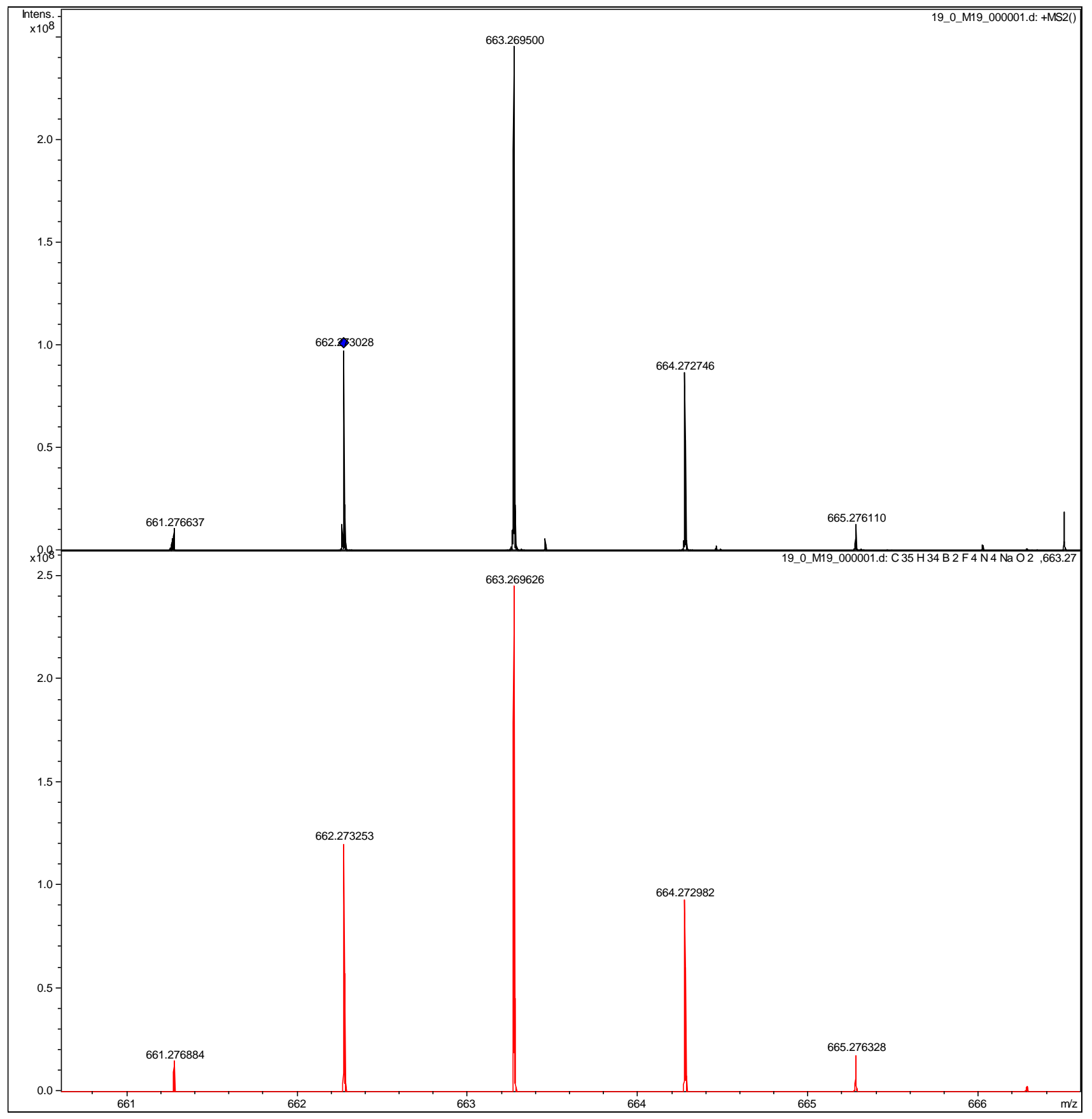

Observed (top) and calculated (bottom) HRMS for 5c 


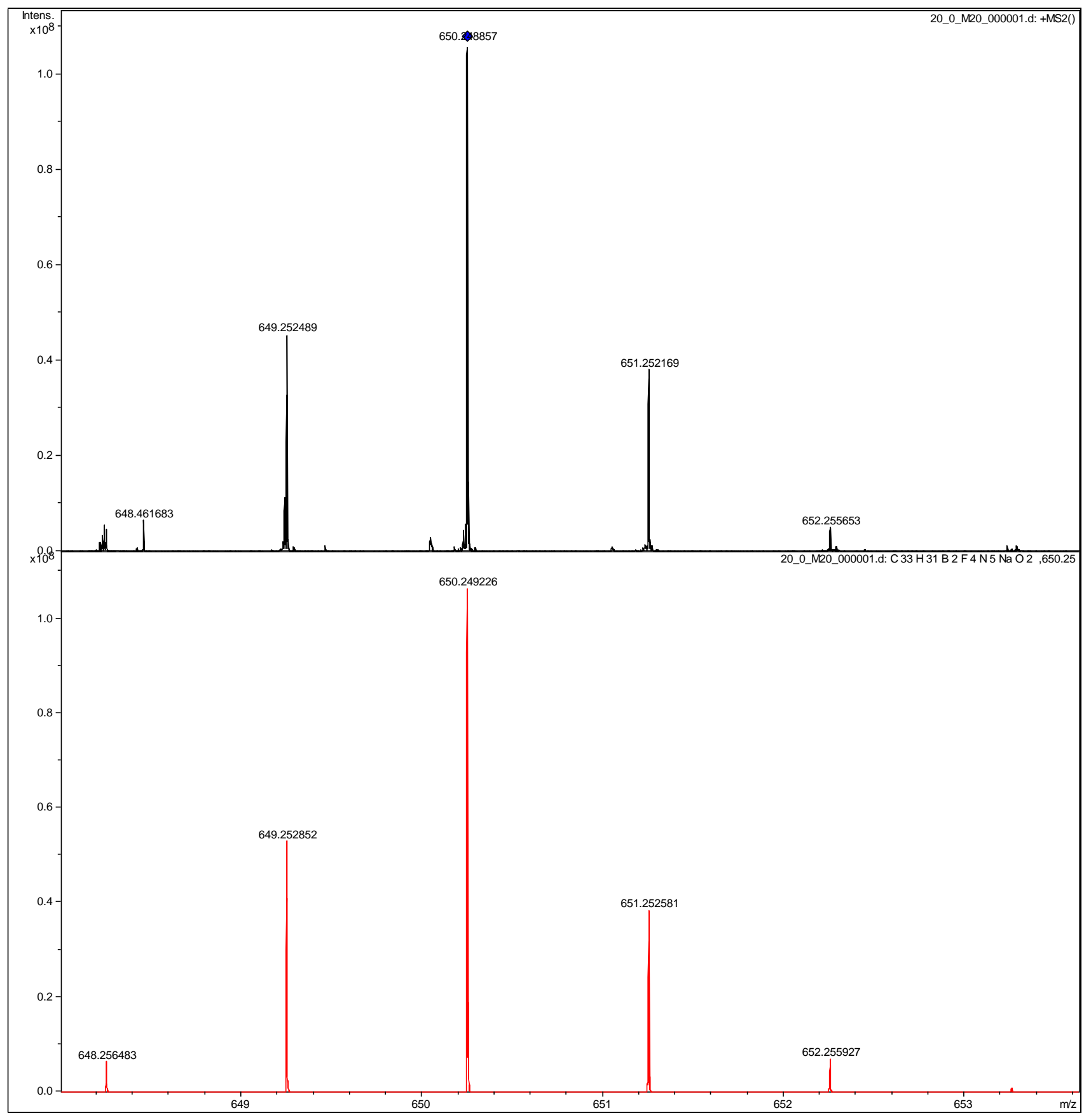

Observed (top) and calculated (bottom) HRMS for 5d 


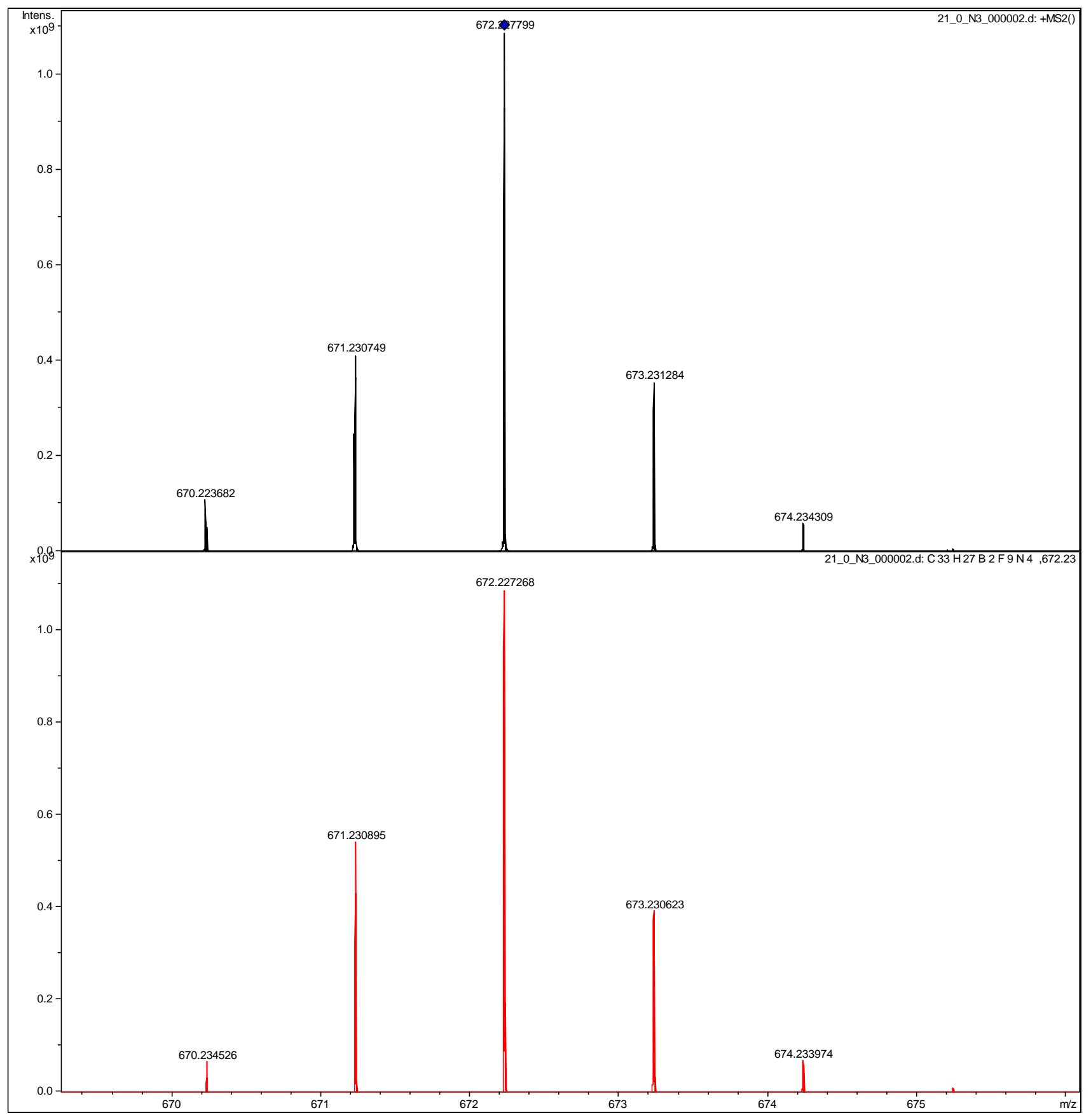

Observed (top) and calculated (bottom) HRMS for $\mathbf{5 e}$ 


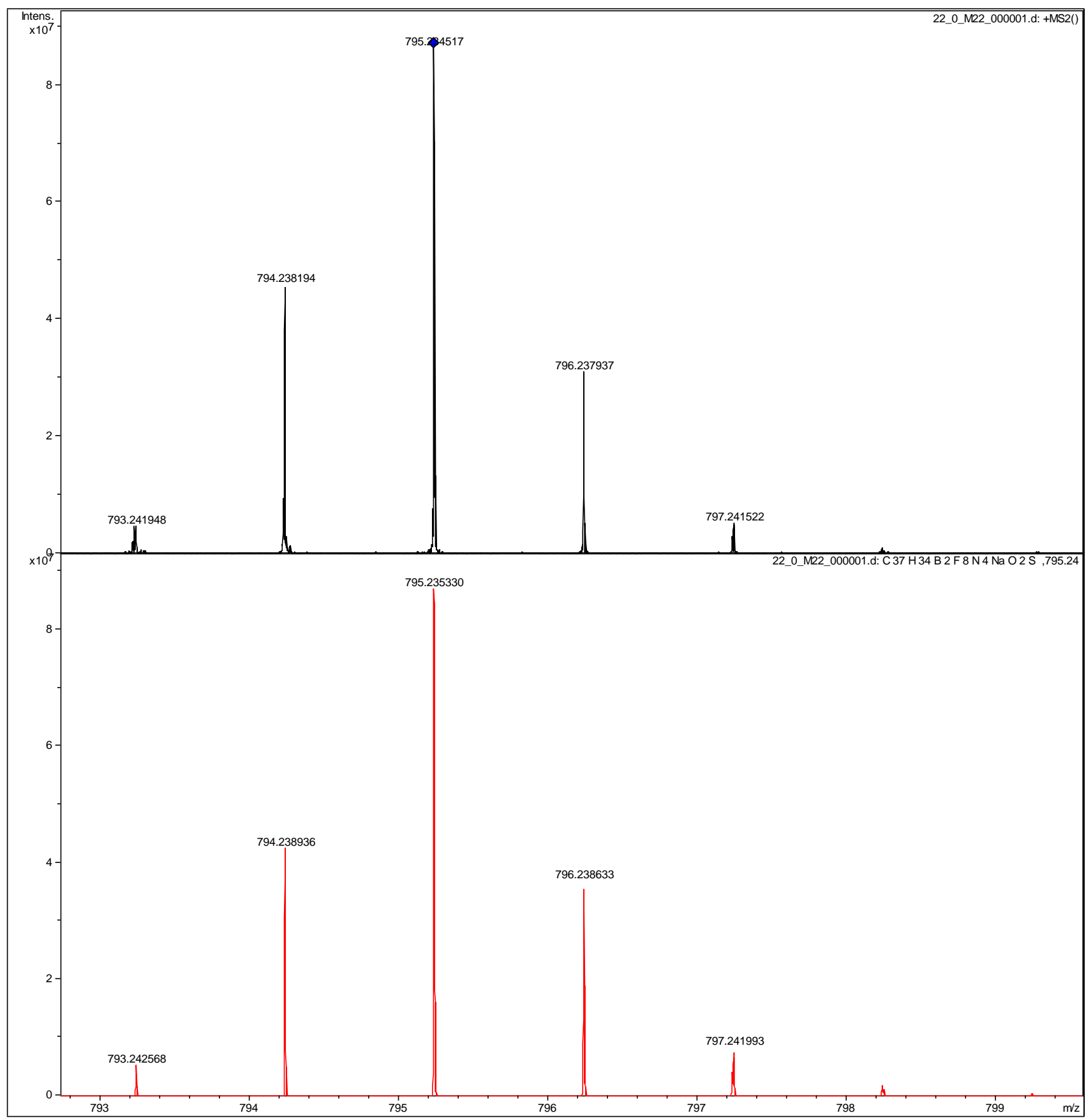

Observed (top) and calculated (bottom) HRMS for $\mathbf{5 f}$ 


\section{Optimized Geometries of the Compounds}

M, optimized $\mathrm{S}_{0}$ state Geometry.

\begin{tabular}{lrrr} 
F & -1.29491400 & -2.02529700 & -1.17982900 \\
$\mathrm{~F}$ & -1.11410000 & -2.05593500 & 1.09828400 \\
$\mathrm{~N}$ & -2.30048600 & -0.21074800 & 0.06900900 \\
$\mathrm{~N}$ & 0.18523900 & -0.41145700 & -0.12503400 \\
$\mathrm{C}$ & 0.26022100 & 0.98652900 & -0.12661200 \\
$\mathrm{C}$ & -4.35902800 & 0.70587400 & 0.22924500 \\
$\mathrm{C}$ & -3.61732600 & -0.48599600 & 0.17262200 \\
$\mathrm{C}$ & 1.63562500 & 1.36572400 & -0.22089800 \\
$\mathrm{C}$ & 1.43990600 & -0.89227200 & -0.21213900 \\
$\mathrm{C}$ & -2.15743700 & 1.17390900 & 0.05518600 \\
$\mathrm{C}$ & -3.44163000 & 1.75430100 & 0.15534500 \\
$\mathrm{H}$ & -3.64673700 & 2.81602200 & 0.17101800 \\
$\mathrm{C}$ & 2.37375500 & 0.18549600 & -0.27424500 \\
$\mathrm{C}$ & -0.88602200 & 1.75387300 & -0.04362600 \\
$\mathrm{H}$ & -0.80624300 & 2.83566200 & -0.05013200 \\
$\mathrm{C}$ & 2.15381600 & 2.77032300 & -0.23517400 \\
$\mathrm{H}$ & 1.39788100 & 3.47989100 & -0.58126500 \\
$\mathrm{H}$ & 3.02428400 & 2.86256000 & -0.89141700 \\
$\mathrm{H}$ & 2.47014500 & 3.08825700 & 0.76574200 \\
$\mathrm{~B}$ & -1.13764300 & -1.24309100 & -0.03399300 \\
$\mathrm{C}$ & 1.72224900 & -2.35806500 & -0.22562300 \\
$\mathrm{H}$ & 1.55472100 & -2.78908500 & 0.76770600 \\
$\mathrm{H}$ & 2.75362600 & -2.55769100 & -0.51923100 \\
$\mathrm{H}$ & 1.04485800 & -2.86873500 & -0.91465200 \\
$\mathrm{C}$ & 3.86959500 & 0.04751500 & -0.34869500 \\
$\mathrm{H}$ & 4.28612600 & 0.92225900 & -0.86074400 \\
$\mathrm{H}$ & 4.13162800 & -0.81735400 & -0.96935500 \\
$\mathrm{C}$ & -3.54355600 & -0.09686300 & 1.02882000 \\
$\mathrm{H}$ & 4.33797500 & 0.77369000 & 1.65966300 \\
$\mathrm{H}$ & 5.62907200 & -0.19014100 & 0.92174000 \\
$\mathrm{H}$ & 4.17815900 & -0.98364400 & 1.55639400 \\
$\mathrm{H}$ & -5.43399100 & 0.77627200 & 0.31437800 \\
$\mathrm{H}$ & -3.96911700 & -1.50806400 & 0.20096600 \\
$\mathrm{HC}$ & & \\
\hline
\end{tabular}

SCF done: -838.68173764 Hartree

No imaginary Frequency.

4a, optimized $\mathrm{S}_{0}$ state Geometry.
$\mathrm{F}$
$2.64000800 \quad-2.16529800$
0.71075900
F
$\begin{array}{lll}3.31115900 & -0.68453500 & 2.31704300\end{array}$ 


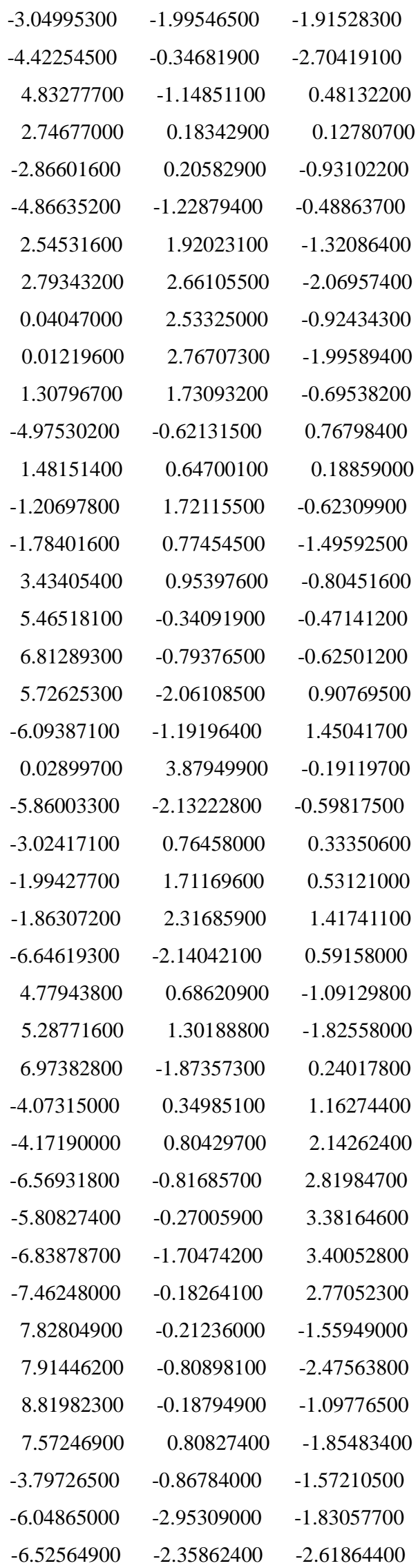




\begin{tabular}{|c|c|c|c|}
\hline $\mathrm{H}$ & -6.67943200 & -3.82106400 & -1.63135100 \\
\hline $\mathrm{H}$ & -5.08321100 & -3.28714900 & -2.21614500 \\
\hline $\mathrm{C}$ & -7.85648000 & -2.99830600 & 0.83953000 \\
\hline $\mathrm{H}$ & -7.96244700 & -3.16665500 & 1.91718900 \\
\hline $\mathrm{H}$ & -7.70644700 & -3.98860000 & 0.39358500 \\
\hline $\mathrm{C}$ & 5.37343700 & -3.08913100 & 1.93084400 \\
\hline $\mathrm{H}$ & 4.86733300 & -2.62153500 & 2.77958100 \\
\hline $\mathrm{H}$ & 6.26132500 & -3.61387600 & 2.28565100 \\
\hline $\mathrm{H}$ & 4.67859700 & -3.82397600 & 1.50989900 \\
\hline $\mathrm{C}$ & 8.20474600 & -2.71778700 & 0.42537900 \\
\hline $\mathrm{H}$ & 9.09122400 & -2.11409900 & 0.20052000 \\
\hline $\mathrm{H}$ & 8.29903900 & -3.01093300 & 1.47758000 \\
\hline B & 3.34951800 & -0.99105300 & 0.95511600 \\
\hline $\mathrm{C}$ & 8.22052000 & -3.98222700 & -0.45408100 \\
\hline $\mathrm{H}$ & 7.36678200 & -4.62959100 & -0.22997500 \\
\hline $\mathrm{H}$ & 9.13582700 & -4.55918200 & -0.28735100 \\
\hline $\mathrm{H}$ & 8.17112700 & -3.72239600 & -1.51618300 \\
\hline $\mathrm{C}$ & 0.59220200 & 4.03982300 & 1.08086100 \\
\hline $\mathrm{H}$ & 1.09202700 & 3.20125000 & 1.55629400 \\
\hline $\mathrm{C}$ & -0.59297400 & 4.98277500 & -0.79178000 \\
\hline $\mathrm{H}$ & -1.03398100 & 4.87418500 & -1.77970100 \\
\hline $\mathrm{C}$ & -0.09169100 & 6.36294700 & 1.13060900 \\
\hline $\mathrm{H}$ & -0.13438900 & 7.32144500 & 1.63943700 \\
\hline $\mathrm{C}$ & 0.52993200 & 5.27088400 & 1.73846300 \\
\hline $\mathrm{H}$ & 0.97339300 & 5.37602800 & 2.72456300 \\
\hline $\mathrm{C}$ & -9.16352900 & -2.39334500 & 0.29356100 \\
\hline $\mathrm{H}$ & -9.36720100 & -1.41976100 & 0.75048500 \\
\hline $\mathrm{H}$ & -10.01285800 & -3.05143200 & 0.50361900 \\
\hline $\mathrm{H}$ & -9.10917300 & -2.24725000 & -0.78998700 \\
\hline $\mathrm{C}$ & -0.65293500 & 6.21488900 & -0.13999500 \\
\hline $\mathrm{H}$ & -1.13404800 & 7.05908400 & -0.62567400 \\
\hline $\mathrm{H}$ & -1.46239000 & 0.49430700 & -2.49020400 \\
\hline $\mathrm{H}$ & 0.75204300 & 0.18939200 & 0.84194100 \\
\hline
\end{tabular}

No imaginary Frequency.

5a, optimized $\mathrm{S}_{0}$ state Geometry.

$\begin{array}{cccc}\text { F } & 1.19238800 & -1.83184200 & -0.60399100 \\ \text { F } & 1.49381600 & -1.08882800 & 1.55853500 \\ \text { F } & -1.18789200 & -1.45537700 & 0.95036400 \\ \text { F } & -1.48421300 & -1.73802000 & -1.32104300 \\ \text { N } & 3.43082300 & -1.41134500 & 0.16696800\end{array}$


N

\begin{tabular}{|c|c|c|}
\hline 00 & 0.48938000 & \\
\hline .79908100 & 0.47809800 & -0.37843100 \\
\hline 42526200 & .40975800 & 5500 \\
\hline .54568800 & 2.62865800 & 074306800 \\
\hline 3.22255700 & 3.45293400 & 510 \\
\hline 700 & 3.568 & 80 \\
\hline 0.04246400 & 3.89322900 & -2.0899300 \\
\hline 1.16953000 & & 640 \\
\hline .48247000 & -0.51980100 & -0.12773300 \\
\hline 900 & & 8300 \\
\hline .13433300 & & \\
\hline .71060400 & & \\
\hline 2.94394000 & .30403600 & 7500 \\
\hline 4.49442100 & -0.53421600 & -0.04248700 \\
\hline 9700 & 9000 & 3500 \\
\hline 3.94305700 & & \\
\hline 2000 & -1.216 & 78100 \\
\hline 0.0084 & .81955900 & -0.16906300 \\
\hline .94705800 & -2.61155100 & \\
\hline 967100 & & 19400 \\
\hline 2.51090000 & 2.62388600 & 3300 \\
\hline 42400 & & 2300 \\
\hline-5.37286300 & -2.52880900 & \\
\hline 4.244 & & \\
\hline 5.072 & & \\
\hline 5.36939600 & -2.58696300 & 5100 \\
\hline & & \\
\hline-5.04679500 & & \\
\hline-7.08276800 & -0.62308200 & 8200 \\
\hline-7.06857900 & & \\
\hline-7.75854800 & -1.04335100 & \\
\hline-7.52664000 & 100 & 1100 \\
\hline 7.09180200 & -0.69950400 & \\
\hline 7.45544700 & -0.86266900 & -1.15431400 \\
\hline 7.81030800 & & \\
\hline 7.11627200 & 2000 & 1000 \\
\hline-1.90616400 & -1.07847000 & 2000 \\
\hline-3.08900500 & -3.80 & 6800 \\
\hline-2.51630200 & -4.05700300 & -0.27352800 \\
\hline-3.69025700 & -4.67061900 & 0.91035700 \\
\hline-2.36065300 & -3.59598500 & 1.41348300 \\
\hline & & \\
\hline
\end{tabular}




\begin{tabular}{lrrr}
$\mathrm{H}$ & -7.22980200 & -3.26319600 & 1.15286300 \\
$\mathrm{H}$ & -5.87082700 & -4.31814200 & 1.47192400 \\
$\mathrm{C}$ & 3.07574600 & -3.81720800 & 0.67892800 \\
$\mathrm{H}$ & 2.39810400 & -3.59942400 & 1.51007000 \\
$\mathrm{H}$ & 3.67457100 & -4.69362600 & 0.92899800 \\
$\mathrm{H}$ & 2.44847400 & -4.05054000 & -0.18670500 \\
$\mathrm{C}$ & 6.29696500 & -3.76030900 & 0.48626800 \\
$\mathrm{H}$ & 7.26286300 & -3.40542100 & 0.86318700 \\
$\mathrm{H}$ & 5.90745500 & -4.44165900 & 1.25175000 \\
$\mathrm{~B}$ & 1.91471800 & -1.00197200 & 0.23572000 \\
$\mathrm{C}$ & 6.52477200 & -4.54480800 & -0.81953400 \\
$\mathrm{H}$ & 5.58376000 & -4.94701200 & -1.20817700 \\
$\mathrm{H}$ & 7.20868500 & -5.38363200 & -0.65430600 \\
$\mathrm{H}$ & 6.95604200 & -3.90202300 & -1.59345800 \\
$\mathrm{C}$ & -0.07125600 & 4.72457600 & 1.22784800 \\
$\mathrm{H}$ & -0.12962900 & 3.74614400 & 1.69664500 \\
$\mathrm{C}$ & 0.08098300 & 6.08765300 & -0.75480500 \\
$\mathrm{H}$ & 0.14170900 & 6.17521400 & -1.83665000 \\
$\mathrm{C}$ & -0.00419100 & 7.13676000 & 1.42347100 \\
$\mathrm{H}$ & -0.00958000 & 8.03091100 & 2.03976900 \\
$\mathrm{C}$ & -0.07763800 & 5.87291800 & 2.01772800 \\
$\mathrm{H}$ & -0.14007000 & 5.78262100 & 3.09837200 \\
$\mathrm{C}$ & -6.67762900 & -4.50680200 & -0.52712100 \\
$\mathrm{H}$ & -7.15732400 & -3.89002500 & -1.29366800 \\
$\mathrm{H}$ & -7.36844300 & -5.31221900 & -0.25747300 \\
$\mathrm{H}$ & -5.78753300 & -4.96034800 & -0.97485400 \\
$\mathrm{C}$ & 0.07516700 & 7.24096500 & 0.03498400 \\
$\mathrm{H}$ & 0.13181500 & 8.21745500 & -0.43729900 \\
$\mathrm{SC}$ & & \\
\hline
\end{tabular}

SCF done: -1945.32004068 Hartree

No imaginary Frequency. 


\section{References:}

1. Isak, S. J.; Eyring, E. M. J. Phys. Chem. 1992, 96, 1738.

2. Benson, R.; Kues, H. Phys. Med. Biol., 1978, 23, 159.

3. Lakowicz, J. R. Principles of Fluorescence Spectroscopy, 3rd ed.; Springer: New York, 2006.

4. SAINT V 6.01 (NT) Software for the CCD Detector System, Bruker Analytical X-ray Systems, Madison, WI 1999.

5. Sheldrick, G. M. SHELXS-90, Program for the Solution of Crystal Structure, University of Göttingen, Germany, 1990.

6. Sheldrick, G. M. Acta Cryst. 2015, 71, 3-8.

7. SHELXTL 5.10 (PC/NT-Version), Program library for Structure Solution and Molecular Graphics, Bruker Analytical X-ray Systems, Madison, WI 1998.

8. Dewanji, A.; Mueck-Lichtenfeld, C.; Bergander, K.; Daniliuc, C. G.; Studer, A. Chem. Eur. J. 2015, 21, 12295.

9. Angelo, C.; Nadia, P. and Ombrerra, P. Tetrahedron.1998, 54, 15679.

10. Zhang, Z.; Shin, J. Y.; Dolphin, D. J. Org. Chem. 2008, 73, 9515. 